\title{
Uber die traumatischen Rückenmarkschädigungen und deren Behandlung, unter besonderer Berücksichtigung der Spätfälle.
}

\author{
Von \\ Dr. Theodor Mauss (Dresden). \\ (Eingegangen am 15. Dezember 1920.)
}

Einleitung (S. 1).

Inhalt.

I. Einteilung der Rückenmarkverletzungen (S. 2).

1. nach ihrer Entstehungweise (S. 2).

2. nach pathologisch-anatomischen Gesichtspunkten (S. 4).

II. Krankheitserscheinungen und Krankheitsverlauf (S. 8).

1. Markläsionen mit dem Syndrom der Bastianschen Lähmung (S. 8).

2. Markläsionen mit den Zeichen der partiellen Leitungsstörung (S. 10).

a) Bilaterale spastische Paresen (S. 10).

b) Brown-Séquardsche Halbseitenlähmungen (S. 12).

c) Hemiplegien von cerebralem Typus (S. 14).

3. Markläsionen radikulären (segmentalen) Charakters (S. 16).

a) Wurzelaffektionen des Halsmarkes (S. 19).

b) Verletzungen der Cauda equina ( $\mathrm{S}, 21$ ).

III. Diagnostische Fragen (S. 25).

1. Artdiagnose (S. 25).

2. Höhendiagnose (S. 26).

3. Differentialdiagnose (S. 34).

IV. Thera peutische Maßnahmen (S. 46).

1. Chirurgische Indikationsstellung (S. 46).

2. Operative Heilerfolge (S. 48).

3. Nachbehandlung (S. 53).

\section{Einleitung.}

Nachstehend sollen die Erfahrungen wiedergegeben werden, die ich als neurologischer Leiter der neuro-chirurgischen Station des ehemaligen XII. Korpsbereiches (während des Krieges in Arnsdorf, später in Dresden) an Rückenmarkverletzten gesammelt habe. Ich veröffentliche dieselben, weil ich glaube, daß das Beobachtungsmaterial, dem sie entstammen, insofern eine gewisse Eigenart besitzt, als es einerseits, infolge seiner Stabilität, eine besonders eingehende wissenschaftlich-diagnostische Durcharbeitung ermöglichte, andererseits, dank der engen Arbeitsgemeinschaft mit dem chirurgischen Stationsleiter (Dr. H. Krüger), reichlich Gelegenheit bot zu einer gründlichen praktisch-therapeutischen Auswertung. Dazu kommt, daß in der Kriegsliteratur neurologischerseits auffallend wenig zur Frage der Rückenmarkverletzungen und ihrer Behand- 
lung das Wort ergriffen worden ist; außer den Arbeiten von Ascher und Licen ${ }^{1}$ ), Berger ${ }^{2}$ ), Marburg und Ranzi ${ }^{3}$ ) liegen ausführlichere Abhandlungen über das Thema nicht vor. Ich halte diese Zurückhaltung für sehr bedauerlich und kann sie mir lediglich damit erklären, daß nur verhältnismäßig wenige Neurologen in der Lage waren, durch intensives Zusammenarbeiten mit dem Chirurgen sich von den erfreulichen Resultaten zu überzeugen, die bei den Kriegsschädigungen des Rückenmarkes unter geeigneter Auswahl der Fälle sich erzielen lassen, sei es durch Eingriffe am Mark selbst, sei es durch orthopädische Maßnahmen irgendwelcher Art.

Die äußeren Umstände zwangen mich, den Rahmen der Arbeit möglichst eng zu stecken. Ich werde daher in der Hauptsache nur meine eigenen Beobachtungsergebnisse erörtern und mich auch hierbei vorwiegend auf die in diagnostischer und therapeutischer Hinsicht praktisch wesentlichsten Gesichtspunkte beschränken, unter Heranziehung jeweiliger Beispiele und besonderer Berücksichtigung der uns jetzt an erster Stelle interessierenden Spätfolgen der Rückenmarkläsionen. Die Leser meiner in Gemeinschaft mit Dr. Kr üger abgefaßten Mitteilung über die traumatische Meningitis serosa circumscripta spinalis ${ }^{4}$ ) werden eine Anzahl der dort bereits besprochenen Fälle im folgenden wiederfinden. Es handelt sich um besonders instruktive Beobachtungen, auf deren nochmalige Wiedergabe ich im Interesse einer geschlossenen Darstellung nicht gern verzichten wollte.

Ich schicke einige Bemerkungen über Ätiologie und Pathogenese der Markverletzungen dem Hauptthema voraus.

\section{Einteilung der Rückenmarkverletzungen.}

1. Vom ätiologischen Standpunkte a us hat man zwei Hauptgruppen von Rückenmarkschädigungen zu unterscheiden, direkte und indirekte. Die direkten Läsionen kommen teils durch Schußverletzungen der Wirbelsäule zustande, teils durch Frakturen oder Luxationen einzelner Wirbel infolge Einwirkung stumpfer Gewalten. Dabei kann das Mark entweder durch Projektile, Knochensplitter oder Calluswucherungen einer dauernden Kompression ausgesetzt werden, oder es kann durch Quetschungen mehr oder weniger sch were Substanzverluste erleiden. Bei den indirekten Schädigungen handelt es sich um Fernwirkungen, d. h. um Prellschädigungen des Markes, deren häufigste Ursache Streifschüsse der Wirbelsäule oder stumpfe, in der Körperachse auftreffende Gewalten zu sein pflegen. Gar nicht so selten

1) Bruns' Beitr. z. klin. Chir. 105, H. 4.

2) Diese Zeitschr. 35. 1917.

a) Arch. f. klin. Chir. 111, H. 1.

4) Dtsch. Zeitschr. f. Nervenheilk. 6\%, H. 1-6. 
findet man aber auch Veränderungen am Rückenmark nach Traumen a u Ber ha lb des Wirbelsäulenbereiches; so nach Schußverletzungen des Brustkor bes oder des Schulter- oder Beckengürtels. Selbst nach Plexusoder hochsitzenden Nervenschüssen haben wir des öfteren Rückenmarksymptome feststellen können, und schließlich glaubten wir auch in einigen Fällen lediglich das brüske Hinstürzen im Moment des Schusses für die Rückenmarkatfektion verantwortlich machen zu müssen.

Daß es bei Traumen, die unmittelbar die Wirbelsäule treffen, leicht zu Rückenmarkschädigungen kommt, hat nichts Utberraschendes an sich. Auffallender schon und bemerkenswerter ist die relative Häufigkeit von Markaffektionen bei traumatischen Einflüssen, die mit dem Wirbelapparat an sich nichts zu tun haben. Wir verfügen über 9 Fälle mit bioptisch festgestellten Rückenmarkveränderungen, bei denen dje Geschoßbahn so weit von der Wirbelsäule entfernt lag, daß man an eine dirckte Lädierung derselben ungezwungen nicht denken konnte. Fünf von diesen Fällen waren hochsitzende Extremitätenschüsse. Zweimal hatte es sich um Streifschüsse der Schulter gehandelt und dreimal um sagittal gerichtete, reichlich handbreit von der Mittellinie entfernte Brustdurchschüsse mit Schlüsselbein- oder Rippenfrakturen. Bei keinem dieser Fälle waren röntgenologisch oder bioptisch irgendwelche Veränderungen an der knöchernen Rückenmarkhülle nachweisbar. Wenn das auch natürlich kein zwingender Beweis ist für die tatsächliche Intaktheit derselben, so sprechen solche Beobachtungen doch immerhin einwandfrei dafür, daß Rückenmarkschädigungen zustande kommen können, ohne daß das Geschoß die Wirbelsäule zu tangieren braucht. Wie das möglich ist, bleibt vielfach unklar. Daß bei einem Schusse, der den knöchernen Brustkorb trifft, die Gewalt des Anpralles sich auf die Wirbelsäule fortzupflanzen und eine Prellwirkung auf den Inhalt auszu üben vermag, ist schließlich zu verstehen; ebenso, da $\beta$ bej hochsitzenden Nervenschüssen ein Zerrungseffekt auf Wurzeln und Mark stattfinden kann. Völlig dunkel ist aber das Zustandekommen einer Markläsion bei hochsitzenden Extremitätenschüssen ohne Nervenverletzung, wie in zwei von uns operierten Fällen (Beob. 7 u. 15), bei denen nur Durchschüsse durch den Deltamuskel vorlagen und keinerlei Anhaltspunkte für eine irgendwie erhebliche Körpererschütterung durch Sturz bei der Verwundung vorhanden wareu.

Übrigens möchte ich nicht unterlassen, mit Marburg davor zu warnen, eine direkt e Wirbelsäulenschädigung lediglich nach Maßgabe des Schußkanales auszuschließen. Der Weg des Geschosses ist durchaus nicbt immer zuverlässig zu rekonstruieren, da dıe Ablenkung deı Flugbahn sehr leicht zu Täuschungen Veranlassung geben kann. Wir werden später noch einen Fall (Beob. 19) genauer kennenlernen, bei dem das Geschoß oberhalb der Gesäßbacke eingedrungen, anscheinend in vertikaler 
Richtung durch die Glutaei hindurchgegangen und nach dem Röntgenbild unterhalb der Gesäßfalte in der Verlaufsrichtung des Ischiadicus steckengeblieben war. Da klinisch alles für eine Verletzung des Ischiadicus zu sprechen schien, war derselbe anderwärts freigelegt und das Geschoß an der vermuteten Stelle gefunden worden, ohne daß jedoch der Nerv makroskopisch sich verändert erwies. Der später von uns erhobene neurologische Befund ließ eine Caudaverletzung im Niveau der unteren Lendenwirbel vermuten. Es wurde dementsprechend geröntgt und eine Subluxation des vierten gegen den fünften Lendenwirbel festgestellt. Die Operation bestätigte diesen Befund und ergab außerdem schwete, das Kanallumen stark verengende Calluswucherungen in der Höhe des dritten und vierten Lendenwirbels. Es war also offenbar das Geschoß oberhalb der Gesäßbacke in horizontaler Richtung, also senkrecht auf die Wirbelsäule eingedrungen, durch den Anprall aber abgelenkt und so der vertikal gestellte, mit dem Ischiadicus parallel verlaufende Schußkanal vorgetäuscht worden.

2. In pathologisch-a natomischer Hinsicht lassen sich die Kriegsverletzungen des Rückenmarkes einteilen in Schädigungen, die die Marksubstanz u n mittelbar betreffen, und in solche, die von außen her auf das Mark einwirken, dasselbe also erst seku ndär in Mitleidenschaft ziehen.

Unter den primär en Markläsionen nehmen, neben den partiellen und totalen Quetschungen und Zertrümmerungen des Querschnittes, die Hämatomyelien, Myelomalacien und zentralen Nekrosen ein sehr breites Feld ein. Besonders die letztere Form scheint unter dem Kriegsmaterial eine große Rolle zu spielen und an Häufigkeit die Blutungen und Erweichungen noch zu übertreffen. Daneben findet man aber auch Zustandsbilder vom Charakter der disse minierten M yelitis oder Myeloencephalitis, die ihrerseits wieder nahe Beziehungen zum Symptomenbild der multiplen Sklerose haben.

So verfügen wir über einen Fall von Gewehrkugelstreifschuß der linken Schultergegend, bei dem sich nach der Verletzung allmählich, im Laufe weniger Wochen, ein sehr unangenehmer Gürtelschmerz in der Brustwarzenlinie und eine leichte Schwäche erst des linken, dann des rechten Beines herausgebildet hatte. Trotzdem konnte der Mann mit Unterbrechung noch anderthalb Jahre Garnisondienst tun, bis ziemlich akut eine Verschlechterung des Leidens einsetzte in Gestalt einer rasch zunehmenden spastischen Lähmung beider Beine und einer gürtelförmigen Schmerz- und Anästhesiezone im Innervationsbereich der Brustsegmente III und IV. Dazu gesellten sich 5 Monate später, ebenfalls ganz plötzlich und ohne ersichtliche Ursache, ausgesprochene Bulbärerscheinungen: halbseitige Facialislähmung, Erschwerung der Kopfbewegungen, Kaubeschwerden, Nystagmus und 
Zwangslachen: Unsere Diagnose sch wankte zwischen multipler Sklerose und Meningomyelitis des oberen Dorsalmarkes. Verschiedene klinische Symptomc, auf die hier nicht näher eingegangen werden kann, ließen uns mehr zu der letzteren Annahme neigen in der Voraussetzung, daß durch adł:̈siv meningitische Verwachsungen und dadurch bedingte Liquorsperrung nach oben von dem Prozeß die Fernsymptome seitens der Medulla ausgelöst wurden. In der Tat fanden sich auch bei der Operation zwischen Mark und Meningen so innige Verwachsungen, daß es auf der einen Seite zu einer erheblichen Verengung, auf der anderen Seite zu einer perfekten Verlegung des Liquorkanales gekommen war. Das Mark erwies sich in seiner Konfiguration normal, zeigte aber eine ungewöhnlich starke Gefäßinjektion. Die Gefäße waren korkzieherartig gewunden und strotzend mit blauschwarz gefärbtem Blute gefüllt. Der operative Erfolg war bezüglich der Bulbärerscheinungen überraschend prompt; Nystagmus und Kaubeschwerden waren nach wenigen Tagen, die Facialislähmung und die Erschwerung der Kopfbewegungen nach einigen Wochen behoben. Sonst aber hat sich an dem Zustandsbild, von einer vorübergehenden Besserung der Beinparese abgesehen, bis heute, 3 Jahre post operationem, nichts geändert.

$\mathrm{Zu}$ den primären Markschädigungen wird man zweckmäßigerweise auch die sog. Rückenmarkerschütterung, die Commotio spinalis im engeren Sinne, zählen. Dieselbe ist dadurch charakterisiert, daß die Funktionen des betroffenen Rückenmarkabschnittes unmittelbar nach der Gewalteinwirkung vollständig oder teilweise ausfallen, sich aber in der Regel schon nach Stunden oder Tagen, längstens innerhalb weniger Wochen, vollkommen wiederherstellen. Zum mindesten gilt dies für den motorischen Ausfall, während man leichte Reflexanomalien oder Spuren von Sensibilitätsstörungen des öfteren auch späterhin noch nachweisen kann. Es ist also kennzeichnend für die Rückenmarkerschütterung, daß die spinalen Funktionsstörungen nur von ganz kurzer Dauer sind und sich so gut wie restlos wieder ausgleichen (Marburg). Über die histologisch-pathologische Grundlagè des Leidens wissen wir nichts Zuverlässiges. Daß es sich, wie man früher annahm, um eine rein funktionelle Störung ohne jegliches anatomische Substrat handelt, ist unwahrscheinlich. Man wird eher mit Finkelnburg, Marburg und Oppenheim annehmen müssen, daß doch leichteste organische Schädigungen vorliegen, die entweder nur vorübergehender Natur oder aber so geringfügig sind, daß sie nach $A b$ klingen der ersten Schockwirkung klinisch ins Gewicht fallende Symptome nicht hinterlassen.

Mehr noch als die bisher erwähnten primären Läsionen, denen wir therapeutisch ja ziemlich machtlos gegenüberstehen, interessieren uns diejenigen Schädigungen des Rückenmarkes, die auf sekundärem 
Wege zustande kommen. Es handelt sich dabei im wesentlichen um Prozesse, die von außen her einen langsam wachsenden Druck auf das Mark ausüben, dem dasselbe bekanntlich oft lange widerstehen kann, ohne dauernden Schaden zu nehmen. Diese Verletzungsformen sind es daher auch, die die eigentliche Domäne der das Mark direkt angreifenden chirurgischen Spättherapie bilden. Der kompressorische Effekt wird dabei entweder durch Geschosse, Knochensplitter oder callöse Wucherungen nach Wirbelfrakturen ausgeübt oder aber häufiger noch durch Prozesse, die von den Rückenmarkshäuten ausgehen. Im letzteren Falle hat man es dann mit dem von Krause und Oppenheim schon in Friedenszeiten beschriebenen Krankheitsbild der chronischen Meningitis serosa circumscripta zu tun, bei dem man nach den Erfahrungen am Kriegsmaterial zwei Formen unterscheiden kann, die Pachymeningitis externa (Marburg) und die Arachnitis adhaesiva.

Die Pach y meningitis externa geht mit schwartigen epiduralen Auflagerungen einher, die den Duralsack in einer Längsausdehnung von mehreren Zentimetern hüllenartig umgeben und teils innig mit der Dura verwachsen sind, teils sich leicht von ihr abziehen lassen. Die Schwielen können, wie wir wiederholt sahen, und wie auch Marburg es beschreibt, sich so eng zusammenziehen, daß es zu sanduhrförmigen Einschnürungen des Durakanales kommt. Bei der Arachnitis findet man Mark- und Wurzelaustritte von mehr oder weniger zarten, weißen oder milchig getrübten Membranen umhüllt. Sie führen zu Verwachsungen oder Verklebungen der Arnchnoidea und nicht selten zu Liquorabsackungen oberhalb der Verwachsungsstelle, die das Mark wie Fremdkörper komprimieren und bei hohem Sitz durch Fernwirkung auf die bulbären Gebilde zu recht bedrohlichen Erscheinungen führen können. Beide Zustandsbilder, Pachymeningitis und Arachnitis, pflegen sich häufig zu kombinieren, treten aber auch unabhängig voneinander, jedes für sich, in Erscheinung.

Pathologisch-anatomisch ist bezüglich dieser Meningitiden zu sagen, da $\beta$ sie sowohl als isoliertes primäres Krankheitsbild vorkommen, wie als sekundäres Leiden im Gefolge von Steckschüssen oder Frakturen der Wirbelsäule, oder auch in Verbindung mit intramedullären Affektionen. Von besonderem Interesse ist die Erfahrungstatsache, da $\beta$ es analog den Markläsionen auch zu derartig isolierten Veränderungen an den Rückenmarkshäuten kommen kann, ohne daß eine Schädigung der Wirbelsäule vorzuliegen braucht. Wir verfügen über mehrere Fälle dieser Art, und auch Marburg berichtet über einschlägige Beobachtungen, die zur Autopsie kamen, und bei denen mit Sicherheit der meningeale Proze $\beta$ auf reine Fernwirkung des Geschosses bei unberïhrtem Wirbelapparat zurückgeführt werden konnte. 
Soweit wir, dank der Liebenswürdigkeit von Prof. Geibel, unser Material mikroskopisch untersuchen lassen konnten, fanden sich bei den pachymeningealen Schwielen in der Dura und in dem epiduralen Fettgewebe zahlreiche pigmenthaltige Zellen. Das Pigment bestand aus umgewandeltem Blutfarbstoff, welcher in Form von Körnchen das Protoplasma gröBtenteils erfüllte. Abgesehen von diesen alten Veränderungen waren frische Blutungen, anscheinend artifizieller Art, vorhanden. Außerdem begegnete man zahlreichen kleinen Entzündungsherden, besonders im epiduralen Fettgewebe, und ferner Lymphscheiden um die Gefäße, die prall mit Eiterzellen erfüllt waren. An den intraduralen zarten Häutchen hat sich, bei den bis jetzt nachgeprüften Fällen wenigstens, eine eigentliche, mit einer fibrinösen Exsudation in Zusammenhang zu bringende Neubildung von Bindegewebe nicht feststellen lassen. Die untersuchten Häutchen erwiesen $s^{:}$ch vielmehr als offenbar abgesprengte Teile der Dura und Arachnoidea ohne pathologische Veränderungen. Danach wären also die schwartigen Auflagerungen der Dura als Entzündungsprodukte im AnschluB an Hämorrhagien aufzufassen, die intraduralen Veränderungen dagegen als traumatisch bedingte Verlagerungen meningealer Gewebsteile, etwa analog den Zerreißungen der Intima von Blutgefäßen, die durch stumpfe Gewalt oder durch Fernwirkung vorbeifliegender Geschosse geschädigt werden.

Natürlich wird man neben diesem mechanischen Entstehungsmodus der arachnoidalen Adhäsionen auch mit der Möglichkeit entzündlichexsudativer Vorgänge zu rechnen haben, ähnlich wie bei den pachymeningitischen Schwielenbildungen. Zum mindesten dürfte eine solche Genese für alle diejenigen Fälle anzunehmen sein, bei denen es intraoperativ nicht ohne Schwierigkeiten und auch nicht restlos gelingt, die Verklebungen zwischen Meningen, Mark und Wurzeln zu lösen, und bei denen auch der weniger günstige postoperative Verlauf vermuten läßt, daß ein mehr oder minder erheblicher Teil der klinischen Ausfallssymptome durch irgendwelche irreparable anatomische Prozesse bedingt sein mußte.

Eine sehr bemerkenswerte Erscheinung, die man immer und immer wieder beobachten kann, ist das Utbergreifen der intraduralen Verklebungen auf Mark- und Wurzelabschnitte, die sich klinisch als absolut intakt erweisen. Diese Tatsache legt den Gedanken nahe, daß die „Häutchenbildung“ an sich ganz harmlos verlaufen kann, und dạß Mark und Wurzeln erst dann gefährdet werden, wenn es zu Strangulatjonswirkungen kommt, oder aber zu lokalen Verlegungen des Duralsackes mit Liquoransammlungen, die ihrerseits wieder durch Kompression zu vorübergehenden Ödemen und Zirkulationsstörungen, unter Umständen wohl auch zu nachhaltigen Schädigungen des Markes 
durch Ernährungsbehinderungen oder entzündlichen Vorgängen führen können.

Auffallend ist die Hä ufigkeit der Meningitis serosa bei dem Kriegsmaterial. Marburg und Ranzi haben im ganzen unter 142 Fällen von Kriegsverletzungen des Rückenmarkes bei 121 meningeale Veränderungen konstatiert; dabei hat es sich $52 \mathrm{mal}$ um isoliertes Auftreten von Arachnitis adhaesiva oder Pachymeningitis externa gehandelt. Wir selbst verfügen unter einem Gesamtmaterial von 71 Laminektomien über 23 Beobachtungen mit bioptisch festgestellter circumscripter, chronischer Meningitis; davon ließen bei 18 Fällen Befund und Verlauf auf isolierte, d. h. primäre meningeale Prozesse schließen. Bei dem Rest war es zweifelhaft, ob es sich um primäre Prozesse an den Meningen mit sekundärer Einwirkung auf das Mark handelte oder um eine Komplikation von meningealen und intramedullären Affektionen.

\section{Krankheitserscheinungen und Krankheitsverlauf.}

Nach Maßgabe des klinischen Symptomenbildes kann man drei große Gruppen spinaler Schädigungen mebr oder weniger scharf auseinanderhalten: 1. Markläsionen mit dem Syndrom der totalen Querlähmung, 2. Markläsionen mit den Zeichen der partiellen Leitungsstörung, und 3. Markläsionen von radikulärem (segmentalem) Typus.

1. Die totalen Querläsionen äußern sich klinisch in einer kompletten schlaffen Lähmung mit Areflexie, Aufhebung der Empfindung für sämtliche Reizqualitäten unterhalb der Unterbrechungsstelle, Funktionsausfall des Urogenitalapparates und Neigung zu schwerem Decubitus. Man hatte früber bekanntlich dazu geneigt, dieses BastianBrownsche Syndrom als unbedingt infaust anzusehen, weil man glaubte, dasselbe als Ausdruck einer kompletten anatomischen Querschnittsunterbrechung auffassen zu müssen. Dieser Standpunkt, dessen Richtigkeit übrigens schon immer von einzelnen Autoren angezweifelt worden war, läßt sich nach den am Kriegsmaterial gesammelten Erfahrungen sicherlich nicht mehr aufrechterhalten. Wir wissen heute, daß das klassische Krankheitsbild der Bastianschen Lähmung vorhanden sein kann, ohne daß eine völlige Durchtrennung oder Zertrümmerung des Rückenmarkes vorzuliegen braucht. Es war durchaus keine Seltenheit, daß man Fälle zu Gesicht bekam, die unmittelbar nach der Verletzung klinisch das typische Bild der Totalläsion boten, sich aber trotzdem verhältnismäßig rasch innerhalb von Wochen oder wenigen Monaten denkbar weitgehend wieder erholten. Marburg und Ranzi berichten sogar über eine ganze Anzahl von Querlähmungen, bei denen selbst noch nach Jahresfrist die Besserung einsetzte und befriedigende Fortschritte machte. Wir haben Fälle dieser Art nicht beobachten können, 
abgesehen von vereinzelten Totallähmungen, bei denen es im Laufe von Jahren zu regionären Aufhellungen der Sensibilität und einigen spärlichen, praktisch völlig belanglosen Bewegungseffekten kam. Anders liegen allerdings die Verhältnisse auch unter unserem Material, wenn man den Begriff der Querläsion etwas weiter ausdehnt und auch noch diejenigen Fälle dazu rechnet, die zwar eine absolute schlaffe Lähmung zeigen, von dem klassischen Bastianschen Symptomenkomplex aber dadurch abweichen, daß der eine oder andere Hautreflex erzielbar und die Sensibilitätsstörung keine komplette ist, sei es, daß die Tiefensensibilität teilweise erhalten oder die Oberflächensensibilität nicht für alle Empfindungsqualitäten gleich schwer betroffen ist. Unter den Markläsionen dieser Kategorie haben auch wir mehrere, die einen relativ günstigen Verlauf nahmen und trotz längerer Persistenz der Lähmung schließlich doch wieder auf die Beine kamen.

Zusammenfassend wird man also sagen können, daß die typischen Bilder der Bastianschen Lähmung, sofern sie nicht in den ersten Wochen nach der Verletzung sich zurückzubilden beginnen, im allgemeinen auf eine schwere organische Schädigung des Rückenmarkquerschnittes schließen lassen. In weitaus der Mehrzahl der Fälle dieser Art pflegt es sich um totale anatomische Leitungsunterbrechungen zu handeln, wobei entweder die Marksu bstanz in bestimmter Höhezertrümmert worden ist oder irgendwelche histologische Veränderungen die nervösen Querschnittsgebilde d a u ernd außer Funktion gesetzt haben. Es bleibt aber immerhin noch die Möglichkeit bestehen, da $\beta$ in dem einen oder anderen Falle der irreversible Zerstörungsprozeß nicht über den ganzen Querschnitt sich erstreckt, so daß dje weniger stark geschädigten Partien sich nach und nach wieder erholen und die Lähmungserscheinungen selbst Jahr und Tag nach der Verletzung bis zu einem gewissen Grade sich noch ausgleichen können. Man wird daher Querschnittslähmungen, auch wenn sie längere Zeit hindurch bestehen bleiben, heute nicht mehr ohne weiteres als verlorene Fälle betrachten dürfen, sondern sie möglichst lange Zeit unter klinischer Kontrolle zu halten und festzustellen haben, ob nicht doch noch Symptome vorhanden sind, die auf eine partielle Erholungsfähigkeit des Querschnitts schließen und zur Förderung derselben chirurgische Maßnahmen geboten erscheinen lassen.

Beachtenswert ist die durch die Erfahrung am Kriegsmaterial erwiesene Tatsache, daß das Erhaltenbleiben einzelner Haut- oder Sehnenreflexe, bei sonst typischer Totalläsion, nicht ohne weiteres in günstigem Sinne, d. h. als Gegenbeweis einer anatomischen Querschnittsunterbrechung gedeutet werden darf. Selbst das Auftreten motorischer Reizerscheinungen, wie Spontanbewegungen in den gelähmten Gliedern oder Gliedabschnitten und ausgeprägte spastische Phänomene, sprechen nicht unbedingt gegen eine völlige Durchtrennung des Markes. 
So haben wir einen Fall (Beob. 1), bei dem klinisch ein totaler Bewegungsausfall in sämtlichen Gelenken beider Unterextremitäten vorlag, eine schwere Blasen-Mastdarmlähmung und eine Anästhesie bis etwa zur Mitte zwischen Rumpfbeingrenze und Nabellinie. Bauchdecken- und Kremasterreflexe fehlten, während die Sehnenreflexe im linken Bein normal, im rechten stark erhöht waren. Außerdem bestand rechts Fußklonus, Babinskisches und Oppenheimsches Zeichen und eine ausgesprochene Neigung zu spontanen Reflexbewegungen. Der spastische Symptomenkomplex ließ uns trotz der absoluten sensiblen Lähmung an eine zwar schwere, aber doch nicht komplette Querschnittsläsion im Niveau des zehnten Dorsalsegmentes denken. Wir entschlossen uns zur Laminektomie und fanden zu unserer Úberraschung eine anatomische Quertrennung in der supponierten Höhe. Eine Schrapnellkugel war zwischen dem achten und neunten Brustwirbel in den Durakanal eingedrungen, hatte das Mark glatt durchschlagen und war dann, im Duralsack nach abwärts gleitend, in der Gegend des XII. Brustwirbels steckengeblieben. Der Durakanal war vom IX. bis zum XII. Brustwirbel völlig leer; nur einige dürftige, mit der Dura unzertrennbar verwachsene Wurzelfäserchen waren als einzige Markreste übriggeblieben. Der Mann ist übrigens heute, 6 Jahre nach der Operation noch am Leben und wie er uns kürzlich brieflich mitteilte, von seiner Beinlähmung abgesehen, bei bestem Wohlbefinden.

2. Von der kompletten oder nahezu kompletten Querlähmung führen ziemlich fließende Utbergänge zu der zweiten Gruppe, de n Markläsionen mit partieller Leitungsstörung.

Die hierher zu rechnenden Fälle sind in erster Linie durch den vorwiegend spastischen Charakter der Motilitätsstörung gekennzeichnet. Die Spasmen sind entweder von vornherein vorhanden oder entwickeln sich allmählich aus einer ursprünglich schlaffen Lähmung heraus. Sensible Störungen sind fast stets nachweisbar, bleiben aber an Intensität meist erheblich hinter den motorischen Ausfallserscheinungen zurück und können bei leichteren Fällen auch ganz fehlen. Blasenund Mastdarmfunktion sind anfänglich fast immer gestört, die Lähmung erreicht aber nur selten höhere Grade und bildet sich in der Regel weitgehend wieder zurück, sofern es sich nicht um tiefsitzende Läsionen handelt, die die entsprechenden spinalen Zentren zerstört haben.

Man unterscheidet zweckmäßigerweise drei Unterabteilungen der partiellen Markläsion, je nachdem es sich um doppelseitige oder einseitige Herde handelt: Fälle mit bilateralen spastischen Paresen, Halbseitenlähmungen im Brown-Séquardschen Sinne und Halbseitenlähmungen von cerebralem Typus.

a) Das klinische Bild bei den spastıschen Paraparesen ist je nach dem Höhensitz der Läsion verschieden. Doppelseitige Herde im 
Niveau der Halsanschwellung werden, neben dem motorischen Ursprungsapparat der Armmuskulatur und den entsprechenden sensiblen Wurzelarealen, gleichzeitig die langen motorischen und sensiblen Bahnen für Rumpf und Beine schädigen. Sie werden also eine degenerativ atrophische Lähmung mit mehr oder weniger ausgesprochenen elektrischen Störungen und einem $\mathrm{r}$ adi k ulär orientierten Sensibilitätsausfall in der Oberextremität bewirken und Lähmungserscheinungen spastischer Natur mit diffusen Sensibjlitätsstörungen in dem distalen Körperabschnitte, insbesondere in den Beinen. Betrifft dje Läsion die obere Hälfte des Cervicalmarkes, so kann sich die schlaffe atrophische Lähmung in der Hauptsache auf die Hals- und Schultergürtelmuskulatur beschränken. Der Biceps- und Tricepsreflex wird fehlen, der Radiusperiostreflex normal oder in spastischem Sinne gesteigert sein, wenn der Herd nach unten nicht über $\mathrm{C}_{6}$ hinausreicht. Eine nicht seltene Erscheinung hochsitzender Halsmarkverletzungen sind mehr oder weniger ausgesprochene Bulbärsymptome: Trigeminusaffektionen, Schluck- und Atembeschwerden und Pulsbeschleunigungen haben wir wiederholt in unseren Krankenpapieren verzeichnet, einmal auch eine Recurrenslähmung. Charakteristisch für die Schädigungen des unteren Halsmarkabschnittes sind Hand- und Fingerlähmungen von Klumpkeschen Typus in Gemeinschaft mit oculo-pupillären Symptomen. Schultergürtel- und Oberarmmuskulatur bleiben für gewöhnlich frei oder sind nur in geringem Grade beteiligt. Von den Sehnenphänomenen ist der Periostreflex meist erloschen, der Triceps- und Bicepsreflex erhalten.

Bei den bilateralen Affektionen des Dorsalmarkes pflegen die Zeichen der Segmentschädigung im allgemeinen weniger augenfällig zu sein. Das klinische Bild wird hier in der Regel beherrscht von mehr oder minder schweren spastischen Paraparesen in den Beinen mit universeller Hypästhesie, die am Rumpf entweder qualitativ unverändert bis zum Niveau der Läsion hinaufreicht oder aber durch eine gürtelförmige, den unmittelbar geschädigten Segmenten entsprechende Zone besonders qualifizierter Art nach oben abgesetzt wird.

Die partiellen Querschnittsschädigungen der Lendenanschwellung, wenigstens ihres oberen Abschnittes, können unter Umständen Zustandsbilder produzieren, die sich den Affektionen des Cervicalmarkes vollkommen analog verhalten, d. h. es kann sich im Versorgungsbereich der Lu m ba l wurzeln eine atrophisch degenerative Lähmung mit EaR., Areflexie und radikulär orientierter Anästhesie finden, während im sakra len Wurzelgebiet die Sensibilität aufgehellt ist und die Lähmung spastischen Charakter trägt, der durch Fußklonus und die entsprechenden Hautreflexe (Babinskj, Oppenheim, Rossolimo) zum Ausdruck kommt. Indessen ist dieser Typus bei den Iumbalmarkschädi- 
gungen traumatischer Herkunft anscheinend doch ziemlich selten (wir verfügen nur über 5 derartige Fälle), da er ziemlich eng umschriebene Prozesse voraussetzt. Die Mehrzahl der die obere Lendenanschwellung betreffenden bilateralen Affektionen hat eine einfache spastische Paraparese der Unterextremitäten mit normalem elektrischen Verhalten zur Folge und eine Sensibilitätsstörung, die sich entweder gleichmäßig über den ganzen lumbosakralen Innervationsbereich erstreckt oder aber auch segmentalen Typus zeigen kann, dergestalt, daß die lumbalen Wurzelfelder sich als stärker affiziert erweisen als die sakralen.

Ein eigenartiges Gepräge tragen die Verletzungen des untersten Rücken markabschnittes, des Conus und Epiconus. Die unter den Kriegsverletzungen anscheinend sehr seltene reine Conusläsion (2 Fälle unseres Materials) ist klinisch gekennzeichnet durch mehr oder weniger schwere Störungen der Blasen-Mastdarmfunktion und des Sexualapparates, in Gemeinschaft mit typischer Reithosenanästhesie und Aufhebung des Analreflexes. Meist ist aber bei den umfangreichen Zerstörungen der Kriegsverletzungen gleichzeitig auch der Epiconus mitbeteiligt. Dann tritt zu dem obigen Symptomenbild eine halboder doppelseitige, schlaffe degenerative Lähmung der Fuß- und Zehenmuskulatur mit Verlust des Plantar- und Achillesphänomens und Sensibilitätsstörungen im Versorgungsbereich von $\mathrm{L}_{2}-\mathrm{L}_{4}$, also an der Hinterseite des Oberschenkels, an Wade und Fuß und evtl. auch an der Außenseite des Unterschenkels.

Das sind die klinischen Bilder, die sich ergeben, wenn beide Rückenmarkshälften affiziert sind. Beschränkt sich die Markschädigung dagegen ganz oder vorwiegend auf eine Querschnittsseite, so kommt es zum Symptomenkomplex der spinalen Hemiplegie, entweder im Brown-Séquardschen oder im Oppenheimschen Sinne.

b) Klassische Brown-Séquardsche Halbseitenlähmungen, d. h. Lähmungen, bei denen den Symptomen der Segmentläsion, der spastischen Parese und der Lagegefühlsstörung auf der Seite der Verletzung, eine Aufhebung oder Herabsetzung des Temperatur- und Schmerzgefühles auf der Gegenseite, nach abwärts von der Verletzungsstelle, entspricht, sind unter dem Kriegsmaterial selten, kommen aber, wie der folgende Fall zeigt, vor.

(Beob. 2.) Füsilier B., 29. VII. 1915 Schrapnellsteckschuß in die linke Schlüssel beingrube. Linkes Bein sofort vollständig bewegungslos; Stuhl und Urin angehalten. 18. XI. 1915 vergeblicher Versuch das Geschoß an Hand des Röntgenbildes im 7. Intercostalraum nahe der Wirbelsäule aufzusuchen. Befund am 10. III. 1916: Gehen durch Schwäche des linken und gesteigerte Frmüdbarkeit des rechten Beines stark erschwert, lanzinierender Halbgürtelschmerz in der linken Brusthälfte unterhalb der Brustwarze. Wasserlassen und Stuhlgang erschwert. Leichte spastische Parese des linken Beines mit Hyperreflexie, Fußklonus. Babinski, Oppen- 
heim und Rossolimo; außerdem statische und lokomotorische Ataxie in demselben. Im rechten Bein normale Motilitäts- und Reflexverhältnisse. Rectus abdominis links schwächer innerviert als rechts. Bauchdeckenreflexe links nicht erzielbar. Spontanzuckungen in beiden Beinen. Sensibel: Hypästhetische Halbgürtelzone links zwischen Xyphoid- und Nabellinie mit inselförmiger Anästhesie in Höhe von $D_{7}$ und $D_{8}$; nach unten davon in der linken Körperhälfte Bathyhypästhesie, in der rechten Körperhälfte Aufhebung für Schmerz- und Temperaturreize. - Laminektomiert am 4. V. 1916 durch Dr. Krüger. Knochen des 5. und 6. Brustwirbels auffallend brüchig. In der Höhe des 7. Wirbels kleiner Knochenvorsprung vorhanden, der von links seitlich auf das Rückenmark wie ein Sporn drückt. Nach oben von diesem kleinen Knochenvorsprung zeigen sich seitlich zwischen Dura und Knochenkanal bröcklige, etwas schmierig aussehende Auflagerungen, bei deren vorsichtigem Auseinanderschieben man auf eine weiche Stelle des Knochens stößt. Von dieser Stelle des Knochens lassen sich die oberen Schichten mit dem scharfen Löffel unter größter Vorsicht entfernen. Sobald eir kleines Loch entstanden ist, schimmert das bläuliche Blei der Kugel durch, dieselbe läßt sich mit Hilfe des scharfen Löffels ohne Schwierigkeiten entfernen.

Wir haben noch zwei weitere Fälle von ,klassischem“ BrownSéquard beobachtet, bei denen es sich um Affektionen des unteren Halsmarkes handelte. Sie boten, neben dem Hornerschen Syndrom, als Zeichen der Segmentläsion, einseitige, atrophisch-degenerative Paresen der Hand- und Vorderarmmuskulatur mit entsprechend orientierter radikulärer Sensibilitätsstörung, während die Leitungsunterbrechung im Mark, wie in dem ersterwähnten Falle, durch eine homolaterale spastische Beinparese mit Bathyhypästhesie bis zur Höhe des lädierten Segmentabschnittes und einer kontralateralen Aufhebung der Schmerz- und Temperaturempfindung von derselben Ausdehnung zum Ausdruck kam. Der eine der beiden Fälle stellte insofern eine Art Kuriosum dar, als sich bei ihm die Diagnose schon aus der Vorgeschichte stellen ließ, indem er spontan angab, beim Baden auf der nicht gelähmten Seite keine Temperaturen mehr unterscheiden zu können. ... Daß es bei den traumatischen Rückenmarkverletzungen überhaupt zu so scharf ausgeprägten Hemisektionen kommen kann, muß überraschen, und es hat in der Tat auch den Anschein, daß derartige Beobachtungen zu den Seltenheiten gehören; jedenfalls ist in der Kriegsliteratur wenig darüber zu finden. Ascher und Licen bezweifeln, daß3 das Kriegsmaterial den Brown-Séquard in reiner Form darbieten könne und auch Berger teilt diese Auffassung. Nur Marburg und Ranzi berichten über gleichartige Beobachtungen; aber auch sie verfügen nur über vier einschlägige Fälle unter einem Gesamtmaterial von 142 Markschädigungen. In der Regel ist es eben doch nach unseren und Marburgs Erfahrungen so, daß das Syndrom nicht, wie in den beschriebenen Fällen, von vornherein in voller Schärfe in Erscheinung tritt, sondern sich erst allmählich aus einer bilateralen partiellen Querschnittsaffektion heraus entwickelt. Und auch dann präsentiert es sich meist nicht in strenger Halb- 
seitigkeit, sondern mehr in der Weise, daß man, wie etwa im nachstehenden Falle, sagen kann, auf der Seite der Verletzung überwiegen motorischer Ausfall und Tiefenhypästhesie, auf der kontralateralen Seite die Störungen der Schmerz- und Temperaturempfindung.

(Beob. 3.) Sergeant M., 1. IX. 1915 Gewehrkugelstecksehuß des Rückens. Beide Beine sofort vollständig gelähmt, bis auf die Zehen des linken Fußes. Rechtes Bein sehr schmerzhaft. Wasserlassen ersehwert. Nach acht Tagen Wiederkehr der Beweglichkeit im linken Bein. Bef und am 30. IX. 1915: Gürtelgefühle in der Hüfte, besonders rechts. Zuckungen und anfallsweise Schweißausbrüche in beiden Beinen. Motoris c h: Alle Bewegungen im rechten Bein kraftlos und aktiv in nur ganz geringem Ausmaße möglich. Relativ am besten gelingen Zehenbewegungen, Plantarflexion des Fußes und Roll- und Spreizbewegungen in der Hüfte. Motilität des linken Beines intakt. In beiden Beinen, im rechten mehr als im linken, ausgesprochene spastische Reflexe: Babinski, Oppenheim, Rossolimo, Fußklonus. Beide Achillesphänomene und linksseitiger Kniescheibenreflex erheblich gesteigert, rechter Plantarreflex nur schwach auslösbar. Cremasterreflexe und rechter unterer Bauchdeckenreflex fehlen. Linker Infraumbilicalreflex abgeschwächt. Obere Bauchdeckenreflexe normal. Sensibel: Vorderseite des rechten Obersehenkels im mittleren Drittel anästhetisch für alle Qualitäten. Nach unten davon bis zum Knie und nach oben bis knapp an die Nabellinie heran Hypästhesie. Außerdem im rechten Bein Bathyhypästhesie bis zur Hüfte. Im linken Bein, analog der Anästhesiezone im rechten Oberschenkel, Hypästhesie. Daran anschließend nach oben, bis zur Höhe der rechtsseitigen Hypästhesie, Hyperalgesie, nach unten totale Aufhebung für Schmerz- und Temperaturreize. Diag n ose: Brown-Séquardsche Halbseitenlähmung. Kompression des Markes von rechts her im Niveau der oberen Lendenanschwellung, entsprechend den Brustwirbeln IX-XII, Sofortiger Eingriff indiziert. Operationsbefund Dr. Kr üger: Infanteriegesehoß in Höhe des X. und XI. Brustwirbels. Dornfortsätze beider Wirbel stehen abnorm weit voneinander entfernt, sind aber intakt und scheinen durch das Geschoß nur auseinandergetrieben zu sein; dasselbe liegt mit der Spitze nach oben in der rechten Kanalhälfte zwischen Dura und Knochen und läßt sich leicht entfernen. Die Dura wird wegen Infektionsgefahr nicht eröffnet.

c) Der zweite Typus der spinalen Hemiplegie, die von Op p en h e im zuerst beschr ebene Halbseitenlähmung cerebralen Charakters, unterscheidet sich vom Brown-Séquard lediglich dadurch, daß Motilitätsund Sensibilitätsstörung auf der gleichen Seite liegen. Unsere Fälle dieser Art betreffen ausnah mslos Läsionen in Höhe der Halsansch wellung. Klinisch liegt das Bild zumeist so, daß sich im Arm der verletzten Seite atruphisch degenerative Läh mungserscheinungen mit radikulär angeordneter Sensibilitätsstörung vorfinden, also Zeichen der Segmentschädigung, wie wir sie bei den bilateralen Affekten des Halsmarkes bereits kennengelernt haben, und wie sie auch bei Brown-Séquardschen Fällen gleichen Höhensitzes in der Regel vorhanden sind. Während aber beim BrownSéquard den segmentalen Ausfallserscheinungen im Arm, als Zeichen der spinalen Leitungsunterbrechung, eine spastische Parese des ho mo lateralen Beines mit gekreuzter elektiver Sensibilitätsstörung des 
Stammes entspricht, fehlt bei der Oppenheimschen Form diese Kreuzung zwischen Motilitäts- und Sensibilitätsausfall, d. h. die sensible Leitungsunterbrechung im Mark äußert sich hier in einem der motorischen Lähmung gleichseitigen Ausfall aller Empfindungsqualitäten.

(Beob. 4.) Musketier F., 25. III. 1916, Brustdurchschuß rechts. Infanteriegeschoß. Einschuß vorne, Mitte des Schlüsselbeines, Ausschuß hinten, Höhe der 6. Rippe, knapp 3 Querfinger neben der Mittellinie. Sofortige Lähmung und Taubheit im rechten Arm, Schwäche im linken Arm und in beiden Beinen, besonders im rechten. Sprach- und Schluckbeschwerden und Stuhlverhaltung. Acht Tage nach der Verletzung wieder Spuren von Beweglichkeit im rechten Arm. Von da an dauernd heftige Schmerzen in der rechten Schulter, ausstrahlend über die radiale Beugeseite des Armes bis in die Hand. - 23. VI. 1916: Hochgradige Atrophie in der rechten Schultergürtel- und Oberarmmuskulatur, besonders im Pectoralis major, Infraspinatus, Deltoides und Biceps. Seitwärtsbewegungen des Kopfes nach rechts behindert. Schultererheben rechts herabgesetzt. Erheben des rechten Armes seitwärts mühsam bis zur Horizontalen. Unterarm in mäßiger, nur passiv teilweise überwindbarer Flexionscontractur. Beugung im Ellbogengelenk einigermaßen leidlich mit Hilfe des Brachioradialis. Beugung von Hand und Fingern durch Schmerzen behindert. Strecker der Hand und der Finger und Daumenballenmuskulatur im wesentlichen frei. Rechte Hand cyanotisch, feucht, kühl, mit stark macerierter Vola. Ständiger feinschlägiger Tremor in der rechten Oberextremität. Elektrisch: EaR. im rechten Biceps, hochgradige Herabsetzung im Cucullaris, pectoralis major (claviculäre Portion) und in Triceps. Parese erheblichen Grades im rechten Bein, leichte Schwäche in den linksseitigen Extremitäten. Sehnenreflexe am rechten Arm erloschen, am rechten Bein gesteigert. Auch Cremaster- und Bauchdeckenreflexe r. $>1$. Pupille r. $<1$. Anästhesie für alle Qualitäten im Bereich von $\mathrm{C}_{4}-\mathrm{C}_{7}$. Hypästhesie im Bereich von $\mathrm{C}_{2}-\mathrm{C}_{3}$ und $\mathrm{C}_{8}-\mathrm{D}_{5}$, relative Hypästhesie in der rechten Körperhälfte, von $\mathrm{D}_{5}$ nach abwärts. Thermhypästhesie und Hypalgesie in der linken Hand, Bathyhypästhesie in der rechten Körperhälfte. Röntgenologisch: Bruch des rechten Sichlüsselbeines. - Diag n ose: Spinale Läsion, hauptsächlich rechtsseitig, vom Charakter der Oppenheimschen Halbseitenlähmung. Niveau: Mittleres und unteres Hals- und oberstes Brustmark; am meisten gesehädigt Segmente $\mathrm{C}_{4}-\mathrm{C}_{8}$, entsprechend den Halswirbeln III-VII. Extramedulläre Erscheinungen anscheinend im Übergewicht. Vermutlich Meningitis serosa circumseripta. Laminektomie mit Rücksicht auf die Stabilität des Zustandes und die eher zu- wie abnehmende Contractur im Ellenbogengelenk indiziert, zumal der Kranke der Schmerzen wegen sehr auf Abhilfe dringt. 23. VI. 1916: O peration (Dr. Krüger): Wegnahme der Halswirbelbogen 3-7. Dura pulslos, von einer zarten dünnen Membran vom 3.-7. Bogen umhüllt, die in querer Richtung in der Mitte hahnenkammförmig verdickt ist. Die Membran läßt sich im ganzen ablösen. Nach Eröffnung der Dura fließt klarer Liquor unter starkem Druck springbrunnengleich heraus. Das ganze Mark ist von zarten Verwachsungen umhüllt, durch die die einzelnen Wurzelfasern auseinandergezogen wie Schollengräten nebeneinander liegen. Erst nach Lösung der Verwachsungen legen sich die einzelnen Wurzelfasern wie sie zueinander gehören, nebeneinander.

Wie diese cerebrale Lähmungsform zustande kommt, ist noch nicht hinreichend geklärt. Will man nicht mit Oppenheim eine anatomische Anomalie in Gestalt eines Ausbleibens der sensiblen Kreuzung 
im Rückenmark für derartige Fälle annehmen, so wird man sich das Zustandsbild nur erklären können, unter Vorausetzung disseminierter Herde, die sich zufällig so über den Querschnitt verteilen, daß sie auf der einen Seite, neben dem motorisch-sensiblen Wurzelareal, vorwiegend das Pyramidensystem und auf der Gegenseite die langen sensiblen Bahnen in Mitleidenschaft ziehen.

3. Neben den totalen und partiellen Markläsionen bleibt dann an dritter Stelle noch eine Gruppe spinaler Affektionen zu besprechen, die dadurch gekennzeichnet ist, da B das Zustandsbild beherrscht wird von Ausfalls- und Reizerscheinungen, die für eine mehr oder weniger circumscripte Schädigung einzelner Rückenmarkwurzeln oder eines bestimmten Segmentabschnittes hindeuten. Symptome der Leitungsunterbrechung im Mark fehlen bei dieser Kategorie entweder ganz oder sind nur in der ersten Zeit nach der Verwundung vorhanden, verlieren sich aber dann spontan wieder, teils restlos, teils unter Hinterlassung dürftiger Spuren, die an praktischer Bedeutung weit hinter den Symptomen der Wurzel- bzw. Segmentschädigung zurücktreten.

Pathologisch-anatomisch hat man in diesen Fällen meist mit Prozessen zu rechnen, die entweder lediglich meningealer Herkunft sind, wie die reine Pachymeningitis und Arachnitis, und erst sekundär durch Druck oder Stauung das Mark mehr oder weniger affizieren, oder aber es handelt sich um Schädigungen, die Mark und Meningen $\mathbf{z} \mathbf{u}$ gleich betreffen, für die Marksubstanz aber weniger nachhaltig sind wie für die Meningen. Im ersten Falle stehen von vornherein die Wurzelsymptome im Vordergrund des Krankheitsbildes, und der ganze Verlauf weist daraufhin, daß eine Affektion vorliegt, die, ähnlich der Neubildung, von außen nach innen auf das Mark einwirkt. Im zweiten Falle dagegen hat man zunächst das Bild einer mehr oder weniger schweren Markläsion vor sich, bei der Mark- und Wurzelsymptome sich überdecken, bis dann nach und nach, mit dem Abklingen der Leitungsunterbrechung im Mark, die Erscheinungen des Wurzel- bzw. Segmentapparates mehr und mehr in den Vordergrund treten. Als Typus der ersten Gattung möchte ich folgenden Fall anführen:

(Beob. 5.) Musketier R., Angust 1917 Gewehrschuß durch die rechte Brusthälfte. Einschuß 2 Querfinger unterhalb der Brustwarze, Ausschuß etwa in der Höhe der siebenten Rippe, knapp medianwärts von der hinteren Axillarlinie. Zunächst keinerlei Lähmungserscheinungen. Erst 4 Wochen später (während des Transportes im Lazarettzuge) ziemlich plötzlich eintretende Schwäche des rechten Armes, die sich in der Folgezeit besonders auf Hand und Finger erstreckte und $a b$ Anfang November von einem stetig zunehmenden Schmerz begleitet war, der vom rechten Schulterblatt ausging und über die Ulnarseite des Armes bis in die Fingerspitzen ausstrahlte. Schmerzen anfallsweise, besonders nachts, von außerordentlicher Heftigkeit. Auf der Höhe des Anfalles krampfhaftes Zusammen- 
ziehen des 4. und 5. Fingers. Beim Treppensteigen oder längerem Gehen krampfendes Gefühl in der rechten Brusthälfte mit Atemnot. Dann gewöhnlich auch Schmerzen und Schwäche im linken Bein. Festes Zufassen mit der rechten Hand unmöglich.

2. I. 18: Alle Bewegungen im Schulter- und Ellenbogengelenk rechts mit verminderter Kraft; am schlechtesten funktionieren Triceps und Pectoralis major. Supination der Hand gut, Pronation schwächer. Flexor carpi ulnaris anscheinend schlechter wie Flexor radialis. Auch von den Handstreckern wirkt der radiale besser als der ulnare. Finger 4 und 5 stehen in halber Beugestellung. Thre Streckung gelingt aktiv nur spurweise, passiv unter heftigen Schmerzen nicht ganz bis zur Geraden. Faustschluß restlos, aber nur gegen minimalen Widerstand. Noch beschränkter und kraftloser sind die Spreizbewegungen der Finger 2-5 und die Abduction des Daumens, die übrigen Fingerbewegungen sind freier, aber auch nicht ganz intakt. Sehnenreflexe an rechter Oberextremität gesteigert. Rechter Ober- und Unterarm etwas weniger voluminös wie der linke. Rechte Hand im ganzen stark atrophisch, mit eingesunkenen Interossealräumen und stark abgeflachtem Hypothenar. Haut der Hand, besonders in der ulnaren Hälfte kalt, runzelig, blaurot verfärbt und mit inselförmigen gelblichen Borken bedeckt. Rechto Achselhöhle und rechte Hand triefen vor Schweiß. Sensibel: Hyperästhesie für Nadel und Pinsel rechts von $\mathrm{C}_{7}-\mathrm{D}_{3}$. Elektrisch: Komplette EaR. in den ulnaren kleinen Handmuskeln. Quantitative elektrische Veränderungen im Sinne einer starken Herabsetzung für beide Ströme in der costalen Portion des Pectoralis major. Linkes Bein überempfindlich für Schmerz- und Berührungsreize. Rechtes Fersenphänomen gesteigert. Diagn ose: Rechtsseitige radikuläre spinale Läsion durch Fernwirkung. In der Hauptsache beteiligt sind die Wurzeln $\mathrm{C}_{7}-\mathrm{D}_{3}$. Bezüglich der Indikation zur Operation dürften Bedenken kaum bestehen, da der Prozeß seit 5 Monaten nicht nur stabil, sondern in letzter Zeit sogar eher progredient ist, wie aus der Steigerung der Schmerzen und der zunehmenden Contractur der Finger sich schließen läßt. Wahrscheinlich handelt es sich um eine serösmeningitische Affektion. Operation am 18. II. 1918 (Dr. Kr üg er): Wegnahmeder Bögen $\mathrm{C}_{5}$ bis $\mathrm{Th}_{2}$. Nach Eröffnung der Dura fließt Liquor unter erhöhtem Druck in großem Bogen ab. Beim Auseinanderziehen des Duralschnittes wölbt sich in ihn die blasig gequollene Arachnoidea quallenartig vor, die mit dem Mark innig verklebt ist, so daß bei stärkerem Zuge an der Dura das Mark mit nach hinten gezogen wird. Die Entfernung der verdickten, dem Mark anhaftenden Arachnoidea macht große Schwierigkeiten und gelingt nur in ganz kleinen Stückchen. Die 7. rechte Wurzel ist besonders eng von ihr umhüllt. Diese Umhüllung, die auch noch auf den Teil des Markes sich erstreckt, an dem die 7. Wurzel deutlich von ihm getrennt und nur ihm angelagert verläuft, gelingt es fast restlos zu entfernen. Bei der Sondierung nach oben werden noch unter deutlich hörbaren knackenden Geräuschen Verwachsungen gesprengt. Sondierung nach unten frei. Die Gefäße, die nicht vermehrt sind, zeigen eine sehr starke Blutfüllung und Schlängelung, namentlich eine rechts von der Mittellinie verlaufende Vene.

Eine andere Krankengeschichte möge den Entwicklungsgang der zweiten Abart radikulärer Läsionen beleuchten.

(Beob. 6) Gefreiter K. Mit dem Verdacht auf Plexusaffektion eingeliefert. 11. VIII. 1916: Brustdurchschuß rechts. Einsehuß vordere Axillarlinie, Niveau der 3. Rippe, Aussehuß in derselben Höhe hinten, 3 Querfinger von der Mittellinie entfernt. Im Moment der Verwundung zusammengebrochen. Rechter Arm total gelähmt und brennend heiß. Beine ,wie mit Blei ausgegossen“. Linker Arm frei beweglich. Während der folgenden Tage an Heftigkeit stetig zunehmende, anfallsweise auftretende Schmerzen in der rechten Brusthälfte, dureh Ober- und 
Unterarm bis in die Hand ausstrahlend. Außerdem ständiges Hitzegefühl und schmerzhafte, schleudernde Zuckungen im rechten Arm. Kurzatmigkeit, besonders während der Schmerzanfälle. 14. VIII. 16: Schlaffe Lähmung des rechten Armes mit Areflexie. In Ellenbogengelenk, Hand und Finger fehlt jede aktive Bewegungsmöglichkeit, im Schultergelenk Bewegungen in beschränktem Ausmaß möglich, aber ohne jede Kraftentfaltung. In beiden Beinen Parese mittleren Grades. Gehen nur mit Unterstützung möglich. Elektrisch: Hochgradige Herabsetzung in Deltoides, Biceps, Pronator teres und in den Interossei; Aufhebung der Erregbarkeit in sämtlichen ibbrigen Muskeln der rechten Oberextremität. Anästhesie für alle Empfindungsqualitäten von $\mathrm{C}_{4}-\mathrm{D}_{1}$; Hypästhesie im Bereich von $\mathrm{C}_{3}$ und $\mathrm{D}_{2}-\mathrm{D}_{5}$. Bathyhypästhesie am stärksten in den distalen Partien der rechten Oberextremität. Lungenbefund: Atmung von normalem costalem Typus, aber auffallend beschleunigt und dyspnoisch. Rechts hinten oben leichte Schallverkürzung. Im Auswurf Spuren von Blut. Diagnose: Traumatische spinale Läsion, vorwiegend radikulären Charakters im Niveau der Halsanschwellung, hauptsächlich rechtsseitig. Am stärksten in Mitleidenschaft gezogen Segmente bzw. Wurzeln $\mathrm{C}_{4}-\mathrm{D}_{1}$, entsprechend Vert. cerv. 3-7. Extravertebrale Wurzelresp. Plexusaffektion nicht mit Sicherheit auszuschliel3en, aber, wenn vorhanden, zur Zeit hinter dem spinalen (meningealen) Prozeß an Bedeutung zurückstehend. Laminektomie vorerst nicht indiziert, jedoch mit Rücksicht auf die Atem. beschwerden, die in keinem Verhältnis zu dem geringfügigen Lungenbefund stehen und den Verdacht auf bulbäre Fernwirkung durch Liquorstauung erwecken, im Auge zu behalten. 25. VIII.: Bei unverändertem Befund an den Lungen plötzlich einsetzende schwere Atemstörungen, die auch am folgenden Tage noch anhalten. Anfallsweise auftretende, laut schnaubende Exspirationen mit anscheinend inspiratorischer Dyspnoe. Laminektomie wegen Gefahr der Atemlähmung beschlossen. 25. VIII.: Operation (Dr. Kr üger): Wegnahme der Wirbelbogen $\mathrm{C}_{3}-\mathrm{C}_{7}$. Dura pulslos. Gering vermehrte Gefäßinjektion, in Höhe von $\left({ }_{3}\right.$ geringf ïgige Auflagerungen. Seitlich zeigen sich beiderseits rötliche, faserige Auflagerungen, die nach vorn die Dura soweit sichtbar, dicht einhüllen. Nachdem die Dura einige Zeit freigelegen hat, setzt Pulsation ein. Nach Eröffnung der Dura spritzt Liquor in hohem Bogen und unter starkem Druck heraus. Beim Auseinanderziehen der Dura wird das ganze Mark durch zarte, rosa gefärbte Verwachsungen, die mit der Achse des Markes durch längsgestellte Häutchen zusammenhängen, mit in die Höhe gezogen. Die längsgestellten Häutchen verbreiten sich auf dem Mark hauptsächlich nach rechts, so daß seine rechte Hälfte beim Zug an der Dura besonders stark ver. lagert wird. Auf dem Mark vermehrte Gefäßinjektion. Die Häutchen zerreißen beim Entfernen mit hörbarem Knacken. In der Höhe von $\mathrm{C}_{3}$ sind sie so kräftig, daß sie das Mark hier wie an der Dura anfgehängt halten. Nach ihrer völligen Lösung bleibt das Mark beim Zug an der Dura in der Tiefe liegen. Sondierung nach oben fast frei, nach unten werden Verwachsungen noch bis ungefähr $D_{2}$ unter blasigem Knacken mit der Sonde gesprengt.

Im ersterwähnten Falle haben wir das klassische Bild der Meningitis serosa, wie es Oppenheim und Krause schon im Frieden und Marburg und Ranzi im Krieg beschrieben haben: Entwicklung des Prozesses unabhängig von der örtlichen Einwirkung des Traumas. Beginn des Leidens mit motorischen und sensiblen Reizerscheinungen in einem umschriebenen Wurzelgebiet. Dann Auftreten degenerativer Lähmungen und radikulär orientierter Sensibilitätsstörungen in dem anatomischen Verbreitungsgebiet dieser Wurzeln und endlich mehr oder 
weniger zur Auswirkung kommende Tiefenwirkung auf die Leitungsbahnen im Mark.

Der zweite Fall bjetet einen ganz anderen Modus des Verlaufes: In unmittelbarem Anschluß an die Verwundung plötzliches Einsetzen einerschlaffen Lähmung mit motorischen und sensiblen Reizerscheinungen und ausgedehnter Anästhesie jm rechten Arm als Ausdruck der Segmentläsion. Außerdem Parese beider Beine, die von vornherein, im Gegensatz zu der Armlähmung, eine sehr ausgesprochene Rückbildungstendenz zeigte und in wenigen Wochen behoben war. Wir haben also nicht ein Leiden vor uns, das, wie in dem ersten Fall, geraume Zeit nach dem Trauma begann und, allmählich von außen nach innen fortschreitend, erst die Wurzeln, dann das Mark ergriff, sondern ein Krankheitsbild, das sofort nach der Verletzung einsetzte und von vornherein den Querschnitt des Markes so in Mitleidenschaft zog, daß Wurzel- und Querschnittsymptome sich miteinander vermischten, und erst allmählich, mit der Rückbildung der Markerscheinungen, das Bild der Wurzelaffektion sich mehr und mehr herauskrystallisierte.

Nach MaBgabe ihres Höhensitzes zerfallen die isolierten Wurzelschädigungen in zwei Untergruppen; die eine umfaßt die radikulären Atfektionen im Niveau der Halsanschwellung, die andere die Läsionen der Cauda equina.

a) Das Symptomenbild der Wurzelläsion des Halsmarkes haben die beiden zuvor erwähnten Beobachtungen in prägnanter Weise gekennzeichnet. Bei den typischen Fällen ist dasselbe determiniert motorischerseits durch vorwiegend unilaterale, degenerativ-atrophische Paresen der Hals-, Schulter- und Armmuskulatur, entweder in ihrer Gesamtheit oder häufi; gruppen, sensiblerseits durch Ausfalls - oder Reizerscheinungen, erstere in Gestalt von Hypïsthesien, die sich scharf an das anatomische Verbreitungsgebiet der geschädigten Wurzeln halten, letztere in Form von Parästhesien oder Schmerzen lancinierenden Charaktels, die sich in ihrer Ausbreitung ziemlich genau mit dem objektiven Sensibilitätsausfall zu decken pflegen. In der Regel differieren auch die Sehnenreflexe in irgendeiner Weise mit der Gegenseite, doch ist dies kein unbedingt konstantes Symptom.

Handelt es sich nicht um isolierte Wurzelaffektionen, sondern wirkt der meningeale Proze $\beta$ noch in irgendeiner Weise auf das Mark ein, so findet man neben den Symptomen der Segmentläsion an der Oberextremität, als Folge der Leitungsstörung im Mark, eine latente Parese mit Hyperreflexie und evtl. auch mit sensiblen Störungen im gleichnamigen oder kontralateralen Bein. Das sind dann die Fälle, von denen fließende U̇bergänge zu den spinalen Hemiplegien im Brown-Séquardschen oder Oppenheimschen Sinne hinüberführen. 
Ein sehr merkwürdiges Symptom radikulärer Affektionen des Cervicalmarkes, das wir in 3 Fällen sehr ausgeprägt gefunden haben, möchte ich hier nicht unerwähnt lassen, weil es mir erhebliche praktische Bedeutung zu besitzen scheint. Es sind das eigenartige motorische Reizerscheinungen, die so hochgradig auftreten können, daß es zu schweren Contracturformen kommt. - Als Beispiel hierfür diene der folgende Fall:

(Beob. 7.) Pionier E. 5. XI. 1916 Weichteilsteckschuß des linken Oberarmes. Einschuß am vorderen Rand des Deltamuskels. Sofort Lähmung des linken Armes, d. h. es waren alle Bewegungen in Schulter- und Ellenbogengelenk aufgehoben; nur Hand und Finger konnte er noch schwach bewegen. Außerdem von vornherein starke Schmerzen im ganzen linken Arm. - 10. XI. 16. Entfernung des Geschosses handbreit unterhalb der Einschußöffnung. Bef und 25. IX. 1917: Linker Arm im Schultergelenk adduziert, im Ellenbogengelenk rechtwinklig gebeugt. Aktive Beweglichkeit im Schultergelenk so gut wie aufgehoben. Passive Bewegungen anscheinend sehr schmerzhaft und durch reflektorische Muskelspannungen erheblich behindert. Schulterheben links schwächer als rechts. Im Ellenbogengelenk Beugung normal, Streckung aktiv bis zu $120^{\circ}$, passiv unter Schmerzäußerungen nicht ganz bis zum Durchdrücken; dabei intensive unwillkürliche Anspannung des Biceps, Pronation, Supination und Streckung der Hand in mäßigem Grade reduziert. Beugung im Handgelenk und Fingerbewegungen 0 . B. Pupille und Lidspalte links etwas weiter als rechts. Sehnenreflexe in beiden Oberextremitäten sehr schwach, aber rechts = links. Brüske Manipulationen am linken Arm lösen regelmäßig ausgiebige klonische Zuckungen im linken Biceps und Pectoralis aus. Sensibilität: Hyp- bis Anästhesie für alle Qualitäten linksseitig im Handteller, in der ulnaren Hälfte des Vorder- und Oberarmes und einem entsprechenden, reichlich handbreiten Streifen an der Vorderund Rückseite des Thorax. Hypästhesie leichteren Grades ebenfalls für alle Reize am Handrücken links. Inkonstante taktile Hypästhesie in der rechten Hand. Leicht livide Verfärbung und mäBige Atrophie des linken Oberarmes. Elektrisch keine sicheren Veränderungen der Erregbarkeit. Grobe Kraft im linken Bein einwandfrei hinter der Gegenseite zurück. Abschwächung des linken Patellarphänomens. Diagnose: Radikuläre, wahrscheinlich intravertebrale Läsion im Niveau von $\mathrm{C}_{6}-\mathrm{D}_{4}$, vorwiegend links. Da Zustand absolut stabil und meningealer Prozeß zu erwarten war, wurde dem Kranken zur Operation geraten und Laminektomie der drei unteren Hals- und der beiden oberen Brustwirbel beschlossen. 3. XI. 1917 Operation (Dr. K r üge r): Wegnahme der Bogenwirbel von $\mathrm{C}_{5}-\mathrm{Th}_{2}$, Dura pulslos, ist in der Ausdehnung von $\mathrm{C}_{6}-\mathrm{Th}_{1}$ von einer dicken, blauroten Membran rings umhüllt. Sie läßt sich stumpf abziehen. Nachdem die Dura einige Zeit freigelegen hat, tritt mit dem Pulse synchrone Pulsation ein. Nach Eröffnung der Dura fließt nur wenig Liquor ab. In den Markkanal kommt man durch den in der Mitte angelegten Scbnitt nicht hinein, da die linke Hälfte des Markes von der Mitte aus, an einzelnen Stellen sogar noch von rechts der Mitte her, innig und fest mit der Innenfläche der Dura verwachsen ist, so daß der Subarachnoidalraum völlig verklebt ist. Stärkerer Liquorabfluß tritt erst ein, sobald die Dura nach rechts abgezogen wird. Beim Anheben der linken Durahälfte wird das Mark mit nach hinten und links verzogen. Die Verwachsungen der linken Hälfte des Markes mit der Dura sind stellenweise außerordentlich fest und knacken bei ihrer stumpfen Lösung. Danach zeigt sich das Mark, scharf halbseitig, nach links mit einer blauroten, starken Membran in der Ausdehnung von Wirbel $\mathrm{C}_{7}$ 


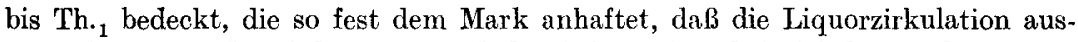
geschaltet war. Es wird dies noch dadurch bestätigt, daß sich bis zu der oberen und unteren Grenze dieser Membran gleichzeitig mit der Atmung die Arachnoidea cystenartig vorwölbt, was rechts fehlt, da der Liquor hier freie Bahn hat. Diese Membran läßt sich stückweise stumpf abziehen. obwohl sie dem Mark innig an. kaftet. Nach ihrer Wegnahme verschwinden die blasenartigen Vorwölbungen, da das Hindernis für die Liquorzirkulation damit beseitigt ist. Das vor der Lösung der Verwachsungen blaurot schimmernde Mark hat nach der Lösung einen frischen rötlichen Farbton angenommen.

Die Frage nach dem pathogenetischen Moment bei dieser Art von Contracturen ist nicht leicht $\mathrm{zu}$ beantworten. Um echte Spasmen infolge Pyramidendegeneration kann es sich nicht handeln. Auch algogene Haltungsanomalien dürften ursächlich kaum in Betracht kommen. Am nächsten scheint uns noch die Annahme zu liegen, daß irgend. welche pathologische Reizzustände im peripheren motorischen Neuron dabei im Spiele sind, daß man es also mit Reflexkrämpfen zu tun hat, ausgelöst etwa durch irritative Einwirkungen adhäsiver Prozesse auf die hinteren Wurzeln. Mit dieser Auffassung würde sich wohl auch am ungezwungensten die außergewöhnliche Schmerzhaftigkeit dieser Hypertonien in allen unseren Fällen erklären und nicht zuletzt ihr geradezu verblüffend prompter Ausglejch nach der operativen Befreiung der spinalen Wurzeln aus ihren arachnitischen Verwachsungen.

b) Eine sehr bedeutende Rolle unter den Kriegsschädigungen des Rückenmarkes kommt der zweiten Gruppe von Wurzelaffektionen zu, den Verletzungen der Ca uda equina; einmal, weil sie zahlenmäßig sehr im Vordergrunde stehen und dann, vor allen Dingen, weil sie ein sehr dankbares Feld für die operative Behandlung abgeben. Die Topographie der Cauda, insbesondere der relativ weite Spielraum der einzelnen Wurzelbündel innerhalb des Wirbelkanales bringt es mit sich, daß Traumen hier weit weniger deletär wirken als beim Rückenmark. Selbst in Fällen, wo das Geschoß den Wirbelkanal durchquert hatte, haben wir wiederholt beobachten können, daß nur ein Teil der Caudawurzeln lädiert und auch dieser noch weitgehend erholungsfähig war. So erklärt es sich wohl, daß komplette traumatische Caudaschädigungen, unserer Erfahrung gemäß, relativ selten sind. Unter zwanzig laminektomierten Caudafällen haben wir nur einen einzigen verzeichnet, bei dem die klinische Untersuchung gleichmäßig verteilte, bilaterale Ausfallserscheinungen ergab und die Freilegung der Cauda eine schwere doppelseitige Läsion aufdeckte. Bei drei weiteren tiefsitzenden Caudaschädigungen waren klinisch wie bioptisch ebenfalls beide Seiten affiziert, aber die eine doch immerhin erheblich schwerer als die andere. Die übrigen 15 Fälle boten die Kennzeichen der streng halbseitigen Wurzelläsion: Schlaffe Lähmung eines Beines mit 
EaR., Hypo- oder Areflexie und radikulär angeordneter Gefühlsstörung.

Schwerere Ausfallserscheinungen seitens des Uro-Genitalapparates sind bei Caudaaffektionen immer nur dann vorhanden, wenn der beiderseitige sakrale Wurzelanteil in den Prozeß mit einbezogen wird. Bei Affektionen, die sich lediglich oder in der Hauptsache auf die Sakralwurzeln einer Seite oder aut den I u mbalen Caudaabschnitt beschränken, fehlen sie entweder ganz oder sind nur anfänglich in geringem Maße vorhanden.

Als Repräsentant der Kategorie doppelseitiger Caudaschädigungen möge der nachstehende Krankenbericht angeführt sein:

(Beob. 8.) Gefreiter P. wurde am 30. XI. 1917 durch Minengeschoß oberhalb der rechten Hüfte verwundet. Sofortige Schwäche und Gefühl der Vertaubung in beiden Beinen. Nach 2 Stunden so weit erholt, daß er langsam zum Verbandplatz sich zurückschleppen konnte. Stuhl und Urin gingen unbemerkt ab. Am 13. II. 1918 Aufnahme auf neuro-chirurgische Korpsstation Arnsdorf. K la g e $n$ : Brennende Schmerzen in beiden Gesäßhälften und an der Innenseite der Oberschenkel und Gefühl als ob er in Brennesseln säße. Spontaner Urin- und Stuhlabgang, absolute Impotenz. Befund: Gang langsam und unbeholfen, anscheinend infolge der Schmerzen in der Gesäßgegend. Bewegung in beiden Unterextremitäten frei bis auf Dorsalflexion des rechten Fußes, die etwa um die Hälfte des normalen Ausmaßes beschränkt und ziemlich kraftlos ist. Rechtes Fersenphänomen nicht, linkes nur schwach erzielbar. Cremasterreflexe beiderseits wechselnd, bald außerordentlich gesteigert und schon durch leichte Pinselberührung an den Oberschenkeln auszulösen, bald schwach und leicht ersehöpfbar. Sonst normale Reflexverhältnisse. Kleine Fußmuskulatur rechts faradisch nicht erregbar, galvanischer Muskelausschlag schwächer als links. Sensibel: Perianogenitale Hypästhesie für alle Qualitäten in typischer Reithosenform, (rechts $=$ links), und Hyperästhesie, ebenfalls für alle Qualitäten, in der rechten Fußsohle. Röntgenbild: Infanteriegeschoß ungefähr in der Mitte der linken Beckenschaufel an ihrer Außenseite gelegen. Diagnose: Läsion der Sakralwurzeln, hauptsächlich der dritten, vierten und fünften beiderseits. $O b$ die Läsion in der Höhe des Ursprunggebietes der Wurzeln oder im Niveau ihrer Austrittsstellen liegt, ist in vorliegendem Falle schwer zu sagen. Die Doppelseitigkeit der Ausfalls- und Reizerscheinungen und die schweren Störungen der Blasen-, Mastdarm- und Genitalfunktionen würden mehr für Conus, Schußkanal und Röntgenbild mehr für Caudaläsion sprechen. Es empfiehlt sich nochmals Stereoaufnahme unter Einstellung der Wirbel $\mathrm{Th}_{12}-\mathrm{L}_{3}$. Bei negativem Resultat derselben wäre auf Caudaläsion zuzukommen und, falls man sich zur Laminektomie entschließ3t, Resektion der Bogen der drei untersten Lendenwirbel und der oberen Hälfte des Kreuzbeinkammes vorzunehmen.

Da die untersten Brust- und die oberen Lendenwirbel röntgenologisch sich als intakt erwiesen, wurde Freilegung der Cauda beschlossen. Ausführung Dr. Kr üger. Operationsbefund: In Höhe des 1 . Kreuzbeinwirbels sehnige Verdickung der Dura, die als Schußrinne aufgefaßt wird. Die 2. Sakralwurzel rechts ist $1 \mathrm{~cm}$ vor ihrem Austritt in das Duraloch durch derbe Verwachsungen mit der Innenfläche der Dura verklebt. Dicht unterhalb davon ist die ganze Cauda neuromartig verdickt. Die verdickte Stelle läßt sich mit der Sonde aufbündeln, so daß man die einzelnen Caudawurzeln zu Gesicht bekommt. Dabei stellt sich 
heraus, daß sämtliche Caudawurzeln unterhalb von $S_{2}$ abgeschossen und zu der neuromartigen Verdickung mit ihren Zentralendenen zusammengeklebt sind. Sie lassen sich sämtlich aus ihrer Verklebung hérausschälen und isolieren. Die letzte rechts und links austretende Wurzel ist die zweite Sacralis. Nach unten davon ist der Durasack obliteriert und eine Fortsetzung der Wurzeln nach abwärts nicht vorhanden. Außerhalb des Durasackes werden entsprechend dem Verlauf der fünften Sacralis zwei dicke Wurzeln gefunden, aus ihren Verwachsungen herausgeschält und nach oben verfolgt. Durch feinste Seidennähte gelingt es, sie mit den aus dem Neurom herausgeholten Caudawurzeln zusammenzunähen.

Demgegenüber stellen die beiden folgenden Krankengeschichten streng halbseitige Caudaschädigungen dar, und zwar die erste eine hochsitzende Caudaaffektion unter vorwiegender Beteiligung des lumbalen Wurzelabschnittes, die zweite eine tiefliegende Caudaschädigung, die nur den sakralen Wurzelanteil betrifft.

(Beob. 9.) Musketier K1. 29. X. 1915. Verwundung durch InfanteriegeschoB. Bauchdurchschuß. Einschuß links hinten in der Höhe des 2. Lendenwirbels; handbreit neben der Mittellinie, Ausschuß rechts vorn, vordere Axillarlinie, Niveau der 8./9. Rippe. Sofort perfekte Lähmung und Taubheit des linken Beines und starke Schmerzen, bzw. schmerzhafte Kältegefühle vom Gesäß durch das ganze linke Bein bis in die Zehenspitzen von unverminderter Heftigkeit bis zuletzt. Mehrere Wochen lang hartnäckige Stuhlverhaltung. Bef und 18. V. 1916 (7 Monate nach der Verletzung): Hochgradige Atrophie im linken Oberschenkel, besonders an der Streckseite. Kann nur mit doppelseitiger Unterstützung gehen. Vollständige Aufhebung der motorischen Funktion und der elektrischen Erregbarkeit in der Streckergruppe am Oberschenkel links. Erhebliche Herabsetzung der motorischen Kraft mit quantitativen Veränderungen der elektrisehen Erregbarkeit in den Adductoren, den Streckern am Oberschenkel und in der Hüftmuskulatur. Fuß und Zehen im wesentlichen frei. Cremaster- und Patellarreflexe links erlosehen. Erhöhung der Sehnenphänomene im rechten Bein. Babinski, Oppenheim, Rossolimo rechts. Anästhesie für alle Empfindungsqualitäten im Segmentbereich $\mathrm{I}_{2}-\mathrm{L}_{3}$, Hypästhesie im Bereich von $\mathrm{L}_{4}-\mathrm{L}_{5}$, relative Hypästhesie im Bereich von $S_{1}-S_{3}$. Bathyhypästhesie im ganzen linken Bein. Ausstrahlende Schmerzen im Innervationsgebiet von $\mathrm{L}_{1}-\mathrm{L}_{4}$. Röntgenbefund negativ. Diagnose: Bild der hochsitzenden, linksseitigen Caudaaffektion. Mit Rücksicht auf die stetig zunehmende atrophische Lähmung und die Stabilität der Schmerzen Laminektomie indiziert. Resektion der Lendenwirbelbögen vom ersten nách abwärts empfohlen. 18. V. Operation (Dr. Kr üger): Wegnahme der Bögen $L_{1}-L_{5}$. Die Dura ist in der Höhe $L_{2}$ bis zur Mitte von $L_{1}$ von schwieligen Schwarten bedeckt, die beim Abtragen selbst der Schere Widerstand leisten, im übrigen frei von Auflagerungen. In den unteren freigelegten Teilen schimmern verschwommen (audawurzeln durch. Sie ist prall gespannt und wölbt sich ballonartig in die Knochenlücke hinein. Dura wird für sich eröffnet. In den zunächst kleinen Schnitt drängt sich mit der Pulsation die Arachnoidea cystengleich vor. Nach Spaltung der Arachnoidea fließt Liquor in größeren Mengen unter mäßigem Drucke ab. Die Cauda ist ganz von einer zarten, schleierartigen, durchsichtigen Membran umhüllt, die sich im Zusammenhang abziehen läßt. In der Höhe des 2. Lendenwirbels ist eine Wurzel links so fest mit der Dura verwachsen, daß sie dadurch in die Breite gezogen erscheint. Sie läßt sich stumpf loslösen, wobei Zuckungen in der Glutäalmuskulatur und im ganzen linken Bein ausgelöst werden. Die Wurzel läßt sich bis zu ihrer Austrittsstelle verfolgen und 
wird als $\mathrm{L}_{3}$ festgestellt. In derselben Gegend ist noch $\mathrm{L}_{2}$ ebenso innig verwachsen. Sie zerreißt bei der Lösung. Das periphere Stück durch Naht mit einer Wurzel zu vereinigen, mißlingt, da es sich völlig auffasert, obwohl feinste Nadel und Gefäßseide benutzt werden. In der linken Hälfte des 2. Lendenwirbels ist eine muldenförmige Vertiefung vorhanden, in der die hier blaurot verfärbte, starke Gefäßinjektion zeigende Dura verklebt ist (Schußkanal). Rechts zeigen die Wurzeln keine krankhaften Veränderungen.

(Beob. 10.) Dragoner M. 10. VIII. 1916. Gewehrschuß quer durch das Becken, knapp unterhalb des Darmbeinkammes. Sofort zusammengebrochen. Linkes Bein vollständig gelähmt und gefühllos, rechtes frei beweglich. Vom 3. Tage an Schmerzen an der Hinterseite des linken Beines und im linken Fuß. 14. VIII. 1916: Linkes Bein im ganzen abgemagert. Fuß- und Zehenbewegungen aufgehoben. Unterschenkelbeugung und Funktion der Gesäßmuskulatur sehr mangelhaft. Strecker des Unterschenkels, Adductorengruppe und Hüftbeuger besser, aber auch nicht frei. Im rechten Bein normale Kraftverhältnisse. Elektrisch: Peronealmuskulatur unerregbar, Gesäßmuskeln und Beuger des Unterschenkels für beide Ströme nur sehr schwach, Waden- und Sohlenmuskeln etwas besser ansprechbar. Sehnenreflexe an der rechten Unterextremität stark abgeschwächt; links Patellarreflex angedeutet, Fersenphänomen erloschen. Cremasterreflex links kaum auslösbar, rechts normal. Gebiet von $\mathrm{L}_{4}-\mathrm{S}_{2}$ anästhetisch für alle Empfindungsqualitäten. Lagegefühl in den Zehen links erloschen, in Fuß-, Knie- und Hüftgelenk erheblich herabgesetzt. Linkes Bein hochgradig ataktisch. Muß katheterisiert werden. 25. VIII. Heute Cremasterreflexe beider. seits normal, während Patellar- und Fersenphänomene rechts wie links fehlen. 3. IX. Streckung des Unterschenkels und Beugnng in der Hüfte scheinbar etwas kräftiger. Auch das Wasserlassen geht besser. Sonst Befund unverändert. Reflexverhältnisse wechseln fortwährend; konstant bleibt nur der Ausfall des linken Fersenphänomens, während das rechte Fersenphänomen und die Patellarreflexe bald fehlen, bald mehr oder minder abgeschwächt sind. Geht mit doppelseitiger Unterstützung, watschelnd, mit Kleben der Fußsohle. Diagnose: Linksseitige Läsion der 4. und 5. Lumbal- und der 1. und 2. Sakralwurzel, und zwar am wahrscheinlichsten während ihres Verlaufes in der Cauda, vom 3. Lendenwirbel nach abwärts. 20. IX. Es ist eine gewisse Besserungstendenz nicht zu verkennen; sie erstreckt sich aber bis jetzt lediglich auf das Gebiet der von vornherein nur relativ wenig beteiligten oberen Lendenwurzeln, während der schwere motorischsensible Ausfall im Bereich von $\mathrm{L}_{4}-\mathrm{S}_{2}$ unverändert bestehen bleibt. Ich halte daher Laminektomie für gerechtfertigt und empfehle Resektion der drei unteren Lendenwirbel und des oberen Kreuzbeinabschnittes. 25. IX. Laminektomie(Dr. Kr ü g e r): Wegnahme der Bögen von $\mathrm{L}_{3}$ bis zur Mitte des Kreuzbeines. 'Blutung gering. Dura in der Höhe von $\mathrm{L}_{5}$ durch eine rosa gefärbte, $1 / 2 \mathrm{~cm}$ breite bandartige Membran eingeschnürt, in den übrigen freigelegten Teilen von dicken epiduralen Fettmassen bedeckt. Beides läßt sich stumpf abziehen. Unter der Membran zeigt die Dura starke Gefäßinjektion, sonst normales bläuliches Aussehen mit Perlmutterglanz. An einigen Stellen schimmern Caudawurzeln durch. Nach Eröffnung fließt Liquor unter starkem Drucke ab, so daß einige Wurzeln durch den Schnitt herausgepreßt werden. Die Wurzeln sind hauptsächlich links unter sich und mit der Innenfläche der Dura verklebt, teilweise entzündlich gerötet und von einer zarten, rosa gefärbten Membran umhüllt. An der Stelle, wo außen die Membran auflag, ist die Dura brüchig und innen rot verfärbt, wie von einer rötlichen Haut bekleidet. Nach abwärts vom 4. Bogen ist ein längsovales Loch von $1 \frac{1}{2} \mathrm{~cm}$ Länge und $1 / 2 \mathrm{~cm}$ Breite in der Dura vorhanden, das teilweise durch darüberziehende Fasern sich wieder geschlossen hat. Nach rechts Verwachsungen geringer. Alle Ver- 
und deren Behandlung, unter besonderer Berücksichtigung der Spätfälle.

klebungen und Membranen lassen sich lösen. Danach fallen die anfangs beim Anziehen der Haltefäden der Dura mit in die Höhe gehobenen Wurzeln in den Durakanal zurück.

Eine auf den ersten Blick verblüffende Erscheinung, der wir wiederholt bei einseitigen Caudaläsionen begegnet sind und die auch der zuvor erwähnte Fall bietet, ist die, daß mit der schlaffen Lähmung spastische Phänomene, wie Babinskisches und Rossolimosches Zeichen, einhergehen. Das läßt sich natürlich nur mit einer gleichzeitigen Beeinflussung des Markes erklären, und zwar scheint uns das meist rapide Verschwinden der spastischen Reflexe mit der Druckentlastung durch die Laminektomie in erster Linie dafür zu sprechen, daß eine erhöhte Liquorspannung die Ursache der Markschädigung abgibt. Ich erwähne diese Erscheinung besonders deshalb, weil sie eine wesentliche Stütze bietet für die gleich noch zu besprechende, nicht immer ganz leichte Differentialdiagnose zwischen einseitiger Caudaläsion und hochsitzender Ischiadicusverletzung.

\section{Diagnostische Fragen.}

Bei der diagnostischen Bewertung einer Rückenmarksschädigung sind 3 Punkte zu berücksichtigen: erstens die Art der Läsion und ihre Beziehung zum Querschnitt des Markes, zweitens die Frage der Höhenlokalisation und drittens die Möglichkeit einer Verwechslung spinal bedingter Ausfalls- und Reizerscheinungen mit Symptomenbildern ähnlicher Art, aber anderer Genese.

1. Für die Art der Verletzung, d. h. ihren pathologisch-anatomischen Charakter, gibt uns der klinische Befund in der Regel nur sehr dürftige Anhaltspunkte. Rasche und weitgehende Rückbildung der Lähmungserscheinungen wird in erster Linie für eine Commotio spinalis sprechen, isoliertes Auttreten von Wurzelsymptomen oder starkes Ưberwiegen derselben gegenüber den Leitungsunterbrechungserscheinungen seitens des Markes für eine adhäsiv meningitische Affektion. Das sind wohl aber auch die einzigen Möglichkeiten, bei denen sich aus dem klinischen Zustandsbild und dessen Verlauf eine einigermaßen sichere Artdiagnose stellen läßt. Im übrigen werden wir in dieser Hinsicht meist auf Vermutungen angewiesen sein.

Bei der Beantwortung der Frage, in welchem Verhältnis die Läsion zum Querschnitt des Markes steht, hat man sich nach folgenden Gesichtspunkten zu richten. Liegt ein ausgesprochenes Kompressionssyndrom vor, oder treten zu anfänglich mehr oder minder isolierten radikulären Ausfalls- und Reizerscheinungen sekundär SymptomederLeitungsunterbrechung im Mark, so ist die Antwort klar; man wird in solchen Fällen kaum fehlgehen mit der Annahme èines raumbeengenden Prozesses im Wirbelkanal, der von außen her auf das Mark einwirkt. Und zwar 
wird es sich dabei entweder um grob mechanische Effekte durch Projektile oder in das Kanallumen vorgeschobene Knochensplitter handeln oder aber, wie uns scheint, besonders häufig, um pachymeningitische Schwielen und arachnoiditische Verwachsungen, die unmittelbar oder durch cystenartige Liquora bsackungen auf das Mark drücken. Je weniger Kompressiverscheinungen das klinische Krankheitsbild bietet, desto mehr sind wir berechtigt, die Diagnose auf einen ausschließlich oder vorwiegend intramedullären Sitz der Läsion zu stellen. Vor allem scheint uns das Fehlen von Schmerzen dafür zu sprechen, daß die Läsion in der Hauptsache den Querschnitt des Markes betrifft, und daß Veränderungen in seiner U'mgebung entweder ganz fehlen oder zum mindesten an Bedeutung hinter der endomedullären Affektion zurücktreten.

2. Günstiger als um die qualitative Bestimmung ist es glücklicherweise um die Höhendiagnose der Rückenmarkverletzungen bestellt. Die genaue Feststellung des Höhensitzes der Läsion ist für jede Markschädigung, bei der es sich um die Frage eines operativen Eingriffes handelt, eine unbedingte Voraussetzung. Sie hat stets in erster Linie auf Grund des klinisch-neurologischen Befundes zu erfolgen und es bedarf dazu wiederholter Untersuchungen, die in ihren Einzelergebnissen sich decken müssen. Ausschlaggebend für die Niveaudiagnose sind die schon des öfteren erwähnten Segmentsymptome, d.h. jene Reiz- und Ausfallserscheinungen, die durch u n mittel bare Schädigung eines bestimmten Wurzel- oder Segementabschnittes zustande kommen. Eine klinische Differenzierung zwischen radikulär und segmental bedingten Symptomen ist natürlich nicht möglich, da die einzelnen Wurzeln und die Segmente, von denen sie ausgehen, in ihren physiologischen Funktionen bekanntlich einander gleichwertig sind. Es ist daher bei segmental orienvierten Störungen nicht zu sagen, ob sie rein radikulärer, extramedullärer Herkunft sind, oder ob sie auf Veränderungen im metameren Ursprungsgebiet des lädierten Wurzelgebietes bezogen werden müssen. Man hat sich also mit anderen Worten für klinisch-diagnostische Zwecke mit der Feststellung zu begnügen, daß ein bestimmter Segmentabschnitt in seiner Funktion gestört ist, muß es aber dahingestellt sein lassen, ob diesem Funktionsausfall ein intraspinaler oder ein meningealer Prozeß zugrunde liegt.

Die Kennzeichen der Segmentläsion sind bekannt; sie präsentieren sich teils als metamer angeordnete, sensible Reiz- und Ausfallserscheinungen, teils als umschriebene Muskellähmungen, wozu je nach dem Höhensitz auch noch Regelwidrigkeiten der Sehnen- und Hautreflexe kommen können. Die topisch-diagnostische Bewertung der sensiblen Reizerscheinúngen erfordert eine gewisse Vorsicht. Was den Wurzelschmerz anbelangt, so ist er für sich allein lokali- 
satorisch ein ziemlich unsicheres Kriterium, einmal weil er ein subjektives Symptom darstellt und dann vor allem auch, weil er weit über das eigentliche Läsionsgebiet hinaus ausstrahlen kann. Wir werden ihn infolgedessen für die Höhenbestimmung nur dann verwerten dürfen, wenn er in seiner Ausbreitung eine gewisse öttliche Konstanz zeigt und sich mit der objektiv nachweisbaren segmentalen Sensibilitätsstörung einigermaßen deckt. Triftt dies $\mathrm{zu}$, so wird man kaum fehlgehen, wenn man die Radikalgie als Ausdruck einer umschriebenen meningealen Veränderung deutet.

In demselben Sinne wie die Schmerzen sind gewisse H y pcrästhesien aufzufassen, sofern sie sich streng an ein bestimmtes Segmentgebiet halten. Wir verfügen über 3 Fälle mit Verletzungen des Dorsalmarkes, bei denen wir bezüglich der Höhendiagnose in der Hauptsache auf eine derartige segmentale Hyperästhesie angewiesen waren und bei denen der bioptische Befund so lag, daß als Ursache derselben eine Reizung der hinteren Wurzeln durch meningeale Verklebungen angenommen werden mußte.

Zuverlässiger als die Reizerscheinungen sind die Sensibilitätsdefekte. Thr Nachweis ist jedoch nicht immer so ganz einfach, wie es auf den ersten Blick scheinen möchte, da es sich keineswegs durchgehends um grob sinnfällige Empfindungslähmungen zu handeln pflegt, sondern viel häutiger nur um Hypästhesien verschiedensten Grades, deren Umgrenzung ein erhebliches Maß von Geduld und Aufmerksamkeit seitens des Untersuchten sowohl wie seitens des Untersuchers erfordert, und neben einer gewissen technischen Erfahrung insbesondere auch strengste Selbstkritik, wenn man nicht sich und dem Kranken Kunstprodukte suggerieren will. Die segmentale Sensibilitätsstörung tritt sowohl halb- wie doppelseitig in Erscheinung und betrifft meist alle Qualitäten der Oberflächensensibulität nach Intensität und Ausdehnung in gleicher Weise, kann aber auch dissozijerten Charakter tragen. Ihre Topik darf jch als bekannt voraussetzen. Wir haben uns zur Bestimmung der Wurzelfelder in der Hauptsache des Seifertschen Schemas bedient und dasselbe als zuverlässig schätzen gelernt.

Als weiteres höhendiagnostisches Merkmal nannten wir Motilitäts stör ungen von radikulärem Typus, d. h. isolierte Paresen einzelner Muskeln oder Muskelgruppen, die in der Regel einen mehr oder minder ausgesprochenen degenerativ-atrophischen Charakter tragen. Der Nachweis dieser segmentalen Muskellähmungen macht bei den Herden im Cervical-und Lumbalbezirk keine besonderen Schwierigkeiten, da sie fast immer mit irgendwelchen Veıänderungen der elektrischen Erregbarkeit einhergehen, sei es in Form von EaR., sei es in Gestalt quantitativer Veränderungen im Sinne einer Herabsetzung oder Erhöhung der Ansprech- 
barkeit für die eine oder andere Stromart. Im Rumpf ist es uns nur einmal gelungen, den segmentalen Charakter der Motilität nach zu weisen, in einem Falle, bei dem der Herd zufällig im Versorgungsbereich der der elektrischen Prüfung zugänglichen abdominalen Muskelgruppe sa B.

Mit dem segmentalen Motilitätsausfall konform gehen vielfach motorische Reizerscheinungen seitens des Wurzelapparates. Wir verfügen über eine große Anzahl ṿon Fällen, bei denen die Neigung zu Reflexbewegungen innerhalb einer bestimmten Wurzelsphäre vorübergehend oder dauernd zutage trat und sich besonders nachts unangenehm bemerkbar machte. Auch fibrilläres Muskelwogen, das sich anfallsweise zu grobem Zittern, ja bis zum Schütteltremor der ganzen Extremität steigerte, fanden wir öfters. Bemerkenswert an diesen Reflexzuckungen und für ihre radikuläre (segmentale) Genese beweisend ist der Umstand, daß sie in der Regel in Wurzelgebieten auftreten, deren peripheres Projektionsgebiet auch sensibel in Mitleidenschaft gezogen ist, sei es durch Reiz-, sei es durch Ausfallserscheinungen. Utber eigentümliche Contracturformen infolge von Wurzelirritation wurde oben schon berichtet; ich möchte an dieser Stelle nur der Vollständigkeit halber auf dieses merkwürdige Zustandsbild nochmals hinweisen.

Neben den sensiblen Störungen und den umschriebenen Muskellähmungen spielen endlich Reflexstörungen aller Intensitätsgrade, Areflexien sowohl, wie Absch wächungen oder Steigerungen der Retlexe für die Höhendiagnostik eine bedeutsa me Rolle; indessen ist bei ihrer lokalisatorischen Wertung doch eine gewisse Zurückhaltung am Piatze. Am brauchbarsten für die topische Diagnostik sind die Sehnenreflexe, da Regelwidrigkeiten ihrerseits wohl stets auf irgendwelche Veränderungen im Reflexbogen bezogen werden müssen. Es bleibt aber zu berücksichtigen, daß auch kleine, versprengte Herde außerhalb der Hauptläsionsstelle den Reflexbogen lädieren können, und vor allem Liquorabsperrungen ober- oder unterhalb des in Frage stehenden Prozesses, wenn sie stark sind, daß sie eine Kompressionswirkung ausüben. An wenigsten brauchbar in höhendiagnostischer Hinsicht sind die Hautreflexe, da sje bekanntlich durch Erkrankungsherde, die weit oberhalb ihres Reflexbogens liegen, in Mitleidenschaft gezogen werden können. Anomalien ihrerseits dürfen daher nur dann zur Niveaubestimmung herangezogen werden, wenn sie mit anderen Segmentsymptomen einhergehen und mit diesen in Einklang zu bringen sind; ganz besonders gilt dies für die Cremasterreflexe und die doppelseitige Abweichung des Plantarphänomens.

Vielleicht empfiehlt es sich an der Hand einiger Beispiele zu zeigen, wie sich praktisch die Durclführung der Höhendiagnose auf Grund der erwähnten klinischen Merkmale gestaltet. 
Pionier A. (Beob. 11) wurde durch vorzeitig krepierte Mine unter dem linken Ohr verwundet und hatte seitdem, neben einer vorübergehenden linksseitigen Taubheit und Sprach- und Schluckbeschwerden, eine ständige Sch wäche im linken Arm zurückbehalten. Einige Tage nach der Verwundung setzten außerdem sehr unangenehme Schmerzen in der linken Nacken- und Schultergegend ein, die zeitweilig durch den ganzen Arm bis in die Finger ausstrahlten. Nach und nach hatte sich auch eine Schwäche in den Beinen, besonders im linken, herausgebildet, so daß Stehen oder Gehen über eine halbe Stunde hinaus unmöglich war. Der Röntgenbefund ergab einen Splitter im Hals, links in der Höhe des dritten Halswirbels. Derselbe wurde kurz nach der Verletzung entfernt und war fest in den Querfortsatz des dritten Halswirbels eingekeilt, von dem er einen kleinen Knochensplitter abgesprengt hatte.

Die Befundaufnahme ergab 4 Wochen nach der Verwundung eine Parese mit Atrophie und qualitativer Herabsetzung der elektrischen Erregbarkeit in der linksseitigen Nackenmuskulatur. Auch die Wirkung der Schulter- und Oberaımmuskeln war links deutlich herabgesetzt und das linke 'Tricepsphänomen abgeschwächt. Hand und Finger waren völlig frei beweglich, die Radius-Periostreflexe von normaler Stärke, r. = 1. Auffällig war, daß bei forcierten Bewegungen der linke Arm sofort ins Zittern kam. Im linken Bein blieb die Kraftentfaltung hinter dem rechten zurück. Die Sehnenreflexe waren erhöht, unter Andeutung von Oppenheimschem Phänomen links und Rossolimoschem Zejchen rechts.

Die atrophisch-degenerative Parese der linksseitigen Nacken- und Schultermuskulatur sprach für eine Schädigung des Wurzel- bzw. Segmentabschnittes von $\mathrm{C}_{3}-\mathrm{C}_{7}$. Damit deckte sich der sensible Befund, der eine Hypästhesiezone für Schmerz- und Berührungsreize aufwies, die in einem 2 Querfinger breiten Stroifen von der linken Nackenhälfte über die Schulter und die radiale Hälfte des Armes bis zur Handwurzel sich erstr eckte und dann sich verjüngend in dien Mittelfinger auslief. Diesem hypästhetischen Gebiet entsprach auch ungefähr der Schmerzverlauf. Wir hatten es also mit sensiblen Ausfalls- und Reizerscheinungen zu tun, die sich genau an das anatomische Verbreitungsgebiet der dritten bis siebenten Cervicalwurzel hielten. Die Höhendiagnose lautete deshalb auf eine Läsion der oberen Hälfte der Halsanschwellung (vorwiegend $\mathrm{C}_{3}-\mathrm{C}_{7}$ ), und zwar mit Rücksicht auf die Geringfügigkeit der Leitungsunterbrechungssymptome im Mark vermutlich adhäsiv meningitischer Art. Da sich zu den ursprünglichen Schmerzen in der Nacken- und Schultergegend und im Arm ein dauernder dumpfer Kopfschmerz, Schwindel mit Scheinbewegung der Objekte, Nackensteifigkeit und eine ständige Pulsbeschleunigung von etwa 120 Schlägen pro Minute gesellten, Erscheinungen, die an bulbäre Fernwirkung durch Liquor- 
stauung denken ließen, wurde auf Drängen des Kranken im sechsten Monat nach der Verletzung die Laminektomie des III. und VI. Halswirbels vorgenommen, und sie ergab, dem klinischen Befund entsprechend, eine Meningitis serosa mit erhöhtem Liquordruck, starker Gefäßinjektion und ziemlich derben Verklebungen der linksseitigen Wurzeln in der supponierten Höhe.

In einem zweiten Fall (Beob. 12) fand sich nach einer Schußfraktur des rechten Akromions und der V. Rippe, motorisch, bei normaler Kraftentfaltung in Schulter und Oberarm, eine atrophische Parese mit EaR. in den kleinen Handmuskeln und eine leichte Herabsetzung der groben Kraft in den Streckern und Beugern der rechten Hand, also im Innervationsbereich der unteren Hals- und oberen Brustsegmente. Sensibel war im Gegensatz zum vorigen Fall, die ulnare Hälfte des rechten Armes und der Hand und eine entsprechende Halbgürtelzone in der rechten Thoraxhälfte hypästhetisch für Nadel-, Pinsel- und Temperaturreize. Die Schmerzen waren in der Hauptsache auf die unterempfindliche Rumpfzone beschränkt und so heftig, daß sie dem Kranken nach den geringfügigsten Anstrengungen (beispielsweise schon nach 10-15 Minuten langem Gehen) direkt den Atem versetzten und ihn zum Ausruhen zwangen. Da dieselben 6 Monate hindurch völlig gleich blieben und auch sonst an dem Befunde sich nichts änderte, wurde auf Wunsch des Patienten die Laminektomie beschlossen. Die Niveaudiagnose lag klar. Es mußte sich um einen Prozeß in der Gegend der unteren Halsanschwellung, d. h. der Wurzelgebiete $C_{8}-D_{3}$ oder $D_{4}$ handeln. Demzufolge wurden die Wirbelbögen des VI. und VII. Halsund des I., II. und III. Brustwirbels reseziert. Es fanden sich pachymeningitische Schwielen in der Ausdehnung von $\mathrm{C}_{6}-\mathrm{D}_{2}$ und in analoger Ausdehnung arachnoidale Verwachsungen, die am stärksten die VII. und VIII. rechtsseitige Halswurzel in Mitleidenschaft gezogen hatten.

Auf diese V'eise wird man in den meisten Fällen von Halsmarkläsionen, die nicht so ausgedehnte Querschnittspartien zerstört haben, daß Segment- und Leitungsunterbrechungssymptome sich gegenseitig überdecken, eine ziemlich scharfe Umgrenzung des Prozesses vornehmen und dem Chirurgen bestimmte Direktiven für den Ort des Eingriffes geben können.

Nicht ganz so einfach ist die Niveaubestimmung bei Dorsalmarkverletzungen, da degenerative Lähmungen in der Bauchmuskulatur nur selten einwandfrei feststellbar und in den Intercostalmuskeln überhaupt nicht nachweisbar sind. Man ist daher für die Segmentdiagnose hier in der Hauptsache auf den Sensibilitätsbefund angewiesen und wird eine präzise Höhenlokalisation nur dann vornehmen können, wenn scharf umrissene segmentale Sensibilitätsstörungen vorhanden sind wie etwa bei nachstehendem Falle (Beob. 13). Derselbe bot eine 
spastische Parese und eine distal zunehmende Stötung der Tiefensensibilität in beiden Beinen. Am Rumpfe fand sich eine, von den Schenkelbeuge bis zur Mitte zwischen Nabel- und Xiphoidlinie reichende, rechtsseitig stärker betonte, hyperästhetische Gürtelzone, die zusammen mit heftigen, konstant in die Unterbauchgegend lokalisierten Radikalgien und einem Ausfall sämtlicher Bauchdeckenreflexe einwandfrei auf eine Läsion im Bereich der Brustsegmente VII-XII, entsprechend den Brustwirbeln VI - X hindeutete. Die danach angelegte Laminektomie ergab in Höhe des VII. Brustwirbels einen Knochensporn, der von rechts her die Dura dellenförmig eindrückte und außerdem eine über den freigelegten Markabschnitt sich erstreckende seröse Arachnitis, die zu Verklebungen der VII. und VIII., in geringem Maße auch noch der IX. und $\mathbf{X}$. Dorsalwurzel beiderseits mit der Innenfläche der Dura geführt hatte.

Die Differenzierung zwischen der durch Segmentläsion und der durch spinale Leitungsunterbrechung bedingten Sensibilitätsstörung ist indessen keineswegs immer so streng durchführbar wie in dem vorerwähnten Falle. Nicht selten gehen beide Arten von Empfindungslähmungen fließend ineinander über, so da $B$ man außerstande ist, die untere Grenze der Läsion festzulegen und sich darauf beschränken muß ihren oberen Pol zu bestimmen.

Am schwierigsten liegen die Verhältnisse in höhenlokalisatorischer Beziehung bei den Affektionen des lumbosakralen Wurzelbereichs, weil hier die Differentialdiagnose zwischen Mark- und Caudaläsion hereinspielt. Nehmen wir wieder ein konkretes Beispiel, etwa den schon oben beschriebenen Fall 9, bei dem ein Bauchdurchschuß vorlag mit Einschußöfnung handbreit nach links vom II. Lendenwirbel und Ausschußöffnung auf derselben Seite in der vorderen Axillarlinie im Niveau der VIII. und IX. Rippe. Unmittelbar nach der Verletzung hatte sich eine totale Lähmung und Vertaubung des linken Beines und Stunlverhaltung eingestellt. 7 Monate nach der Verletzung bestand noch eine perfekte Lähmung des Quatriceps mit EaR. und Aufhebung des Patellarreflexes. Das deutete auf eine schwere Schädigung des motorischen Anteils der 2.-4. Lumbalwurzel hin. Aber auch sensibel war der entsprechende Wurzelbereich stark in Mitleidenschaft gezogen. $\mathrm{L}_{2}$ und $\mathrm{L}_{3}$ waren vollständig anästhetisch, $\mathrm{L}_{1}$ und $\mathrm{L}_{5}$ hypästhetisch und überdies $\mathrm{L}_{3}$ und $\mathrm{L}_{4}$ der Sitz sehr intensiver Radikalgien. Das Innervationsgebiet der sakralen Wurzeln dagegen war sowohl motorisch wie sensibel nur ganz leicht affiziert, die in ihm gelegenen Reflexbögen frei leitungsfähig. Dieser Befund sprach eindeutig für eine Läsion im Bereich der linksseitigen Lumbalwurzeln, und zwar schien die Annahme gerechtfertigt, daß hauptsächlich die Wurzeln 2, 3 und 4 geschädigt waren. 
Fraglich war es nur, ob mit einem Herd im Niveau des Abganges der Wurzeln vom Mark oder mit einem solchen in der Höhe ihres Verlaufes in der Cauda gerechnet werden mußte. Im ersteren Falle wäre ein Prozeß in der Gegend der oberen Lendenanschwellung, also entsprechend dem X. und XI. Brustwirbel, anzunehmen gewesen, im letzteren Fall ein Prozeß im Niveau des II., III. und IV. Lendenwirbels. Das machte eine Differenz von 4 Wirbelbögen aus, die natürlich für die Laminektomie stark ins Gewicht fiel. Der Röntgenbefund gab uns keinerlei Anhaltspunkte; er war negativ. Auch die Richtung des Schußkanales konnte uns nicht weiter helfen. Wir waren also lediglich auf den klinischen Befund angewiesen. Nun hat uns schon die Friedenspraxis hinreichend gelehrt, daß die klinische höhendiagnostische Differenzierung zwischen Erkrankungen der Cauda und solchen des unteren Rückenmarkabschnittes eine sehr unsichere Sache ist, und Marburg erklärt für das Kriegsmaterial, da $\beta$ alle Angaben bezüglich differentieller Anhaltspunkte in dieser Hinsicht sich als illusorisch erwiesen haben. Ich möchte diese Auffassung nicht ohne Einschränkung gelten lassen; wir verfügen über eine ganze Anzahl von Beobachtungen, bei denen es möglich war, wenigstens die Wahrscheinlichkeitsdiagnose auf eine Caudaläsion zu stellen und deren Richtigkeit durch den bioptischen Befund nachzuprüfen.

Wir glauben nach unseren Erfahrungen sagen zu können, daß man so gut wie sicher mit einer reinen Caudaaffektion rechnen darf, wenn die motorischen und sensiblen Lähmungserscheinungen sich von vornherein auf eine Seite beschränken, wenn ferner Decubitalgeschwüre ausbleiben und Störungen seitens der Blasen-, Mastdarm- und Genitalfunktion ganz fehlen oder wenigstens nicht sehr ausgeprägt sind. Unsicher dagegen bleibt die Differentialdiagnose zwischen Mark- und Caudaläsionen dann, wenn längere Zeit hindurch oder gar dauernd das beiderseitige lumbosakrale Wurzelgebiet an der motorischsensiblen Lähmung beteiligt ist, ausgesprochene Neigung zu Decubitus besteht und schwere Funktionsstörungen seitens des uropoetischen Systemes vorhanden sind. Da in dem vorliegenden Falle Lähmungen und Taubheit von Anfang an streng auf das eine Bein lokalisiert blieben, nie Decubitus sich gẹzeigt hatte und auch nur in den ersten Wochen nach der Verletzung eine gewisse Erschwerung der Defäkation bestand, so nahmen wir einen Prozeß im Austrittsgebiet der lädierten Wurzeln, d. h. in der Höhe ihres Verlaufes in der Cauda an und richteten danach die Laminektomie ein. Sie ergab eine pachymeningitische Schwielenbildung in Höhe des II. Lendenwirbels und derbe arachnoiditische Verwachsungen der II. und III. linken Lumbalwurzel.

Anders liegen die Verhältnisse bei dem nachstehenden Fall (Beob. 14), den ich als Gegenbeispiel anführen möchte. Er betrifft einen Steck- 
schuß der Wirbelsäule. Das Röntgenbild ergab einen linsengroßen Granatsplitter an der Grenze zwischen dem I. und II. Lendenwirbel, ließ also sehr wohl an eine hochsitzende Caudaschädigung denken, zumal der motorische Befund, $1 \mathrm{Jahr}$ nach der Verletzung, eine streng halbseitige, schlaffe Beinlähmung ergab und nur ganz geringfügige Stuhlbeschwerden. Der Annahme einer reinen Caudaschädigung widersprach aber der sensible Befund, der eine Anästhesie des gelähmten und eine ausgedehnte Hypästhesie des contralateralen Beines ergab, und es widersprach ihr insbesondere auch die Anamnese, derzufolge monatelang nach der Verletzung eine schwere Paraplegie der Beine bestanden hatte mit hochgradiger, nur langsam sich zurückbildender Blasen-Mastdarmlähmung und ausgedehntem Decubitus. Das alles machte eine isolierte Caudaschädigung sehr wenig wahrscheinlich und legte mehr den Verdacht nahe, daß mit den oberen Caudawurzeln gleichzeitig auch der unterste Markabschnitt geschädigt war. Wir dehnten demzufolge die Laminektomie vom II. Lenden- bis zum $\mathrm{X}$. Brustwirbel aus, um mit dem oberen Caudaabschnitt zugleich auch die Lendenanschwellung zu Gesicht zu bekommen. Das bioptische Bild entsprach den Erwartungen des klinischen Untersuchungsergebnisses. Es ergab eine schwere epidurale Schwartenbildung, dje vom XI. Brust- bis zum I. Lendenwirbel reichte. Der freigelegte Markabschnitt war in seiner ganzen Ausdehnung bis hinauf zum I. Lendensegment mit der Dura verwachsen, und der Splitter fand sich eingebettet in ein Gewirr derber Verwachsungen der linksseitigen oberen Lumbalwurzeln unter sich und mit der Dura. Seine Entfernung gelang ohne Sch wierigkeiten.

Im Vergleich zur Bewertung des neurogenen Symptomenbildes haben sich uns äußere klinische Merkmale, wie Richtung der Geschoßbahn, Röntgenbefund oder umschriebener Druckschmerz als höchst unzuverlässige höhendiagnostische Kennzeichen erwiesen, und zwar vor allem wegen des oft recht krassen topischen Mißverhältnisses zwischen Wirbelverletzung und Rückenmarkschädigung. Während Cassirer, Henneberg, Schuster, Bruns, Ascher und Licen über kommotionelle Schädigungen der Marksubstanz berichten, die in ihrer Ausdehnung sehr-weitgehend. mit dem Wirbelsäulenabschnitt differierten, der von dem Geschoß getroffen oder sonst irgendwie in stärkerem $\mathrm{Maße}$ erschüttert worden war, sind es in unseren und ähnlich liegenden Fällen von Marburg und Ranzi außerdem besonders häufig meningitische Prozesse gewesen, Schwartenbildung auf der Dura oder Verklebungen und Abschnürungen der Arachnoidea, die oft mehrere Zentimeter nach oben und unten über den lokalen Schußverlauf oder die örtliche Einwirkung einer stumpfen Gewalt hinausreichten. Im allgemeinen haben wir es uns jedenfalls zur Regel gemacht, für die örtlịche 
Bestimmung des operativen Eingriffes immer in erster Linie den neurologischen Status heranzuziehen. Dieser Standpunkt wird auch von neurochirurgisch so erfahrenen Autoren wie F. Kra use und Marburg und Ranzi geteilt. Krause fordert, daß ,,bei jeder Rückenmarkverletzung zunächst auf Grund der Nervenuntersuchung die Höhendiagnose gestellt wird, um so mehr, als sie eine außerordentliche Sicherheit bietet; dann erst sollen Wundrevision und Röntgenaufnahme erfolgen; zudem liefert letzterer ein um so zuverlässigeres Ergebnis, einen je kleineren Bezirk der Wirbelsäule wir für die photographische Aufnahme abblenden".

Wie sehr Geschoßbahn und Markprozeß differieren können, illustrieren am besten die Beobachtungen 5 und 12, beides Brustdurchschüsse in horizontaler ventrodorsaler Richtung. Im ersteren Falle lag die Geschoßbahn in Höhe der VII. Rippe, reichlich handbreit neben der Mittellinie. Röntgenologisch waren die Rippen intakt. Klinisch sprach alles für eine Wurzelaffektion im Bereich von $\mathrm{C}_{7}$ bis $\mathrm{D}_{3}$, also in Höhe der drei untersten Hals- und der beiden obersten Brustwirbel. Dementsprechend wurde laminektomiert. Es fanden sich starke arachnoidale Verwachsungen, in die besonders die VII. Cervicalwurzel einbezogen war. Bei Beob. 12 verlief der Schußkanal in Höhe der V. Rippe, und der Röntgenbefund ergab eine Schußfraktur derselben dicht an ihrem Wirbelansatz. Außerdem erwies sich der Dornfortsatz des V. Brustwirbels als besonders druckempfindlich. Der klinische Befund sprach für eine Läsion, die in der Hauptsache die VII. und VIII. Cervical- und I. Thorakalwurzel betraf, also im Niveau des VI. und VII. Hals- und I. Brustwirbels zu suchen war, d. h. um 3-4 Wirbel höher als Geschoßbahn und Röntgenbefund vermuten ließen. Daß das klinische Zustandsbild uns den richtigen Weg gewiesen hatte, bestätigte die Operation.

3. Bei der Häufigkeit, mit der uns diagnostische Irrtümer bei der Beurteilung von Rückenmarkverletzungen begegnet sind, dürfte es hier am Platze sein, einiges zu diesem praktisch sehr wichtigen Punkte zu sagen. Besonders leicht verkannt werden die minder schweren Affektionen mit vorwiegend radikulärem Symptomenkomplex und nur geringfügigen Markerscheinungen. Es hat nichts Uberraschendes an sich, daß in solchen Fällen die Störungen der Sensibilität entweder ganz übersehen oder in ihrer Genese verkannt werden; liegen doch, wie wir bereits gesehen haben, keineswegs immer evidente Empfindungslähmungen vor, sondern sehr oft nur relative Störungen für die verschiedenen Empfindungsqualitäten, Hyp- oder Hyperästhesien der verschiedensten Grade, deren Nachweis, um das nochmals zu betonen, viel Zeit und Geduld und zur Verhütung von Selbsttäuschung auch ein gewisses Maß von Utbung erfordert. Aber auch die Art des motorischen 
Ausfalles pflegt den Beobachter leicht irrezuführen. Vielfach handelt es sich um Monoparesen oder selbst nur um Ausfälle einzelner Muskelgruppen, was naturgemäß zu Verwechslungen mit peripheren Nervenschädigungen führen oder aber auch an psychogene Lähmungsformen denken lassen kann, zumal wenn elektrische Veränderungen und sinnfällige Reflex* und Sensibilitätsstörungen fehlen. Nicht selten wird der Verdacht der Psychogenie auch dadurch noch gestützt, daß die Kraftentfaltung im Liegen mitunter eine ganz gute ist, während beispielsweise die Beine sofort versagen, sobald der Kranke gehen oder stehen soll. Und noch auffallender sind gewisse zeitliche Intensitätsschwankungen dèr Motilitätsstörung insofern, als die paretischen Erscheinungen tageweise oft so weit zurückgehen, daß die Kranken sich notdürftig auf den Beinen halten, während sie zu anderen Zeiten wieder dazu völlig außerstande sind. Vjelfach geht damit konform auch eine gewisse Labilität der Haut- und Sehnenreflexe, die in ihrer Auslösbarkeit in ähnlicher Weise auf und ab schwanken können. Da wir dieses paradoxe Verhalten wiederholt bei Fällen fanden, die sich bioptisch als Meningitis serosa circumscripta mit hochgradiger Liquoransammlung erwiesen, liegt der Gedanke nahe, daß derartige Liquorstauungen $\mathrm{zu}$ verschiedenen Zeiten einen verschieden starken Druck auf das Mark ausüben und damit die Ursache für die Unbeständigkeit des klinischen Zustandsbildes abgeben.

Wie kompliziert das Krankheitsbild bei manchen Markläsionen, zumal bei solchen mit vorwiegend meningealen Veränderungen, sich gestalten kann, mag die folgende, einer neurologischen Beobachtungsstation entstammende Krankengeschichte zeigen, die ich ihres besonderen Interesses wegen in extenso wiedergebe.

(Beob. 15.) Musketier B. 29.' XII. 1915: Akut erkrankt und in verworrenem Zustand der Nervenstation eines Kriegslazarettes überwiesen. Aus dem Krankenblatt: Wälzt sich halb benommen dauernd im Bett herum. Nackensteifigkeit und etwas eingezogener Leib. Rechter Mundfacialis schwächer als linker. Klagt über heftigen Kopfschmerz. Temperatur $38,6^{\circ}$. - 30. XII. Liquor klar, keine Meningokokken. 2. I. 1916: Psychisch klarer, Brechreiz geringer, Nackensteifigkeit kaum mehr vorhanden. Starker Dehnungsschmerz des linken Hüftnerven. 5. I. 1917: Seit gestern wieder mehr Kopfschmerzen. Zeitweilig auch wieder benommen und desorientiert. 8. I.: Bedeutende Besserung. Kein Kopfschmerz mehr. Nacken vollständig frei beweglich. Dehnungsschmerz im Hüftnerven geringer. 11. 1.: Seit 4 Tagen fieberfrei. Keine Augenmuskellähmung mehr. Facialislähmung fast ganz verschwunden. 29. I.: Immer wieder leichte Temperatursteigerungen und dann auch wieder jeweils stärkeren Kopfschmerz. Hoch am Arm Atrophie des Deltoides durch frühere Verwundung. 28. II.: Seit 31. I. keine Temperatursteigerungen mehr. Mehrere Stunden außer Bett. Immer noch Dehnungsschmerz in beiden Beinen, rechts mehr als links. 3. III.: Reagiert jedesmal nach Heißluftbehandlung mit einer Temperatursteigerung (Unfähigkeit zur Temperaturregulierung ?). 9. III.: Die unregelmäßigen Temperatursteigerungen hängen doch 
nicht nur mit dem Heizen zusammen. Rechtes Bein knickt beim Gehen ein. Rechter Mundfacialis bleibt noch immer leicht zurück. Kraft im ganzen rechten Bein herabgesetzt. Patellar- und Achillessehnenreflex rechts etwas stärker. Andeutung von Fußklonus. Sensibilitätsstörung im Bein anscheinend nicht peripher, sondern spinal. Ebenso entspricht die Schwäche im rechten Bein einer Pyramidenbahnläsion; für Neuritis spricht nur der Dehnungsschmerz. 19. III.: Tageweise auffallend verstimmt, ohne äußeren Anlaß; vor seiner Krankheit nie derartiges. 4. XI. Bauchdeckenreflexe rechts schwächer. Bei forciertem Aufsetzen des rechten Beines Zittern und Einknicken desselben. Starkes Mißverhältnis zu der im Liegen entwickelten Kraft (funktionell). Auch bei Prüfung einzelner Muskelgruppen im Liegen häufig völliges Fehlen des Willensimpulses. 15. IV.: Bei der allmählichen Rückbildung der Sensibilitätsstörung tritt doch mehr ein peripherer Typus mit besonderer Störung des Cut. lat. und des Peroneus hervor. Diagnose (Prof. K.): Vermutlich anfangs Meningitis mit Wurzelschädigung und periphere Neuritis. Rückbildung in der Form, daß die Meningitis und Wurzelschädigung zurückgeht und zuletzt nur die periphere Neuritis nachweislich bleibt. Keine Symptome für Halbseitenlähmung des Rückenmarkes. Ausgesprochene funktionelle und psychisch beeinträchtigte Willenskraft beim Gehen.

29. IV. 1917: Verlegung auf Neurochirurgische Korpsstation XII Arnsdorf. Zur Anamnese: 30. VIII. 1914 erstmals verwundet. Gewehrkugeldurchschuß durch den rechten Oberarm. Sofort bewußtlos. Lähmung des rechten Armes und Schwäche im rechten Bein. Erschwerung der Kopfbewegungen. Sprachund Schluckbeschwerden. Heftige Schmerzen im ganzen rechten Arm. Stuhlverhaltung. 3-4 Wochen nach der Verletzung zunächst Besserung der Sprach- und Schluckbeschwerden. 5-6 Monate später auch langsame Rückbildung der Arm- und Beinlähmung bis auf leichte Schwäche im rechten Arm. Trotzdem Oktober 1915 freiwillig wieder ins Feld. Daselbst im Dezember 1915 in der oben beschriebenen Weise erkrankt. Status: An der Vorder- und Rückseite des Deltamuskels knapp unterhalb des Akromions zwei Schußnarben. Deltoides hochgradig atrophisch. Schlaffe Parese des ganzen rechten Armes unter besonders starker Beteiligung des Triceps und der Beuger der Hand. Rechter Facialis schwächer innerviert als der linke. Spastische Parese des rechten Beines, so daß èr nur mit Krücke kurze Strecken (höchstens 10-15 Minuten) gehen kann. Abschwächung der Sehnenreflexe an Oberextremität rechts. Erhöhung der Bauchdecken- und Cremasterreflexe rechts, und der Sehnenreflexe an der rechten Unterextremität. Rechte Pupille enger als die linke. Anästhesie für alle Qualitäten im Bereich $\mathrm{C}_{4}, \mathrm{C}_{6}$ und $\mathrm{C}_{7}$. Hypästhesie für alle Qualitäten in der ganzen rechten Körperhälfte, distalwärts von der Halsrumpfgrenze, lateralwärts stärker als medialwärts. Bathyhypästhesie in der rechten Körperseite bis hinauf zur Clavicularlinie. Zittern bis zum Schütteltremor im rechten Bein. Röntgenbefund negativ. Diagnose: Traumatische Rückenmarkaffektion (vermutlich Meningitis serosa circumscripta) vorwiegend rechtsseitig im Bereich des mittleren und unteren Hals- und obersten Brustmarkes. Hauptsächlich in Mitleidenschaft gezogen sind die Segmente $\mathrm{C}_{4}-\mathrm{C}_{7}$, entsprechend dem 3., 4., 5. und 6. Halswirbel. Da mit der Wiederkehr bulbärer Erscheinungen (Liquorabsperrung) gerechnet werden mußte, wurde Laminektomie dem Kranken vorgeschlagen, aber seinerseits abgelehnt. Vier Wochen später wieder plötzlich soporös; lallende Sprache, automatische Kauund Schluckbewegungen, kleiner, abwechselnd verlangsamter und beschleunigter Puls. Keuchende unregelmäßige Atmung, tickartige Zuckungen im rechten Facialis, Déviation conjuguée nach links. Dauer des Zustandes mit kurzen Unterbrechungen und vorübergehender Aufhellung des Bewußtseins etwa 1 Stunde, dann wieder freier. Einwilligung zur Laminektomie. Ausgeführt am 31. V. 17 (Dr. Krü - 
ger): Wegnahme der Wirbelbogen $\mathrm{C}_{3}-\mathrm{C}_{6}$. Starke Gefäßblutung, die nach kurzer Abklemmung ohne Unterbindung steht. Dura zeigt schwache, aber deutlich sichtbare mit dem Puls synchrone Pulsation, ist stark nach hinten vorgewölbt und verbreitert und von $\mathrm{C}_{5}$ nach aufwärts bis unter den Bogen von $\mathrm{C}_{3}$ auf der rechten Hälfte von einer teils zarten, teils auch derberen rosa gefärbten Membran bedeckt, die sich seitlich zwischen Dura und Knochen auf die Vorderseite des Durasackes erstreckt und einen schmalen Strang auch nach links ungefähr an die Grenze zwischen $\mathrm{C}_{5}$ und $\mathrm{C}_{6}$ schickt. Die zarten Auflagerungen lassen sich leicht insgesamt abziehen, während die stärkeren mit der Schere abgetragen werden müssen. Nach Eröffnung der Dura spritzt Liquor springbrunnengleich bis zu einer Höhe von $40 \mathrm{~cm}$ hervor. Es fließen abnorm große Mengen von Liquor ab. Das ganze Mark ist von einer zarten, häutigen Membran umhüllt, die an der Dura festhängt, so daß beim Zuge der Dura nach rechts das Mark mit nach rechts verzogen wird. Es besteht starke Gefäßinjektion. Die häutigen Verwachsungen werden mit der Pinzette gefaßt und soweit möglich entfernt. Danach fällt das Mark in sein Nest zurück und die bereits nach Abfluß deutlichere Pulsation wird völlig normal. Sondierung nach oben frei, wäbrend nach unten unter deutlich vernehmbaren, knackenden Geräuschen Verwachsungen gesprengt werden.

Für das labile Verhalten der Motilitäts- und Reflexstörungen bei chronischer adhäsiver Meningitis ist der nachstehende Fall besonders charakteristisch :

(Beob. 16.) Unteroffizier R. wurde am 21. IV. 1916 durch einschlagende Granate verschüttet, wobei er große Erdschollen und Steine ins Kreuz bekam. Gleich von Anfang an Schwächegefühl in beiden Beinen und Schmerzen vom Kreuz gürtelförmig ausstrahlend in die Unterbauchgegend und in die Schenkelbeugen, besonders stark in der Nacht und beim Husten oder Niesen. Tat in diesem Zustand noch ungefähr 3-4 Wochen Dienst, dann mußte er sich krank melden, „weil ihn die Beine nicht mehr tragen wollten" und die Schmerzen immer heftiger wurden. Er konnte die Bauchpresse nicht mehr anwenden und bekam auch Harnbeschwerden. Bef und am 23. V. 1916: Gehen oder Stehen unmöglich. Auch Umwenden oder Aufrichten nicht ohne Unterstuitzung. Alle Bewegungen in Knieund Hüftgelenk beiderseits kraftlos und nur gegen geringsten Widerstand. Am meisten gestört ist Beugung in der Hüfte und Streckung im Knie. Fuß- und Zehenbewegungen nahezu normal. Bauchpresse sehr schwach, rechts $=$ links. Patellarreflexe nicht auslösbar. Fersenphänome erhöht, rechts $>$ links. Mäßige Hypertonie in der Unterschenkelmuskulatur. Beiderseitig ausgesprochener Babinski, Oppenheim, Rossolimo. Cremasterreflexe rechts kaum, links nur schwach zu erzielen. Bauchdeckenreflexe (obere und untere) fehlen vollständig. Anästhesie für alle Qualitäten der Oberflächenempfindung von $\mathrm{D}_{10}-\mathrm{D}_{12}$, Hypästhesie von $\mathrm{D}_{3}-\mathrm{D}_{9}$ und $\mathrm{L}_{1}-\mathrm{L}_{4}$. Lage- und Knochengefühl in beiden Unterextremitäten herabgesetzt. 25. V. 1916: Bauchpresse heute kraftvoller. Kann auch mit Unterstützung einige Schritte gehen. Patellarreflex links schwach, rechts kaum auslösbar; dasselbe gilt für die Cremasterreflexe. Sensibilität wie bei der ersten Prüfung, nur daß Nadel heute in der Hyp- und Anästhesiezone (von der Xiphoidlinie bis zur Rumpfbeingrenze) unangenehm empfunden wird. GesäB, Rückseite der Beine und Fußrücken intakt. Blasenbeschwerden scheinen sich zu bessern. 28. V.: Röntgenologische Untersuchung negativ. 30. V.: Stetig wechselnder Befund. Motilität der Beine wieder schlechter, ebenso Bauchpresse. Ist selbst mit doppelseitiger Unterstützung nicht in der Lage, sich auf den Beinen zu halten. Patellarreflexe beiderseits schwach, aber deutlich zu erzielen. Cremasterreflex links normal, rechts $\theta$. Von den Bauchdeckenreflexen sind die oberen andeutungs. 
weise vorhanden. Rechts Fußklonus. Die übrigen spastischen Phänomene wie zuvor. Von den sensiblen Störungen bleibt konstant nur die Hypästhesie an der Vorderseite der Beine und die taktile Empfindungslähmung am Rumpf, während die Störung des Schmerz- und Temperatursinnes in der Rumpfzone ständig wechselt. So ist heute die Hyperalgesie wieder in Hyp- bzw. Analgesie umgeschlagen und dafür das Temperaturgefühl wieder aufgehellter; dabei machen die Angaben des intelligenten Kranken einen durchaus bestimmten und zuverlässigen Eindruck. Hartnäckige Verstopfung. Auch wieder zunehmende Erschwerung des Wasserlassens. Im Urin Spuren von Eiter. Gibt auf Befragen zu, daß unmittelbar nach der Verletzung Spontanzuckungen in beiden Beinen (Adductionsbewegungen) bestanden hatten, rechts $>$ links, die mit Zunahme der Läbmung in der letzten Zeit wieder allmählich nachgelassen haben, ohne indessen ganz zu verschwinden.

Aus dem Bericht für den Chirurgen: Das ganze Bild spricht ziemlich eindeutig für eine Läsion des Rückenmarkes im Niveau des X., XI. und XII. Dorsalsegmentes. Teilweise, $d . h$. in schwächerem Grade ist anscheinend auch noch das Wurzelgebiet $\mathrm{L}_{1}-\mathrm{L}_{4}$, sowie der proximalwärts anschließende Segmentbereich bis hinauf zu $\mathrm{D}_{4}$ mit affiziert. Am meisten Wahrscheinlichkeit für sich hat ein adhäsiv meningitischer Proze $ß$ (nach Meningealhämorrhagie oder Wirbelfraktur), der seinen Hauptsitz in der Höhe der untersten 3 Dorsalsegmente hat und die nach oben und unten angrenzenden Segmente oder Wurzeln durch leichtere Verwachsungen, oder wahrscheinlicher noch durch Liquordruck in Mitleidenschaft zieht. Die Stabilität des Zustandes seit Wochen und die beginnende. Cystitis dürften Laminektomie rechtfertigen. Es empfiehlt sich zur möglichst ausgedehnten Freilegung des supponierten Prozesses Resektion der Wirbelbogen 9-12. 31. V. 16. Operation (Dr. K r üger): Wegnahme der Bogen $\mathrm{D}_{9}-\mathrm{D}_{12}$. Knochen von $\mathrm{D}_{12}$ auffallend brüchig. Dura pulslos, von $\mathrm{D}_{9}-\mathrm{D}_{11}$ ist sie von einem zarten, dünnen, rosa gefärbten, faserigen Überzug umhüllt, der sich stumpf abziehen läßt. Von $D_{10}$ bis zur Mitte von $D_{12}$ schimmert sie gelblichblau, im übrigen normal. Nach Eröffnung fließt Liquor unter mäßigem Druck ab, bei jedem Atemzuge wölben sich die Reste der Arachnoidea in den Duraschnitt vor. Nach rechts bestehen spinnwebenartige Verwachsungen zwischen Mark und Dura, die so fest sind, daß beim Zug an der rechten Hälfte der Dura das Mark in seiner ganzen Ausdehnung mit nach rechts verzogen wird. Auf dem Mark erweiterte, geschlängelte, prall gefüllte Gefäße. Von oben her wird eine gelatinös aussehende Membran cystenartig in den eröffneten Duraraum bei den einzelnen Atemzügen vorgetrieben, die die Liquorabsperrung bedingt. Nach Lösung aller Verwachsungen und Eröffnung der cystenartigen Membran unter Wegnahme ihrer Wände fällt das Mark in sein Nest zurück und Liquorabfluß tritt von oben her ein. Die Schlängelung der Gefäße verliert sich, das Mark selbst sieht normal aus. Glatter Wundverlauf. 7 Monate nach der Operation im wesentlichen beschwerdefrei als g. v. Heimat entlassen.

Die relative Geringfügigkejt des objektiven Befundes bei radikulären Markläsionen hat sehr oft auch zur Folge, daß die subjektiven Beschwerden, insbesondere etwaige Wurzelschmerzen, eine falsche Deutung finden, $d . h$. entweder als psychogen ignoriert oder auf ein anderes Leiden bezogen werden. Es sind derartige Febldiagnosen um so bedauerlicher, als die Radikalgien infolge ihrer Intensität und ihrer Steigerung bei den geringfügigsten Anstrengungen die Kranken in ihrem Allgemeinbefinden und.ihrer Leistungsfähigkeit einerseits aufs 
schwerste schädigen, andererseits gerade dasjenige spinale Symptom sind, das durch einen Eingriff am leichtesten und restlosesten zu beheben ist. Dafür als Beispiele die 3 folgenden Fälle:

(Beob. 17.) Soldat W. verunglückt am 5. II. 1915 beim Tragen schwerer Baumstämme, stürzte und kam unter einen Stamm, der ihn im Rücken traf, zu liegen. Seitdem dauernd Schmerzen von wechselnder Intensität. 19. VI. 15 deswegen zum Ersatztruppenteil. 15. XI. wieder ins Feld. Kreuzschmerz war geblieben, strahlte jetzt in beide Beine bis zu den Füßen aus und wurde nach und nach so stark, daß er sich im Februar 1916 abermals krank melden mußte. 26. II. 1916 Feldlazarett B.: Patellar- und Achillessehnenphänomene beiderseits nicht auslösbar. Bücken und Aufrichten des Oberkörpers, ebenso Beugen der gestreckten Beine und der Knie nicht möglich. Ischiadicusdruckpunkte beiderseits sehr schmerzhaft, desgleichen die ganze Rückenmuskulatur. Temperatursteigerungen bis zu 38,3 . 10. IV.: Medikamente ohne Einfluß auf die Beschwerden, die auch nachts bestehen. 1. V.: Steht auf, geht mit Hilfe eines Stockes. 10. V.: Weitere Besserung; geht ohne Stock, bekommt aber nach längerem Gehen angeblich immer wieder heftige Schmerzen. Nn. ischiadici nur noch mäßig druckempfindlich. Ein Teil der Beschwerden ist sicher psychisch bedingt. 5. VI. Rückfall: Bekommt wegen großer Schmerzen nachts Morphium. Abendtemperatur zwischen $38,5^{\circ}$ und $39,0^{\circ}$. Selbstaufrichten nicht möglich. Streng lokalisierte Druckempfindlichkeit der Dornfortsätze des 2. und 3. Lendenwirbels und geringer ausgeprägt an den Dornfortsätzen vom 7. Brustwirbel abwärts. 6. VIII. Schmerzhaftigkeit der erkrankten Rückenwirbel und der Unterschenkelmuskulatur besteht fort. Abendtemperatur bis zu 39,0 $0^{\circ}$ 2. IX.: Untersuchung durch Prof. W.: „Rheumatische Erkrankung der unteren Brust- und der Lendenwirbel in Verbindung mit Hysterie." 16. IX.: Untersuchung durch beratenden Orthopäden: „Tuberkulöse Spondylitis der Lendenwirbelsäule mit Nervenstörungen der Beine“. Extensionsliegekur. 9. XII.: Verlegung auf orthopädische Station D. zur An. fertigung von Stützkorsett.' Diagnose: "Insufficientia vertebrae traumatica“. 10. VII. 1917: Urteil der Beobachtungsstation D.: „Da nach dem objektiv fast negativen Befund seitens der Wirbelsäule eine psychogene Funktionsstörung als Ursache des Zustandes für das Wahrscheinlichste gehalten wird, so wird der Versuch einer psychischen Beeinflussung auf der neurologischen Station in A, zur Wiederentwöhnung vom Gipskorsett vorgeschlagen mit dem Hinzufügen, daß die Beschaffung eines Stützkorsettes empfohlen wird, sobald die neurologisehe Behandlung in A. für aussichtslos gehalten wird."

28. VII. Neuro-chirurgische Korpsstation XII, Arnsdorf: Klagt über stän. dige Kreuzschmerzen, der teils nach unten in die Beine, teils nach oben bis zu den Schulterblättern ausstrahlt. Geht an zwei Stöcken mit durchgedrücktem Kreuz stark vornübergeneigt, breitspurig, steifbeinig unter Schütteln des ganzen Körpers und unter Nachziehen des linken Beines, dessen Fußspitze am Boden klebt. Ängstlich gespannter Gesichtsausdruck. Grobe Kraft in beiden Beinen, besonders im linken, in toto erheblich herabgesetzt. Patellarreflexe beiderseits, besonders links sehr schwach. Fersenphänomene, Cremaster- und Bauchdeckenreflexe o. B. Keine spastischen Phänomene. Normales elektrisches Verhalten. Sensibilität: Streng angeordnete radikuläre Hyp- bis Anästhesie für alle Empfindungsqualitäten im Versorgungsbereich der Lumbalwurzeln, Hypästhesie mittleren bis leichteren Grades, ebenfalls für alle Qualitäten, in der sakralen Innervationssphäre. Ausgeprägte Druckempfindlichkeit der unteren Brust- und oberen Lendenwirbel, besonders des II. und III. und des linken Ischiadicus. Sonst keine Veränderungen an der Wirbelsäule nachweisbar, auch röntgenologisch nicht. 
Vorläufige Diagnose: Prozeß im lumbo-sakralen Wurzelgebiet mit. psychogen überlagerter Bewegungsstörung in den Beinen. Adhäsive Meningitis ? Genauere Höhenlokalisation und operative Indikation von weiterer Beobachtung abhängig. 29. VIII.: Klagt seit einigen Tagen wieder über „rasende“ Schmerzen in der Kreuzgegend. Kann nicht aufstehen. Kein Fieber. Objektiver Befund wie früher; nur das Verhalten der Patellarreflexe scheint insofern zu schwanken, als sie zeitweise völlig fehlen, dann wieder spurweise vorhanden sind. 17. IX. WaR. (Blut) negativ. Patellarreflexe heute nicht auslösbar, im übrigen Befund unverändert. Endgültige Diagnose: Annahme einer doppelseitigen Erkrankung im Bereich der Lumbo-Sakral-Segmente bleibt bestehen. Der Mangel eines objektiven Wirbelsäulenbefundes spricht zugunsten eines serös-meningitischen Prozesses. Über den Höhensitz ist eine sichere Entscheidung nicht zu treffen. Die Doppelseitigkeit des sensiblen Ausfalls, an dem die Wurzeln $\mathrm{L}_{1}-\mathrm{L}_{6}$ am stärksten beteiligt sind, spricht für eine Erkrankung derselben in ihrem medullären Abschnitt, also in der Gegend des X., XI. und XII. Brustwirbels. Dagegen würde das Fehlen jeglicher Marksymptome und die besonders große Druckempfindlichkeit des II. und III. Lendenwirbels mehr auf eine Affektion im Austrittsgebiet der Wurzeln (I.-IV. Lendenwirbel) hindeuten. Es empfiehlt sich daher, da der trostlose, seit $2^{1 / 2}$ Jahren unveränderte Zustand des Kranken eine Probelaminektomie gerechtfertigt erscheinen läßt, dieselbe so anzulegen, daß man zunächst die Resektion der Wirbelbogen $\mathrm{Th}_{12}$ und $\mathrm{L}_{1}$ und $\mathrm{L}_{2}$ vornimmt und dann je nach dem Durabefund nach oben bis zum $X$. Brust- oder nach unten bis zum IV. Lendenwirbel geht. 20. IX. Operation (Dr. Krüger): Wegnahme der Bogen von $D_{12}-L_{2}$. Blutung gering. Knochen von $D_{12}$ nach aufwärts auffallend weich, dies der Grund der Wegnahme von $D_{11}$ und $D_{10}$, da die Dura auch der Wegnahme von $\mathrm{D}_{12}-\mathrm{L}_{2}$ keine Anhaltspunkte ergibt, nach welcher Richtung noch Knochen entfernt werden müßten. Dura pulslos, von zarten einzelnen Strängen bedeckt. Nachdem sie einige Zeit freigelegen, tritt mit dem Pulse synchrone, gerade sichtbare Pulsation ein. Am unteren Rande von $D_{22}$ drückt ein von rechts vorragender Knochensporn die Dura grübchenförmig ein. Dura wölbt sich von $D_{10}-I_{1}$ prall hahnenkammartig nach hinten vor. Nach Eröffnung fließt Liquor unter stark erhöhtem Druck ab. Die Lendenanschwellung ist von $D_{11}$ ab mit außerordentlich prall gefüllten, stark geschlängelten, blauschwarzen Gefäßen bedeckt, die in der Achse des Markes nach abwärts ziehen und sich am Ende des Conus in den Caudawurzeln verlieren. In gleicher Höhe beginnt ein stricknadeldickes, mäßig geschlängeltes, prall gefülltes, blauschwarzes Gefäß, das sofort nach links von der Mittellinie abweicht, sich der 12. Brustwurzel anlegt und mit ihr durch eine zarte Membran innig verklebt durch das Duraloch austritt. Zarte, spinnwebenfeine Verwachsungen lassen sich leicht lösen. Danach fallen die Gefäße zusammen, verlieren etwas ihre Schlängelung, behalten aber ihre Farbe. Fortlaufende Duranaht, Schichtnaht der Muskeln.

Auf Grund der Schmerzen hatte man also hier zunächst eine doppelseitige Ischiadicusschädigung diagnostiziert. Nachdem die übliche Behandlungsmethode versagt hatte, wurde von orthopädischer Seite eine Spondylitis tuberculosa angenommen und als auch Gipsbett- und Korsettbehandlung erfolglos geblieben waren, kam der Kranke wegen Hysterieverdachtes nach $1^{1 / 2}$ jähriger Irrfahrt in unsere Behandlung. Er konnte wenige Monate nach der Operation fast beschwerdefrei entlassen werden, hat dann längere Zeit als Landbriefträger Dienst getan und ist Jetzt als Schaffner angestellt, ohne in den seit der 
Operation verstrichenen 3 Jahren in irgendeiner Weise rückfällig geworden zu sein.

(Beob. 18.) Soldat Sch. 1. X. 1914 verwundet durch Gewehrkugelsteckschuß in der linken Schulter. 22. X. 1914 operative Entfernung des Geschosses. Gleich nach der Verletzung Schwäche und Schmerzen im rechten Arm, besonders in der Schultergegend. Die Schmerzen steigerten sich allmählich im Laufe von Wochen und lokalisierten sich hauptsächlich in der rechten Brusthälfte und in der rechten Schulter, von wo sie in die Kleinfingerseite des rechten Armes, in die rechte Nackenhälfte und nach unten bis in den rechten Oberschenkel ausstrahlten. Mit der Zunahme der Sehmerzen hatte sich nach und nach eine Schwäche in den Beinen, zumal im rechten, eingestellt, so daß er schließlich nur noch an zwei Stöcken gehen konnte. Im Laufe von 3-4 Monaten waren die Gehstörungen im wesentlichen wieder behoben, nur die Schmerzen bestanden unverändert fort. Er wurdo zunächst beim Grenzschutz, und als dort die Beinschwäche wieder zunahm, mit leichtem Arbeitsdienst beschäftigt. Die fortgesetzten Klagen über Schmerzen, denen kein augenfälliger Objektivbefund entsprach, hatten den Mann schließlich in den Verdacht der Simulation gebracht. Wir bekamen ihn infolgedessen am 16. II. 1918, 31/2 Jahre nach der Verwundung, zur Beobachtung iiberwiesen. Die Klagen waren unverändert wie früher. Die Schmerzen behinderten ihn angeblich an jeder Betätigung und ließen ihn nachts nur stundenweise schlafen. Objektiv fand sich Hyperästhesiezone für Nadel und Pinsel in der ulnaren Hälfte der rechten Hand und des rechten Armes, die auf die rechte Brusthälfte übergriff und hinten wie vorn, zwischen Halsrumpfgrenze und Xyphoidlinie, bis zur Mittellinie reichte. Auch die radiale Hälfte der Hand und des rechten Armes war hyperästhetisch, aber in erheblich geringerem Maße, desgleichen eine etwa handbreite Partie ober- und unterhalb der Halsrumpf- bzw. Xyphoidlinie. Die grobe Kraft war im ganzen rechten Arm mäßig herabgesetzt bei regelrechten Reflexverhältnissen und normalem elektrischen Verhalten. Linkes Bein und Unterextremität o. B. Röntgenbild: Zwischenraum zwischen dem VI. und VII. Halswirbel-Querfortsatz stark verschattet, aber keine sichere Fraktur. Diagnose: Rechtsseitige radikuläre spinale Läsion im Bereich von $\mathrm{C}_{7}-\mathrm{D}_{4}$, entsprechend den Wirbeln Cervicalis V bis Thoracalis II. Vermutlich Meningitis serosa chronica circumscripta. Da 4 monatige Behandlung mit physikalischen Hilfsmitteln den Zustand in keiner Weise beeinflußte, der Sensibilitätsbefund konstant blieb und sich genau mit der Lokalisation des Hauptschmerzes deckte, wurde Laminektomie beschlossen. Sie ergab nach Befund von Dr. Kr üger zwischen $\mathrm{C}_{5}$ und $\mathrm{Th}_{2}$ zarte rosa gefärbte Auflagerungen auf der Dura, die sich leicht entfernen ließen. In der Höhe von $\mathrm{C}_{7}$ wird die Dura eröffnet und es sprudelt mit Blut gemischter $\mathrm{Li}$ quor unter mäßigem Druck heraus. In der Mitte des Markes ist ein blauschwarz gefärbtes, stark gefülltes Gefäß sichtbar, aus dem das dem Liquor beigemischte Blut entstammt. Die rechte Hälfte des Markes ist in der Ausdehnung von $\mathrm{C}_{5}$ bis $\mathrm{Th}_{1}$ von dünnen, aber außerordentlich festen Verwachsungen umbüllt, die die Wurzeln unter sich und mit dem Marke verklebt haben. Bei dem Versuch, diese Verwachsungen zu lösen, kommt es immer wieder zu reichlichen Blutungen, so daß außerordentliche Vorsicht geboten und eine völlige Lösung und Entfernung dieser Verwachsungen nicht möglich ist. Auffallend ist noch die starke Wölbung des Markes nach hinten, wodurch es so nahe an die Dura angepreßt wird, daß ein Subarachnoidealraum so gut wie nicht vorhanden ist. Die Sondierung nach oben und unten kann deswegen nur mit äußerster Vorsicht und mit gewissen Schwierigkeiten ausgeführt werden, ergibt aber keine weiteren Verwachsungen zwischen Mark und Dura. 
Das Eigenartige dieser Beobachtung liegt darin, daß trotz der bioptisch erwiesenen, relativ schweren meningealen Veränderungen klinisch in der Hauptsache nur radikuläre Reizerscheinungen vorhanden waren, während motorisch der lädierte Wurzelabschnitt fast normal funktionierte und medulläre Leitungsstörungen, von der anfänglichen Beinschwäche abgesehen, vollständig fehlten. Es ist daher auch sehr wohl begreiflich, daß dieser Kranke, genau wie der vorige, von einem Lazarett zum anderen wanderte, ohne daß es gelang, die Ursache seiner Beschwerden zu entdecken. Der operative Erfolg war übrigens hier infolge der nicht vorauszu sehenden technischen Schwierigkeiten weniger erfreulich wie im ersteren Falle; immerhin konnte doch eine gewisse Besserung erzielt und dem Manne wenigstens zu der ihm zukommenden Rente verholfen werden.

(Beob. 19.) Ersatzreservist R. 13. X. 1915 durch Granatschuß an der rechten Halsseite und am rechten Oberschenkel verwundet. 2. XI. Chirurgische Universitäts-Klinik M. Röntgenbefund: Lokalisation des Geschosses im Oberschenkel nach hinten in der Nähe der Glutäalfalte, in der Tiefe von 2 Querfingern, etwas oberhalb des Verlaufes des N. ischiadicus, seinem Verlauf entsprechend, 20. XI. Nervenbefund (Prof. S.): Motorisch fehlen sämtliche Funktionen des $\mathrm{N}$. peroneus und $\mathrm{N}$. tibialis. Totale Anästhesie des ganzen Ischiadicusgebietes bis hinauf zur Glutäalfalte. Die Nerven sind elektrisch nicht ansprechbar. Die faradische Reaktion fehlt. Die galvanischen Reaktionen sind dagegen prompt sowohl in der Tibialis- wie in der Peroneusmuskulatur. Es könnte jedoch sein, daß die Trägheit der galvanischen Zuckung entsprechend der kurzen Zeit seit der Verwundung noch nicht ausgebildet sind. Ich würde bei den außerordentlich starken Schmerzen, die R. hat, und in Anbetracht der Schwere der Lähmung zu einer Operation raten. 3. XII. Operation: Schnitt über der Glutäalfalte. In der Tiefe ein Geschoß, das dem $\mathrm{N}$. ischiadicus aufsitzt und entfernt wird. Nerv unverletzt, auch nicht verdickt. Nur etwas oberhalb bestehen leichte Verwachsungen mit der Umgebung, die gelöst werden. 3. II. 1916 Befund im Bein unverändert. Anhaltende Schmerzen und anfallsweise ,Nervenschläge", die, in der Fußsohle beginnend, blitzartig in das Bein heraufziehen. Seit 2-3 Wochen Magenbeschwerden: unangenehmes Druck- und Spannungsgefühl in der Magengegend, besonders beim Aufsitzen und Vorbeugen. Duodenaldruckpunkt empfindlich. 23. II. Fortdauernde Magenbeschwerden. Röntgenologisch: Antrum dextroponiert. Beschleunigte Motilität. Im Verein mit eventuellen klinischen Symptomen könnte der Verdacht auf Ulcus duodeni ausgesprochen werden. 3. III. Laparotomie. Kein Ulcus. 17. V. Magenbeschwerden gebessert, sonst Zustand unverändert. 25. XI. Wieder ständig Druckschmerzen in der Magengegend, öfters mit Brechreiz, sonst wie früher. 21. XII. Verlegung nach einem Vereinslazarett in Dresden. Untersuchung durch Ref.: Massige Atrophie im ganzen rechten Bein, besonders im Unterschenkel. Glanzhaut an Fußsohle und Zehen. Fußgelenk schlottert. Jede aktive Beweglichkeit in Fuß und Zehen rechts aufgehoben. Aktive und passive Bewegungen im Kniegelenk unbeschränkt, aber nur mit halber Kraftentfaltung, und zwar Streckung (!) noch schlechter als Beugung. Hüftgelenk bis auf mäßige Reduktion der Beugung intakt. Fersenphänomen rechts $\theta$. Patellarreflex links normal, rechts stark erhöht. Cremasterreflex rechts so gut wie nicht, links schwach auszulösen und leicht erschöpfbar. Totale Anästhesie im ganzen Ischiadicusgebiet, 
außerdem deutliche Herabsetzung für Schmerz- und Berührungsreize in der rechten Scrotumhälfte und an der Vorderseite des rechten Oberschenkels mit scharf abgesetzter, segmental verlaufender oberer Grenze, etwa handbreit unterhalb der Schenkelbeuge. Elektrisch: Spuren einer trägen ASZ in der Wadenmuskulatur. Sonst fehlt jede elektrische Ansprechbarkeit im Ischiadicusgebiet. Überdies erhebliche quantitative Veränderungen in der Strecker- und Adductorengruppe am rechten Oberschenkel für beide Stromarten. Diagnose: Schwere motorisch-sensible Lähmung im Gebiet des rechtsseitigen Sakralplexus. Störung leichteren Grades im lumbalen Wurzelgebiet. Wahrscheinlich tiefsitzende traumatische Caudaaffektion. Kombination mit peripherer Nervenläsion nicht auszuschließen. 26. III. 1917. Aufnahme auf die neuro-chirurgische Korpsstation Arnsdorf. Anamnestisch: Im Moment der Verwundung bewußtlos zusammengebrochen. Als er wieder zu sich kam, rechtes Bein vollständig gelähmt. Tags darauf Einsetzen heftiger Schmerzen im ganzen Bein und besonders im Fuß. Stuhl- und Urinverhaltung. Schmerzen häufig begleitet von unwillkürlichen Schleuderbewegungen im rechten Bein. Wiederkehr der Beweglichkeit im Hüft- und Kniegelenk etwa nach 3 Monaten. Geht zur Zeit ( $1 \frac{1}{2}$ Jahr nach der Verwundung) mit Hilfe eines Schienenapparates ganz leidlich, hat aber dabei immer noch sehr viel Schmerzen, hauptsächlich im Fuß. Ohne Stützapparat kann er nur einige Schritte im Zimmer gehen, weil die Schmerzen beim Auftreten mit dem Fuße alsbald unerträglich werden und auch das Knie schon nach kurzer Zeit versagt. Auch bei der heutigen Untersuchung hochgradige Herabsetzung für beide Stromarten im rechten Quadriceps. Ebenso ist nach wie vor eine einwandfreie Hypästhesie im lumbalen Wurzelbereich vorhanden. Im übrigen Befund wie oben. 26. IV. Röntgenologisch: Die ganze rechte Hälfte des rechten IV. Lendenwirbels von Callusmassen eingenommen, die sich nach unten teilweise über die rechte Hälfte und seitlich neben dem V. Lendenwirbel fortsetzen. Zeichnung des IV. Wirbelkörpers unscharf und verschwommen. Subluxation des IV. Lendenwirbels gegen den V. nach rechts. Am linken unteren Rande des IV. Wirbels über den Wirbelschatten bogenförmig vorspringende Knochenmassen, die wahrscheinlich von einem Bruch der Gelenkfortsätze des IV. und V. Lendenwirbels herrühren. 30. V. Streckergruppe am Oberschenkel funktionell sehr schwach; auch Hüftbeugung rechts hinter links zurück. Rechts Cremasterreflex höchstens angedeutet, Kniephänomen gesteigert. Achilles- und Fußsohlenreflex erlosehen. Diagnose: Rechtsseitige Caudaaffektion, die sich in der Hauptsache auf die Wurzeln $\mathrm{L}_{4}-\mathrm{S}_{2}$ erstreckt und zu deren Erfassung Resektion der 3 unteren Lendenwirbelbogen und des oberen Kreuzbeinabschnittes erforderlich wäre. Die Frage, ob eine gleichzeitige Schädigung des Ischiadicus vorliegt, muß offen gelassen werden. Da er bereits freigelegt worden ist und grobe Veränderungen sich an ihm nicht gefunden haben, wird man aber wohl berechtigt sein, die schwere motorisch-sensible Lähmung, zu ihrem größeren Teile wenigstens, auf einen zentralen Prozeß zu beziehen und bei der absoluten Stabilität des Leidens seit $1 \frac{1}{2}$ Jahren die Laminektomie zu empfehlen. 3. V. O peration (Dr. K r üg er): Wegnahme der Wirbelbogen $L_{2}-I_{5}$ und vom halben Kreuzbein. Weichteil- und Muskelblutung gering, läßt sich durch Tamponade stillen. Zwischen $\mathrm{L}_{4}$ und $\mathrm{L}_{5}$ ein $1 \mathrm{~cm}$ breiter Spalt, durch den in der Tiefe die Dura zu sehen ist. Durakanal wird in der Höhe von $\mathrm{L}_{3}$ durch einen von rechts her vorspringenden Knochensporn verengert und wölbt sich oberhalb davon ballonartig in längsovaler Form vor, unterhalb wird er durch ringförmig ihn umschließende, rosa gefärbte, faserige Auflagerungen taillenförmig eingeschnürt, die sich stumpf abziehen lassen. Darunter zeigt sich ein blauschwarzes Aussehen, während sie im übrigen gerade durchsichtigem Mattglas gleicht, so daß man im 
Rückenmarkskanal klaren Liquor und einige in ihm schwimmende Caudawurzeln erkennt. Die Dura ist prall gespannt und pulslos, während sich einzelne Wurzeln im Kanal pulsatorisch synchron mit dem Pulse bewegen. Nach Eröffnung der Dura fließt Liquor unter so stark erhöhtem Druck ab, daß durch das kleine, gesetzte Loch sofort eine Wurzelfaser herausgepreßt wird, die es verstopft. Dasselbe ereignet sich nochmals mit einer größeren, darunter angelegten Öffnung, nur werden hier gleich mehrere Wurzeln herausgedrängt, die dann den Liquorabfluß verhindern. Erst nach breiter Spaltung der Dura und weiter Auseinanderhaltung ihrer Wundränder durch Haltefäden strömt Liquor gleichmäßig in größeren Mengen ab. Danach setzt mit dem Pulse gleichzeitig Pulsation ein. Sobald nach stärkerem Liquorabfluß der Druck nachgelassen hat, treten aus dem Venenplexus stärkere Blutungen auf, die sich durch Aufdrücken von frischen Muskelstückchen stillen lassen. Einige Caudawurzeln liegen der vorderen Durawand an und sind mit ihr durch zarte Verwachsungen verklebt, die sich sämtlich leicht lösen lassen. Sondierung nach oben frei.

Bemerkenswert an diesem Falle ist, daß er zweimal zu Fehldiagnosen Veranlassung gegeben hat. Zunächst hatte man aus den, offenbar durch meningitische Wurzelreizung bedingten Leibschmerzen irrtümlicherweise auf ein Ulous duodeni geschlossen und laparotomiert, ohne etwas Positives zu finden. Und das zweitemal war die Beinlähmung in ihrer Genese verkannt worden. Da der klinische Befund sowohl, wie die röntgenologische Geschoßlokalisation eindeutig für eine Ischiadicusschädigung zu sprechen schienen, hatte man den Nerven freigelegt und bei der Operation festgestellt, daß das Geschoß dem Nerven aufsa B, ohne ihn aber makroskopisch geschädigt zu haben. Ein Erfolg der Operation war ausgeblieben. Als wir den Mann $5 / 4$ Jahi nach der Verletzung zu sehen bekamen, bot er das Bild der schweren, hochsitzenden Ischiadicusverletzung. Es fanden sich aber außerdem noch Ausfallserscheinungen motorischer und sensibler Art in der l u mbalen Wurzelsphäre, die unmöglich auf eine Ischiadicusschädigung bezogen werden konnten. Dazu kamen anamnestisch Stuhl- und Urinbeschwerden in der ersten Zeit nach der Verletzung. Das alles legte den Verdacht auf einen Prozeß im Caudagebiet nahe, und es wurde daher eine Röntgenaufnahme des untersten Wirbelsäulenabschnittes gemacht, die überraschenderweise eine Subluxation des IV. Lendenwirbels gegen den V. ergab und damit den Verdacht auf eine Caudaschädigung sehr wesentlich verstärkte. Da der neurologische Befund für einen in der Hauptsache auf die beiden untersten Lenden- und die zwei obersten Sakralwurzeln beschränkte Affektion sprach, wurde Laminektomie des II. bis V. Lendenwirbels und der oberen Kreuzbeinhälfte beschlossen. Sie deckte das oben beschriebene Bild auf: Der Durakanal war in Höhe des III. Lendenwirbels durch einen von rechts her vorspringenden Knochensporn stark verengt, und der Duralsack wölbte sich oberhalb dieser Stelle in längsovaler Form ballonartig vor. Der Liquor stand unter so hohem Druck, daß sich bei Eröffnung der Dura einzelne 
Wurzeln hernienartig in den Schlitz vorwölbten und ihn so verschlossen, daß kein Liquor abfließen konnte. Erst nach breitem Spalten der Dura und weitem Klatfen ihrer Wundränder strömte der Liquor in großen Mengen ab. Einige Caudawurzeln lagen der vorderen Durawand an und waren durch zarte, lejcht lösbare Verwachsungen mit ihr verklebt.

Die zweite bei diesem Falle unterlaufene Fehldiagnose gibt Anla B mit besonderem Nachdruck darauf hinzuweisen, wie leicht bei der Beurteilung vorwiegend radikulärer Rückenmarkläsionen irrtümliche Deutungen entstehen können, wenn nach Maßgabe des Befundes und nach Lage und Verlauf des Schußkanales eine Plexus- oder eine hochsitzende periphere Nervenlähmung sich nicht ohne weiteres ausschließen läßt. Bei Lähmungen im Bereich der Cervicalnerven wird man ja me st in der Lage sein, aus der Topographie der Sensibilitätsstörung und der Verteilung des motorischen Ausfalles sich ein Bild davon zu machen, ob eine radikuläre Lähmung vorliegt oder eine Plexusaffektion. Nur wird im ersteren Falle nicht selten die Frage offen bleiben müssen, ob die Läsion im Ursprungsgebiet der Wurzeln zu suchen ist oder in ihrem extravertebralen Verlauf, wenn nicht zufälligerweise das eine oder andere klinische Symptom sich entdecken läßt, das mehr für e nen Prozeß im Mark oder dessen unmittelbarer Umgebung spricht. So gab uns beispielsweise bei Beoback, tung 12 lediglich die Dóppelseitigkeit der schweren vasomotorisch-sekretorischen Störungen im cervicalen Wurzelgebiet Veranlassung, die unilaterale Klumpkesche Lähmung und die sensiblen Störungen in dem entsprechenden Wurzelareal auf eine intravertebrale radikuläre Affektion zu beziehen, obwohl der Verlauf der Geschoßbahn sehr wohl die Annahme einer peripheren Schädigung der Plexuswurzeln gerechtfertigt hätte. Und ähnliche Uberlegungen leiteten uns bei Beobachtung 7, wo sich neben Parese und segmentalem Sensibilitätsausfall an der linken Oberextremität, eine Hyperästhesie in der kontralateralen Hand nachweisen ließ und eine zwar nur leichte, aber doch überzeugend ausgesprochene Schwäche im homolateralen Bein mit Abschwächung des Patellarreflexes.

Daß übrigens alle diese Spinalsymptome nur sehr mit Vorbehalt zugunsten einer primären Läsion innerhalb des Wirbelkanales in die Wagschale geworfen werden dürfen, versteht sich von selbst, da natürlich auch extravertebrale Wurzelschädigungen und Plexusverletzungen unter Umständen mit medullären Erscheinungen kombiniert sein können. Indessen hat es doch den Anschein, als ob diese sekundären, vermutlich duı ch Zerrungseffekt ansgelösten Marksymptome dadurch besonders sich kennzeichnen, daß sie nur leichter Natur sind und sich nach kurzer Zeit mehr oder minder restlos wieder zurückbilden. 
Fast noch komplizierter wie beim Halsmark liegen die Verhältnisse in der lumbosakralen Wurzelsphäre. Man wird zwar hier bei der Kürze und Gedrungenheit des extravertebralen Wurzelabschnittes eine isolierte radikuläre Schädigung außerhalb des Wirbelkanales kaum je in Betracht zu zjehen haben und demzufolge Lähmungen segmentalen Charakters wohl stets ohne weiteres als Ausdruck einer zentralen Läsion auffassen dürfen. Dafür macht sich aber bei diesen Lähmungen, zumal im Sakralgebiet, eine neue Schwierigkeit geltend, nämlich das Fehlen hinreichend sicherer Kriterien für die Differenzierung zwischen segmentalem und peripherem Lähmungstypus.

Eine hochsitzende Ischiadicusverletzung kann unter Umständen genau denselben motorisch-sensiblen Ausfall zeitigen wie eine etwa auf die V. Lumbal- und I. und II. Sakralwurzel beschränkte Caudaaffektion, und es bedarf oft einer sehr genawen Beobachtung und wiederholter Untersuchung bis es gelingt, das eine oder andere Symptom zu entdecken, das nicht in das Bild einer peripheren Lähmung hineinpaßt.

Gerade die für radikuläre Störungen im Bereich des Halsmarkes sonst so au ßerordentlich charakteristische Topographie der Empfindungslähmung läßt uns bei lumbosakralen Affektionen nicht selten vollständig im Stich. Sind, wie bei Fall 18, sämtliche Sakralwurzeln in Mitleidenschaft gezogen, so wird natürlich die Reithosenbesatzform der Anästhesie ohne weiteres die spinale Natur des Leidens verraten. Beteiligt sich aber wie bei Fall 19, nur die unterste Lumbal- und die I. und II. Sakralwurzel an dem Ausfall, so ist es schlechterdings ausgeschlossen, sich über die Herkunft der Sensibilitätsstörung ins klare zu kommen, da eine durch Ischiadicusausschaltung im Becken bedingte sensible Lähmung geographisch genau dasselbe Bild ergeben wird. Hier schien uns lediglich die Abschwächung der Patellar- und Cremasterreflexe auf der gelähmten und der Nachweis spastischer Phänomene auf der Gegenseite für die Diagnose einer Caudaschädigung und g e g e n die Annahme einer peripheren Ischiadicusverletzung zu sprechen.

Das wären so ungefähr die Hauptgesichtspunkte, die in diagnostischer Hinsicht zu erwägen sind und als Richtschnur für das nun zu besprechende therapeutische Vorgehen zu dienen haben.

\section{Therapeutische Maßnahmen.}

1. Chirurgische Indikationsstellung. Bei Aufstellung des Behandlungsplanes steht obenan die Frage des operativen Vorgehens. Sie liegt ohne weiteres klar in Fällen, bei denen das Röntgenbild eine Fremdkörpereinwirkung auf das Mark vermuten läßt, sei es durch Projektile, die in den Wirbelkanal eingedrungen sind, sei es durch Knochensplitter oder callöse Wucherungen, die sich in das Kanallumen 
vorschieben. Bej solchen Befunden wird man stets sobald wie möglich operieren, gleich viel, ob klinisch eine totale oder partielle Lähmung vorliegt; ja, man wird unter Umständen selbst dann zum Eingriff sich entschließen, wenn spinale Ausfallserscheinungen schwererer Art fehlen. Es sei in dieser Hinsicht an Fall 6 erinnert, der, abgesehen von einem sensiblen Brown-Séquard mit latenter Parese der Beine nur subjektive Beschwerden in Form von Radikalgien bot, und wo die Operation ein intravertebral liegendes Geschoß aufdeckte, das mittels eines vorgelagerten spitzen Knochenspornes das Mark dellenförmig eingedrückt hatte. Daß ein in den Wirbelkanal eingedrungener Fremdkörper, auch wenn er zunächst keine evidenten Kompressionserscheinungen macht, stets eine ernste Gefahr für das Mark bildet, liegt auf der Hand, und es kann daher keinem Zweifel unterliegen, daß man bei einer derartigen Sachlage nicht nur berechtigt, sondern verptlichtet ist, unverzüglich zur Laminektomie zu schreiten.

Zeigt das Röntgenbild keinerlei Veränderungen im obigen Sinne, so wird man zu alsbaldigen operativen Maßnahmen nur dann raten, wenn die klinische Beobachtung hinreichende Verdachtsmomente für das Vorliegen eines progredienten Krankheitsprozesses ergibt, oder wenn bei hochsitzenden Affektionen - ich denke insbesondere an adhäsiv meningitische Prozesse der Halsanschwellung - bedrohliche Bulbärsymptome auftreten, die das Leben des Kranken in Gefahr bringen. Alle anderen Fälle mit negativem Röntgenbefund werden wir zunächst auf ihren Verla uf beobachten und mit der operativen Indikation solange zurückhalten, bis wir die Überzeugung gewonnen haben, daß ein stationärer Zustand vorliegt. Mit einem solchen darf man nach unseren Erfahrungen im allgemeinen rechnen, wenn 5-6 Monate nach der Verletzung k ei ner lei Besserungstendenz sich zeigt, oder wenn eine anfängliche Besserung wieder haltmacht und Monate hindurch keine weiteren Fortschritte erkennen läßt. Natürlich wird man sich um so leichter zu einem Eingriff entschließen, je mehr man Aussicht hat, auf einen, dem Messer zugänglichen, reparierbaren Prozeß zu stoßen. Da wir aber, wie eingangs ausführlich besprochen, nicht in der Lage sind, klinisch-diagnostisch diese Frage mit Sicherheit zu entscheiden, so wird man von ihr die Indikationsstellung nicht abhängig machen können, sondern man wird operieren, sofern nur einigermaßen Hoffnung besteht, daß man dem Verletzten durch den Eingriff nützen kann. Ganz besonders nachdrücklich möchte ich darauf hinweisen, daß es absolut verkehrt ist, die Operationsfrage von der Schwere des Falles, d. h. dem Grad der Lähmung, abhängig zu machen. Wir haben genügend Beispiele angeführt, aus denen ersichtlich ist, daß, wie etwa bei Meningealaffektionen, allein schon die Schmerzen den Kranken so belästigen können, daß er nicht viel besser daran jst wie ein durch Lähmung ans 
Bett gefesselter Rückenmarksverletzter. Gerade diese Fälle sind es, bei denen die Rückenmarkschirurgie ihre Triumphe feiern kann, und wer die Dankbarkeit dieser Patienten kennengelernt hat, wird es nicht begreifen können, wie man immer noch in der Literatur die Anschauung vertreten finden kann, daß die Behandlung der Rückenmarkverletzungen eines der traurigsten Kapitel der Kriegschirurgie bilde. Das trifft zu, wenn man nur die Querläsionen oder die allerschwersten Kompressivlähmungen der Laminektomie unterzieht. Dann wird man allerdings therapeutisch nur wenig Freude erleben. Bemüht man sich aber, wie wir es von vornherein getan haben, insbesondere diejenigen Fälle zu operieren, bei denen man vorwiegend meningeale, das Mark mehr sekundär treffende Affektionen vermuten zu dürfen glaubt, so wird sich die Erfolgsziffer gleich ganz anders gestalten. Dieselben Ansichten vertreten übrigens auch Marburg und Ranzi, indem sie besonders hervorheben, daß auch bei ihrem Material Fälle dieser Art das beste operative Resultat ergaben, daß sie vielfach sogar wieder dienstfähig gemacht werden konnten, auch wenn sie lange Zeit schwer unter ihrem Zustand gelitten hatten.

Einigermaßen skeptisch stehe ich für meine Person lediglich den Operationserfolgen bei der wirklich stationären Querläsion gegenüber. Wir verfügen über 25 einschlägige Fälle, von denen wir 10 laminektomiert haben. Kein einziger davon hat sich auch nur spurweise gebessert, obwohl wir die Fälle, soweit sie nicht ad exitum kamen, nun doch schon jahrelang übersehen. Bei den übrigen Fällen haben wir uns schon gar nicht zur Operation entschließen können, und das Sektionsergebnis war auch derartig hoffnungslos; daß ein Eingriff absolut zwecklos gewesen wäre. Damit möchte ich aber nicht gesagt haben, daß komplette Querläsionen, auch wenn sie irreversibel zu sein scheinen, unter allen Umständen eine operative Gegenindikation abgeben. Ich konstatiere nur, daß wir bei unseren Fällen nie das Glück gehabt haben, auf einen restituierbaren Prozeß zu stoßen. Daß man aber immerhin mit der Möglichkeit einer Rückbildung auch beim Bild der typischen Querläsion rechnen darf, habe ich eingangs bereits erwähnt und darauf hingewiesen, da $\beta$ andere Autoren, wie beispielsweise Marburg und Ranzi, über erfolgreich operierte Fälle dieser Art berichten, so daß man jedenfalls berechtigt ist, ausnahmsweise auch bei Totallähmungen im Basti a n schen Sinne die Laminektomie zu befürworten. Marburg und Ranzi wollen lediglich die Fälle mit pastöser Schwellung der Beine von der Operation ausgenommen wissen, weil es sich bei ihren, durch Sektionsbefunde belegten Beobachtungen dieser Art immer nur um anatomisch irreversible Markprozesse gehandelt hat.

2. Operative Heilerfolge. An der Hand dieser Anzeigen haben wir unter einem Gesamtmaterial von 250 Rückenmarkläsionen 72 Fälle 
operiert. Bei 15 Fällen wurde von einem Eingriff Abstand genommen, weil ein solcher bei der Schwere des klinischen Bildes von vornherein aussichtslos erschien. Die noch verbleibenden 163 Fälle, also mehr als die Hälfte unseres Materiales, waren teils so leichter Natur, daß sie besonderer therapeutischer Maßnahmen nicht bedurften, teils machten sie spontan unter Anwendung physikalischer Hilfsmittel so befriedigende Fortschritte, daß keine Veranlassung zu operativem Vorgehen vorlag.

Von den 72 operierten Fällen können 24 als ganz oder nahezu geheilt, 20 als mehr oder weniger gebessert bezeichnet werden. Völlig unbeeinflußt geblieben sind 9, nach der Operation gestorben 13 Fälle, davon 4 an den unmittelbaren Operationsfolgen.

Unter den als geheilt geführten Fällen befinden sich 10 Caudaschädigungen, 9 Verletzungen des Dorsal- und 5 Verletzungen des Halsmarkes. Als mehr oder weniger gebessert sind 2 Caudafälle gebucht, 4 Verletzungen des Lumbo-Dorsalmarkes und 2 Halsmarkläsionen. Von den unbeeinflußt gebliebenen Fällen entfallen 2 auf das Lumbal-, 3 auf das Dorsal- und 3 auf das Halsmark.

Die besten Heilerfolge ergaben die vorwiegend meningealen, $d . h$. auf den Wurzelapparat beschränkten Affektionen, und zwar insbesondere diejenigen des Caudagebietes und des Lumbo-Dorsalmarkes, während für die entsprechenden Schädigungen des cervicalen Markabschnittes Voraussetzung war, daß die degenerativ-atrophischen Lähmungen keine allzu schweren waren.

Eine relativ gute Prognose boten auch die spinalen Hemiplegien vom cerebralen oder Brown-Séquardschen Typus; nur blieb auch hier Vorbedingung, daß der Lähmungsherd nicht allzu ausgedehnte irreparable Segmentschädigungen, besonders auf motorischem Gebiet, gesetzt hatte. Zweifelhaft war der Erfolg bei unseren Fällen mit schweren spastischen Paraplegien und am schlechtesten das Resultat bei schlaffen Lähmungen. Was man aber unter Umständen auch bei schweren Spastikern durch einen das Mark entlastenden Eingriff noch erreichen kann, sollen die beiden nachstehenden Fälle zeigen:

(Beob. 20.) Landsturmmann M., verwundet durch Infanteriegeschoß am 6. VIII. 1915. Einschuß linke Schlüsselbeingrube, Ausschuß in Höhe der Xyphoidlinie handbreit nach rechts von der Wirbelsäule. Sofortige Lähmung beider Beine, der Blase und des Mastdarmes. In den Oberschenkeln Gefühl des ,,Eingeschlafenseins", Unterschenkel und Füße ,abgestorben". Im Laufe von 6-8 Wochen Wiederkehr der Beweglichkeit in den Beinen so weit, da $B$ mit doppelseitiger Unterstützung die ersten Gehversuche gemacht werden können. Seitdem keine nennenswerte Änderung mehr. Bef und am 10. IV. 1916: In beiden Oberschenkeln hochgradige Muskelspannungen. Kniegelenke dauernd in Streckcontractur. Beugeversuche gelingen aktiv wie passiv nur spurweise unter mühsamer Überwindung heftigster Muskelwiderstände und lösen sofort starken Schütteltremor beider 
Unterextremitäten aus. Streckung und Beugung in der Hüfte und Bewegungen der Füße und Zehen sind selbsttätig in nur geringem Ausmaße möglich. Besonders schlecht gelingt infolge Adductorencontractur die Abduction des rechten Oberschenkels. Passive Bewegungsversuche in Hüft-, Fuß- und Zehengelenken sind in normalem Umfange und ohne nennenswerte Widerstände ausführbar. Aufrichten aus Rückenlage nur mit Unterstützung. Fortbewegung im Zimmer an 2 Krücken möglich, aber durch die Spasmen und den sofort sich einstellenden Schüttelklonus der Beine aufs äußerste behindert. Spastische Reflexe in beiden Unterextremitäten sehr ausgeprägt, links mehr als rechts. Achillesphänomene beiderseits stark gesteigert, ebenso die Cremasterreflexe. Die Patellarreflexe sind infolge der Streckcontractur in den Knien nicht zu beurteilen. Von den Bauchdeckenreflexen sind die unteren normal, die oberen herabgesetzt. Sensibel: Gürtelzone mit Anästhesie links, Hypästhesie rechts, handbreit ober- und unterhalb der Nabellinie $\left(\mathrm{D}_{\mathbf{8}}-\mathrm{D}_{11}\right)$. Nach unten davon bis zur Rumpfbeingrenze relative Hypästhesie. Unterhalb der Schenkelbeuge setzt rechts eine schwere Hypästhesie für alle Qualitäten der Oberflächensensibilität ein, die in Höhe des Knies in Anästhesie übergeht. Lin ks sind Unterschenkel und Fuß ebenfalls anästhetisch, während im Oberschenkel Pinselberührungen unsicher, Schmerz- und Temperaturreize leicht abgestumpft empfunden werden. Die Tiefensensibilität ist im ganzen linken Bein erheblich gestört, im rechten nur in den distalen Partien. Röntgenbild: Dornfortsätze der Brustwirbel VI-VIII unscharf gezeichnet. Zahlreiche Geschoßsplitter rechts neben dem VI. und VII. Wirbel.

Da der Charakter der Sensibilitätsstörung im Verein mit dem motorischen Befund (Utberwiegen der Spasmen und der Bathyhypästhesie links, der Oberflächensensibilitätsstörung rechts) den Verdacht auf eine Kompression des Markes nahelegte, wurde die Freilegung des erkrankten Markabschnittes zwischen dem V. und $\mathrm{X}$. Brustwirbel beschlossen.

Operationsbef und vom 17. IV. 1916 (Dr. Kr üger): Fibrinöse Schwarten zwischen Dura und Knochen eingekeilt. In Höhe des VI. und VII. Brustwirbels ist das Mark von links vorn und seitlich rechts konvex verschoben und nach hinter gegen den Wirbelbogen gedrückt. Bei Duraeröffnung spritzt Liquor in großem Bogen hervor. Markgefäße stark injiziert. Zwischen Wurzeln und Dura beiderseits leichte Verwachsungen, die sich gut lösen lassen. Postoperativer Verla uf: 18. IV. 1916 Spasmen in beiden Beinen erheblich gebessert, Kniegelenk aktiv frei beweglich, Patellarreflexe sehr lebhaft. 24. V. Gang freier, geht mit einem Stock. 14. VI. Auf Urlaub; Weg zur Bahn ( $1 / 2$ Stunde) zu Fuß mit öfteren Ruhepausen. 5. VIII. Wieder auf Urlaub, versucht leichte Feldarbeit, Beine aber immer noch „steif und zitterig“. 29. 1. 1917 entlassen. Kann, wenn auch langsam, bis zu einer Stunde gehen. Aktive Bewegungen in allen Gelenken der Unterextremitäten mit etwa halber Kraftentfaltung möglich, aber immer noch mühsam und infolge von Muskelwiderständen nicht bis zum vollen Ausmaße.

(Beob. 21.) Hauptmann E. wurde durch Schrapnellkugelsteckschuß am 6. X. $1915 \mathrm{im}$ Ruicken verletzt. Sofortige Lähmung beider Beine, der Blase und des Mastdarmes und Gefühllosigkeit bis zum Nabel. 3 Wochen nach der Verletzung Entfernung des Geschosses aus dem Wirbelkanal; trotzdem zunehmende spastische Contracturen in beiden Unterextremitäten.

Bef und am 10. IX. 1916, also $1 \mathrm{Jahr}$ nach der ersten Operation ergibt. eine schwere spastische Paraparese der Beine mit maximaler Flexionscontractur in beiden Knie- und Hüftgelenken und hochgradige Adductorenspannung. Die Beine sind nur unter größtem Kraftaufwand passiv in halbe Streckstellung zu bringen, um bei Nachlassen des Druckes sofort wieder in die Ausgangsstellung zurückzuschnellen. Aktive Beweglichkeit im rechten Bein vollständig aufgehoben, 
im linken in allen Gelenken nur spurweise erhalten. Cremaster- und Bauchdecken* reflexe nicht auslösbar. Die Sensibilitätsstörung beginnt in Höhe der Xyphoidlinie und nimmt nach abwärts immer mehr zu bis zur nahezu vollständigen Anästhesie im Unterschenkel. Andeutung von Brown-Séquardschen Typus insofern, als rechts, also auf der motorisch am schwersten geschädigten Seite mehr die Tiefensensibilität, auf der Gegenseite mehr die Temperatur- und Schmerzempfindung in Mitleidenschaft gezogen ist. Diese Erscheinungen, zusammen mit sehr ausgesprochenen motorisohen Reizsymptomen (schmerzhafte Spontanzuckungen in beiden Beinen, zumal nachts), bestimmten uns, eine partielle Querschnittsaffektion mit komprimierenden Veränderungen in den Rückenmarkhäuten anzunehmen und nochmals zu laminektomieren, in der Voraussetzung, daß bei dem ersten Eingriff der spinale Prozeß nicht in hinreichender Ausdehnung freigelegt worden ist. 28. VIII. 1916 Laminektomie (Dr. Krüger): Hautschnitt von der Höhe des 3. bis zum Dornfortsatz des 8. Brustwirbels. Wegnahme der Wirbelbogen von unten her nach aufwärts mit dem 8. beginnend. Oberhalb des Brustwirbels kommt man auf eine fingerkuppengroße Stelle des Kanales, die scheinbar nur durch Bindegewebe geschlossen ist. Dura, soweit freigelegt, von einer dicken, rosa gefärbten Membran umhüllt. Ungefähr in Höhe des 5. und 6. Brustwirbels kommen von rechts her einige Bindegewebsstränge, die sich vom Knochen aus bis fast zur Mitte des Durasackes erstrecken und eng mit der Dura verwachsen sind. Sie werden sorgfältig gelöst und im ganzen entfernt. Bei Eröffnung der Dura wölbt sich die Arachnoidea cystenartig in den Schnitt vor. Das Mark wird von einer spinnwebenartigen Haut in seinem ganzen Umfang umgeben, die sich nur schwer abziehen läßt. Nach rechts bestehen ausgedehnte derbe Verwachsungen (besonders in Höhe des 5., 6. und 7. Wirbels) zwischen Dura, Mark und Wurzelfasern. Die Verwachsungen haben zum Teil fibrinösen Charakter, sind milchig verfärbt und undurchsichtig. Die Wurzeln sind in ihrem intraduralen Verlauf innig mit dem Mark verwachsen und lassen sich nur mühselig allmählich lösen. In Höhe des 5. Wirbels und oberhalb davon erscheint das Mark abgeflacht und in sich zusammengefallen. Post opera tiver Verla uf: 24. IX. Erstmalige willkürliche Streckbewegungen im rechten Kniegelenk. 6. XI. Beide Kniegelenke passiv fast bis zur Geraden durchdrückbar, auch willkürliche Bewegungen bessern sich zusehends. 13. III. 1917. Beginnt mit Widerstandsbewegungen, die in beiden Beinen ganz leidliche aktive Kraftleistungen ergaben, zumal links. 25. V. Seit 1 Woohe UUbungen mit Gehstuhl, Linkes Kniegelenk kann jetzt aktiv fast völlig gestreckt werden, rechts zu etwa 2 Dritteln. 28. VIII. Aktive Beweglichkeit macht gute Fortschritte, linkes Bein dem rechten immer etwas voraus, auch die Adductorencontractur beginnt sich zu lösen, das rechte Knie kann jetzt ebenfalls willkürlich fast restlos in Streckstellung gebracht werden. Spasmen der Wadenmuskulatur so weit gelockert, daß die Fußsohlen aufgesetzt werden können. Sensibel keine nennenswerten Änderungen. 20. VI. 1918. Geht am Gehbänkchen, steht ohne fremde Stütze vom Stuhl auf. 6. III. 1919. Wandert mit 2 Stöcken im Korridor hin und her, und fängt bereits an, Treppen zu steigen. 7. I. 1920. Hat seine regelmäßige Bureautätigkeit wieder aufgenommen, läßt sich zur Arbeitsstelle fahren, steigt Treppe mit Stock.

Bei dem zweiten Fall hatte man andererorts bereits laminektomiert, aber in so zaghafter Weise, daß von einer auch nur annähernd genügenden Freilegung des Markprozesses nicht die Rede sein konnte. Deshalb war wohl auch das Resultat ein vollständig negatives geblieben. Derartige Beobachtungen haben wir wiederholt machen können, und sie bestätigten 
uns immer wieder die Richtigkeit unseres Bestrebens, in der Anlage der Laminektomie nicht zu engherzig zu sein. Möglichst ausgedehnte Trepanationen haben unseres Erachtens zwei Vorzüge: Sie geben einerseits eine gute Ubersicht über den lädierten Markabschnitt und ermöglichen es, Dura und Mark in tunlichst ausgedehntem Maße von Sch wielen und Verwachsungen zu befreien, und sie begünstigen andererseits die Erholungsfähigkeit der erkrankten Markpartien, indem sie in ausgiebiger Weise für Druckentlastung und Verbesserung der Zirkulationsverhältnisse sorgen. Irgendwelche Nachteile haben wir von umfangreichen Resektionen nicht gesehen. Defekte bis zu 6 und 7 Wirbelbögen haben keinerlei Folgen für die Stabilität der Wirbelsäule, da ja die eigentlichen Tragknochen, die Wirbelkörper, intakt bleiben. Nur wenn diese frakturiert sind, können, wie das Marb urg und Ra nzi in 5 Fällen ihres Kriegsmateriales beobachtet haben, Verkrümmungen der Wirbelsäule auftreten, zumal im Halsabschnitt. Diese Autoren empfehlen daher, in solchen Fällen mit der Wegnahme der Wirbelbögen möglichst sparsam zu sein und nach der Operation bis zur definitiven Heilung der Fraktur Stützapparate tragen zu lassen.

Die Bestimmung der zu entfernenden Wirbelbögen macht, wenn durch den neurologischen Befund die lädierten Segmente festgestellt sind, keine besonderen Sch wierigkeiten. Das Flatausche skeletotopische Schema hat sich uns hierbei als unbedingt zuverlässiges Hilfsmittel erwiesen, so da $\beta$ wir immer in der Lage waren, bei Festlegung des Operationsplanes genau die Wirbel anzugeben, die den geschädigten Segmenten entsprachen. Einige Vorsicht ist nur bei tiefer sitzenden Rückenmarksverletzungen notwendig, weil die Dornfortsätze, die die äußeren Anhaltspunkte abgeben, um so schräger gestellt sind, je weiter man abwärts in der Wirbelsäule kommt, so daß beispielsweise dem 9. Brustsegment, das in der Höhe des 10. Brustwirbels liegt, der 12. Dornfortsatz entspricht, also die Differenz zwischen Segment und gleichnamigem Dornfortsatz volle 3 Segmente beträgt.

Eine bei jeder Laminektomie zu erwägende Frage ist die, ob die Dura zu eröffnen ist oder nicht. Wir haben bereits angedeutet, daß der dekompressive Effekt der Laminektomie für die Erholung nicht vollständig zugrunde gegangener Querschnittsteile des Markes von nicht zu unterschätzender Bedeutung sei. Es liegt aber auf der Hand, daß eine möglichst vollkommene Druckentlastung nur dann erzielt werden kann, wenn dafür Sorge getragen wird, daß die mit den extra duralen Veränderungen fast stets einhergehenden inneren Verwachsungen der weichen Rückenmarkhäute und die dadurch bedingten Liquorabsackungen behoben werden. Aus diesem Grunde sollte man es, sofern nicht strikte Gegenindikationen vorliegen, nie versäumen, den Duralsack zu eröffnen, die Verklebungen oder Verwachsungen der 
weichen Häute und der Wurzeln zu lösen oder, wenn dies nicht restlos möglich ist, die Passage wenjgstens so weit frei zu machen, daß der Liquor wieder unbehindert zirkulieren kann. Nur wenn eine direkte Infektionsgefahr vorliegt, wird man von diesem Schritt Abstand nehmen und sich mit der Freilegung und Säuberung der Dura begnügen.

Mit der Beseitigung epiduraler Schwielen und leptomeningitischer Verwachsungen bzw. der Entfernung etwaiger Fremdkörper dürfte in der Regel die chirurgische Aufgabe erfüllt sein. Zu operativen Eingriffen im Mark selbst wird nur höchst selten eine Veranlassung vorliegen. Man ist zwar versucht, bei Zerstörung des Markes, in Analogie zur Durchtrennung peripherer Nerven, an Anfrischung und Naht zu denken. Experimente in dieser Hinsicht sind wohl gemacht, einwandfreie Erfolge, auch bescheidenster Art, bis jetzt jedoch nicht erzielt worden. Von amerikanischen Ärzten liegen aus der Zeit vor dem Kriege Berichte vor, die von einer Regeneration nach Naht wissen wollen. Sie erwecken aber den Verdacht, daß es sich dabei nicht um perfekte Lähmungen gehandelt hat, so da $B$ die Wiederkehr der Leitung weniger auf Konto der Naht gesetzt werden darf als auf eine Funktionsübernahme durch erhaltengebliebene Querschnittsteile. Henneberghat nach seinen Beobachtungen betont, da $B$ die Neigung der markhaltigen Nervenfasern des Rückenmarkes zur Neubildung nach ihrer Durchtrennung äußerst beschränkt und für die Wiederherstellung der Leitung praktisch kaum von Bedeutung sei. Auch Stroebe hat bei seinen Untersuchungen keinerlei Neubildungen von Rückenmarksfasern nachweisen können, wohl aber eine Regeneration von Fasern der hinteren Wurzeln, die zwischen Mark und Spinalganglien durchschnitten worden waren. Man wird daher bei der Durchtrennung von Caudawurzeln immerhin den Versuch einer Naht machen können. Marburg und Ranzi ist das in 3 Fällen, Krüger einmal geglückt. Die erstgenannten beiden Autoren haben keine Wiederherstellung der Funktion eints eten sehen und wir haben unseren Fall (Beob. 8) zu früh aus den Augen verloren, um uns ein Urteil bezüglich des Erfolges bilden zu können.

3. Zum Schlusse noch einige Worte über die Nachbehandlung operierter Rückenmarksverletzungen.

Besondere Aufmerksamkeit bedarf die Bekämpfung von Blasenkatarrhen und Decubitus. Bei der eitrigen Cystitis hat uns neben täglichen Spülungen und den üblichen, intern zu gebenden Antisepticis, die Anwendung der von den sächsischen Serumwerken hergestellten Autovaccine besonders gute Dienste geleistet, selbst bei sehr schweren Infektionen mit Schüttelfrösten und Fieber. Für den Decubitus ist die allem überlegene Behandlung das Dauerbad. Wir haben ausgedehnten Gebrauch davon gemacht und sind mit den Erfolgen recht 
zufrieden gewesen. Auch Marburg und Ranzi empfehlen es sehr warm, warnen aber vor allzu wahlloser Anwendung und wollen Fälle mit gleichzeitiger frischer Lungenverletzung, sowie schwere Nierenschädigungen oder kachektische Patienten mit schlechtem Herzen von der Wasserbehandlung ausgenommen wissen.

Von hohem therapeutischen Werte für die Spättherapie der Rückenmarkverletzungen mit Bewegungsstörungen ist eine systematische, zeitlich nicht zu kurz bemessene Anwendung physikalischer Maßnahmen, unter denen an erster Stelle Heißluftbäder des Rumpfes, Massage und Widerstandsgymnastik zu nennen sind. Besonders wichtig erscheint uns die energische Durchführung einer manuellen Massagebehandlung bei den spastischen Lähmungen, sowohl zur Verhütung von Contracturstellungen der Gelenke, wie auch zum allmählichen Ausgleich der Muskelspannungen. Es ist oft ganz auffallend, wie unter einer sachgemäß durchgeführten Handmassage (von Pendelapparaten haben wir nur wenig Gebrauch gemacht) die spastisch gelähmte Muskulatur lockerer und gefügiger wird, und man sieht nicht selten, daß eine Unterbrechung der Behandlung bei Beurlaubungen von wenigen Wochen genügt, um die Spasmen wieder zu steigern. Es erscheint uns allerdings erforderlich, daß diese Massagebehandlung von männlichem Personal durchgeführt wird, weil die weiblichen Kräfte nicht genügend durchgreifen können und bei der passiven Uberwindung der Contracturen zu rasch ermüden. Sobald als möglich wird mit Steh- und Gehübungen begonnen, zunächst mit doppelseitiger Unterstützung, dann im Gehstuhl, schließlich am Gehbänkchen und am Stock. Von orthopädischen Behelfsapparaten ist, solange die Wiederkehr der Motilität Fortschritte macht, tunlichst Abstand zu nehmen, da sie der Einübung paretischer Muskelgruppen nur hindernd im Wege stehen. Nur bei Paresen der Peroneusmuskulatur, die häufig die Gehübungen stark beeinträchtigen und durch Verordnung hoher Schaftstiefel leicht zu korrigieren sind, wird man von dieser Regel eine Ausnahme machen. Für Dauerlähmungen hat v. Eiselsberg sehr sinnreiche Apparate angegeben, die den Zweck verfolgen, die intakt gebliebene Rumpfmuskulatur für die gelähmte Unterextremität nutzbar zu machen und so den beklagenswerten Patienten wenigstens die selbsttätige Bewegung im Zimmer zu ermöglichen.

Liegen spastische Lähmungen vor, die trotz Freilegung dẹs Markprozesses und hinreichender medico-mechanischer Maßnahmen nicht zu bessern sind, so ist in Erwägung zu ziehen, ob man dem Kranken noch durch eine orthopädische Nachoperation irgendwie nützen kann. Handelt es sich nur darum, die Hypertonie einer bestimmten Muskelgruppe zu beheben, so wird man mit der einfachen Sehnendurchtrennung auskommen. Insbesondere gilt dies für spastische Spitzfußstellungen 
und Abductorencontracturen. Bei ausgedehnteren Spasmen dagegen sind die Tenotomien zwecklos; es müssen da schon eingreifendere Verfahren zu Hilfe genommen werden, unter denen als gut erprobt und besonders empfehlenswert die Stoffelsche neurogene Muskelschwächung und die Foerstersche Radikotomie zu nennen sind.

Die Stoffelsche Operation, von F o er s ter an Hirn- und Rückenmarkverletzten weiter ausgebaut, verfolgt den Zweck, die innervatorische Ubbererregbarkeit des spastjschen Muskels zu beheben und auf diese Weise das statische Gleichgewicht zwischen ihm und dem normal funktionierenden Antagonisten wieder herzustellen. Dazu wird der motorische Nerv freigelegt, aufgebündelt und der einzelne Faszikel, nach Feststellung seiner Funktion durch faradische Reizung, entweder im Stamm oder kurz vor seinem Eintritt in den Muskel durch totale oder partielle Resektion soweit als nötig geschwächt. Beschränkt man sich auf die teilweise Resektion, so ist es Sache der Erfahrung, wieviel man von dem Nerven fortzunehmen hat, um den erforderlichen Grad der Muskelschwächung ohne Gefährdung der Funktionstüchtigkeit zu erzielen. Die Erfolge der Stoffelschen Operation sind nach unseren Erfahrungen ganz hervorragend gute bei den spastischen Beinlähmungen. An der Oberextremität dagegen sind wir mit den Resultaten des Verfahrens weniger zufrieden. Vor allem haben uns da die Flexionscontracturen in den Ulnaris- und Medianusmuskeln unüberwindliche Schwierigkeiten bereitet. Sie ließen sich wohl zunächst immer ganz gut ausgleichen, die Besserung war aber in der Regel nur von kurzer Dauer; innerhalb weniger Monate hatte sich fast bei allen unseren Fällen der alte Zustand wieder hergestellt.

Das Anwendungsgebiet des Stoffelschen Eingriffes erstreckt sich natürlich nur auf solche Paresen, bei denen der spastische Zustand die Lähmungskomponente überwiegt, wo also hochgradigere Beeinträchtigungen der willkürlichen Bewegungsfähigkeit oder gar Contracturzustände nicht vorliegen. Die schönsten Resultate geben die einseitigen Lähmungen, doch verfügen wir bereits auch über einen Fall von multipler Sklerose mit typischer doppelseitiger Parese, bei dem sich die Gehfähigkeit durch die Operation ganz wesentlich gebessert hat.

Im allgemeinen ist aber für schwere, zumal dop pelseitige spastische Lähmungs- und Contracturzustände, die Foerstersche Radikoto mie dem Stoffelschen Verfahren vorzuziehen. Dieselbe geht bekanntlich von dem Prinzip aus, durch partielle Resektion der hinteren Rückenmarkwurzeln den sensiblen Teil des Reflexbogens so weit zu unterbrechen, daß die peripherogenen sensiblen Reize nicht mehr in vollem Maße zur Auswirkung kommen können, und so aus der H y per toni e eine Hy potoni e wird. Selbstverständlich ist auch bei der Foerster- 
schen Operation Vorausetzung, daß es sich nicht um komplette Paraplegien handelt, sondern nur um Motilitätsstörungen, bei denen die paretischen Erscheinungen hinter den Spasmen zurückbleiben. Wie gute Dienste dieses Verfahren auch in ganz trostlos erscheinenden Fällen leisten kann, lehrt die folgende Beobachtung:

(Beob. 22.) Es handelte sich um einen Schrapnellsteckschuß des unteren Wirbelsäulenabschnittes. Verletzung am 31. VII. 1917. Das Geschoß war in einem englischen Feldlazarett entfernt und zu diesem Zwecke, nach dem Röntgenbild zu schließen, der 10. und 11. Brustwirbel laminektomiert worden. Der Verletzte bot $1 \mathrm{Jahr}$ später eine völlig stabile spastische Paraparese der Beine mit den denkbar schwersten Contracturen. Beide Oberschenkel waren fest an den Leib angezogen, prall aneinandergepreßt und so nach innen rotiert, daß der rechte den linken überkreuzte. Die Füße befanden sich in spastischer Spitzfußstellung, die Zehen in maximaler Plantarflektion. Die aktive Beweglichkeit war in Fuß und Zehen beiderseits vollständig aufgehoben, desgleichen in Knie- und Hüftgelenk rechts, während das linke Bein, wenn auch unter großer Mühe, in Knie und Hüfte selbsttätig leidlich gestreckt werden konnte. Die Spasmen in den Fußgelenken waren auch passiv nicht zu überwinden, die Flektionscontracturen, in Knie und Hüfte rechts nur spurweise, unter Auslösung heftiger Klonismen. Umwenden und Aufrichten aus Rückenlage war selbsttätig ausführbar. Stehen oder Gehen selbst mit doppelseitiger Unterstützung ausgeschlossen. Sensibel: Hyp- bis Anästhesie in beiden Beinen bis zur mittleren Höhe der Oberschenkel, hauptsächlich an der Vorderseite. Bauchdecken- und Cremasterreflexe o. B. Haut- und Sehnenreflexe an den Unterextremitäten infolge der Contracturen nicht zu beurteilen. Diagnose: Prozeß in der oberen Hälfte der Lendenanschwellung. Da mit einer spontanen Besserung des Zustandes nicht mehr gerechnet werden konnte, wurde nochmalige Laminektomie unter Einbeziehung des 12. Brust- und 1. und 2. Lendenwirbels (Brustwirbel 10 und 11 waren bereits laminektomiert) beschlossen, und, je nach dem bioptischen Befunde, gleichzeitig die Vornahme der Foersterschen Tenotomie in Aussicht genommen. Operation 16. IX. 1918 durch Dr. Kr üger ausgeführt: Resektion der Bogen von $\mathrm{Th}_{12}$ und $\mathrm{L}_{1}$ und $\mathrm{L}_{2}$, der besseren Übersicht wegen nachträglich auch noch von $\mathrm{L}_{3}$ und $\mathrm{L}_{4}$. Dura pulslos. Die Bogen $L_{1}$ und $L_{2}$ drücken hauptsächlich von rechts her stark auf die Dura. Die rechte Hälfte des 3 . Bogens ist zerbrochen, einige Splitter haben die Dura verletzt und ragen in den Rückenmarkskanal hinein; sie lassen sich nur unter ausgedehnter Verletzung der Dura entfernen. Die einzelnen Rückenmarkwurzeln zeigen sich nach ausgedehnter Eröffnung der Dura derartig untereinander verwachsen, daß eine Differenzierung nur mit Hilfe des elektrischen Stromes möglich ist. Cauda und unterer Rückenmarkabschnitt sind von einem zarten, aber ziemlich festen Häutchen überzogen, das sich fast im ganzen abziehen läßt. Ebenso werden nach Möglichkeit die Verwachsungen zwischen den einzelnen Wurzeln gelöst. Da dies aber nur in sehr beschränktem Maße ausführ. bar ist, wird links die Hälfte, rechts $2 / 3-3 / 4$ des sensiblen Anteiles von $\mathrm{L}_{2}-\mathrm{S}_{2}$ reseziert. Pos to perati ver Verlauf: 3. XII. 1918. Unter Heißluft-, Massagebehandlung und Widerstandsgymnastik in den letzten Wochen merkliches Nachlassen der Spasmen. 20. VI. 1919. Adductions- und Rotationscontractur in den Hüft. gelenken behoben. Die Beine liegen, ohne sich zu berühren, nebeneinander, das linke ist fast völlig gestreckt, das rechte bildet im Knie noch etwa einen Winkel von $110^{\circ}$ und ist infolge unüberwindbarer Widerstände der Beugergruppe am Oberschenkel auch passiv nicht in Streckstellung zu bringen. Spitzfuß rechts ausgeglichen, links unverändert. Die Zehen beider Füße stehen nach wie vor in 
extremer Beugestellung. Um den Beginn der Gehübungen nicht allzulange hinausschieben zu müssen, werden die Beuger am rechten Oberschenkel teno: tomiert und gleichzeitig, zwecks Behebung der Spitzfußstellung und der Flektionscontractur der Zehen, die Durchtrennung der linken Achillessehne, der Plantarfascie und der kurzen Zehenbeuger beiderseits vorgenommen. 10. IX. 1919. Übt im Gehstuhl mit gutem Erfolg. 25. X. 1919. Geht an 2 Stöcken. 10. II. 1920. Macht langsame, aber stetige Fortschritte bei seinen Gehübungen.

Einige Schwierigkeiten macht die Frage, welche Spastiker für die Radikotomie geeignet sind. Die Operation ist nicht ungefährlich und erfordert große Vorsicht und Erfahrung, wenn man dem Patienten nicht mehr schaden als nützen will. Foers ter selbst zieht die Indikationsgrenzen reichlich eng, und auch wir waren mit der Anwendung sehr zurückhaltend. Vor allen Dingen handelt es sich, um das nochmals zu betonen, bei der Auswahl der Fälle darum, zu entscheiden, ob alles getan ist, was zu einer Entlastung des Markes an der Stelle der Läsion dienen kann. Nur wenn diese Fragen bejaht und mit ausreichender Wahrscheinlichkeit angenommen werden kann, daß die spastischen Erscheinungen in der Hauptsache auf eine endomedulläre, chirurgisch nicht angreifbare Narbe bezogen werden müssen, wird man mit gutem Gewissen zur Wurzelresektion schre ten können. Schwere und Stabilität der spastischen Contracturen bietet an sich noch keine Indikation für die Foerstersche Operation. Dies beweist zur Genüge der oben mitgeteilte Fall des Hauptmanns E. (Beob. 26), bei dem reichlich $1 \mathrm{Jahr}$ lang eine extreme Beugecontractur in beiden Hüft- und Kniegelenken bestanden hatte, die durch Freilegung des Markprozesses so weit behoben werden konnte, daß der Kranke wieder auf die Beine gekommen ist. Wir dürfen doch eben nicht vergessen, daß die Erholungsfähigkeit des Markes eine sehr weitgehende ist, wenn es sich um Schädigungen handelt, welche die histologischen Querschnittselemente nicht restlos zerstört, sondern nur zum Teil durch Druck, Ödem oder Behinderung der Zirkulation außer Funktion gesetzt haben. Allgemein bekannt sind die glänzenden therapeutischen Resultate bei komprimierenden Tumoren, wie sie Oppenheim, Schulze, Nonne u. a. aus der Friedenspraxis mitgeteilt haben. Auch wir haben über einen Fall berichtet, bei dem der Lumbalabschnitt des Markes durch ein Psammom auf wenige Millimeter seines Querschnittes zusammengepreßt war. Es hatte 6 Monate lang eine absolute spastische Paraplegie der Beine bestanden, und trotzdem war nach Entfernung des Tumors die Lähmung so weit zurückgegangen, daß die Kranke wieder ohne Stock gehen lernte. Mit diesen günstigen Erfahrungen sollte man auch bei den tra u matischen Rückenmarkschädigungen mehr rechnen als es im allgemeinen geschieht. Wenn auch hier die Verhältnisse insofern wesentlich ungünstiger liegen, als die Erschütterung des Trau mas viel leichter irreparable Querschnittsveränderungen setzen wird wie der langsam wachsende Tumor, so ist 
58 Th. Mauss: Úber die traumatischen Rückenmarkschädigungen usw.

dies nach unseren Erfahrungen doch kein Grund zu einer allzu resignierten Auffassung bezüglich der chirurgischen Behandlung schwerer Wirbelsäulen- und Rückenmarkverletzungen, wie sie mit Lewandowsk y zahlieiche Neurologen vertreten haben und auch heute noch vertreten. Wir möchten im Gegenteil dringend raten, auch bei schweren Rückenmarkverletzungen, sofern sie nur einigermaßen den Verdacht auf eine Kompressionswirkung offenlassen, das Mark am Orte der Läsion in a usgedehntestem Maße freizulegen und erst dann, wenn das geschehen und erfolglos geblieben ist, zu einer so eingreifenden Behelfsoperation wie der Radikotomie Zuflucht zu nehmen. 